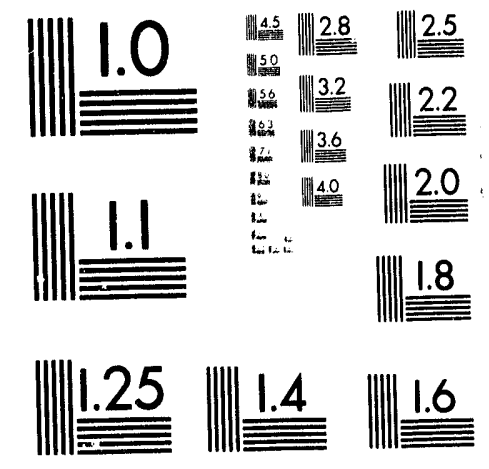



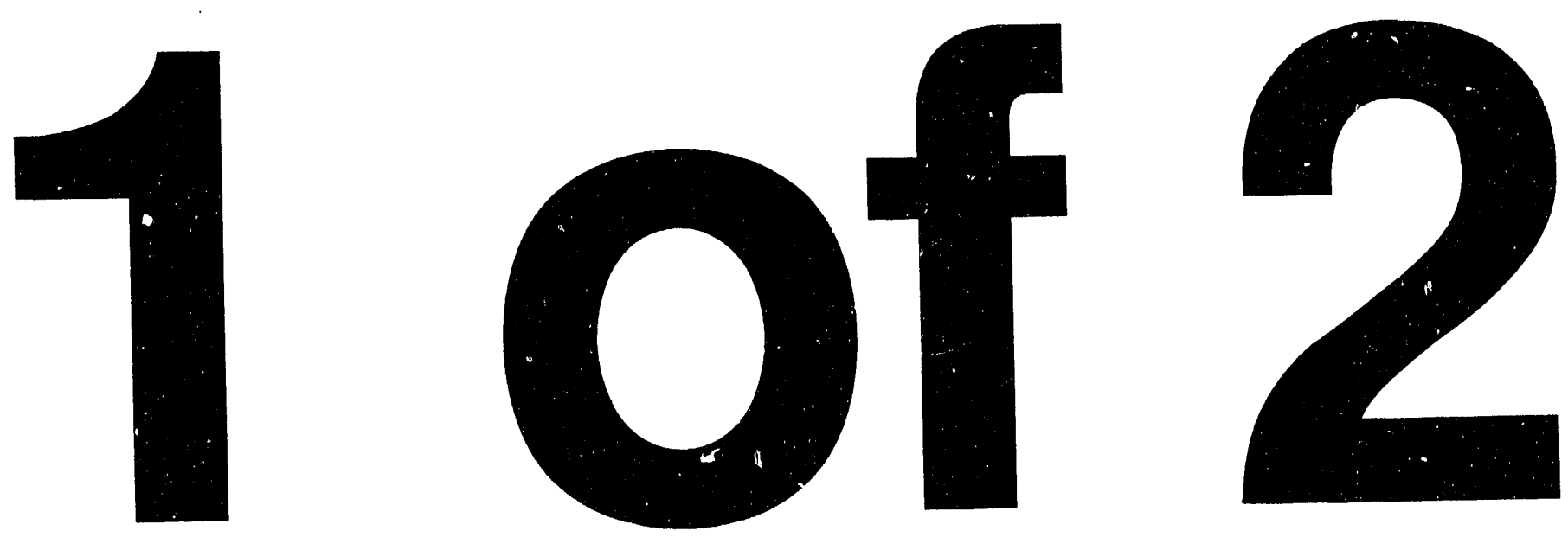
MCNP: Multigroup/Adjoint Capabilities

John C. Wagner

Everett L. Redmond II

Scott P. Palmtag

John S. Hendricks 


\title{
MCNP: MULTIGROUP/ADJOINT CAPABILITIES
}

\author{
by
}

John C. Wagner, Everett L. Redmond II, Scott P. Palmtag, and John S. Hendricks

\begin{abstract}
This report discusses various aspects related to the use and validity of the general purpose Monte Carlo code MCNP for multigroup/adjoint calculations. The increased desire to perform comparisons between Monte Carlo and deterministic codes, along with the ever-present desire to increase the efficiency of large MCNP calculations has produced a greater user demand for the multigroup/adjoint capabilities. To more fully utilize these capabilities, we review the applications of the Monte Carlo multigroup/adjoint method, describe how to generate multigroup cross sections for MCNP with the auxiliary CRSRD code, describe how to use the multigroup/adjoint capability in MCNP, and provide examples and results indicating the effectiveness and validity of the MCNP multigroup/adjoint treatment. This information should assist users in taking advantage of the MCNP multigroup/adjoint capabilities.
\end{abstract}




\section{INTRODUCTION}

\section{A. Multigroup MCNP}

The multigroup option in $\mathrm{MCNP}^{1,2}$ is a powerful method for a number of important applications:

(1) comparison of deterministic $\left(S_{N}\right)$ transport codes to Monte Carlo in general, and MCNP in particular;

(2) utilization of adjoint calculations in problems where it is more efficient than forward transport calculations, specifically problems where the detector region is relatively small and the source region relatively large;

(3) generation of adjoint importance functions to enhance calculational efficiency in forward multigroup or continuous-energy Monte Carlo calculations;

(4) cross-section sensitivity studies;

(5) solution of problems with multigroup cross sections when continuous-energy cross sections are unavailable; and

(6) charged particle transport using the Boltzmann-Fokker-Planck multigroup capability.

Effective use of the multigroup method requires the availability of appropriate multigroup cross sections. A standard multigroup set, MGXSNP, is available for MCNP for coupled neutron-photon transport. However, this available set is not suitable for all problems, and there is a need for users to be able to generate multigroup libraries tailored to their specific applications. Further, comparisons with deterministic codes and cross-section sensitivity studies require that the Monte Carlo code utilize the same data as deterministic codes. Thus, a translator is needed to generate MCNP multigroup cross sections from deterministic multigroup cross sections. For these purposes CRSRD (a coinputer code that processes deterministic multigroup cross-section libraries into a format suitable to MCNP) is available.

In the past, some discrepancies ${ }^{3,4}$ have been noted between MCNP multigroup results and continuous-energy results. It was concluded that the representation of the angular scattering distributions by the Carter and Forest equally probable step function method in CRSRD was most likely responsible for the poor agreement. ${ }^{5}$ Thus, a new method of treatment for angular scattering has been developed and implemented into CRSRD. It is believed that this new representation will significantly reduce the aforementioned discrepancies. 


\section{B. Motivation}

The main purpose of this report is to enhance the utilization of the multigroup/adjoint capability in MCNP. To this end we describe the uses of the multigroup/adjoint method, how to generate multigroup libraries with CRSRD, and how to run MCNP in the multigroup/adjoint mode. We then provide examples and benchmarks demonstrating the usage, applicability, and validity of the multigroup/adjoint treatment in MCNP.

The second purpose of this report is to benchmark the MCNP multigroup/adjoint capability. Although MCNP has been thoroughly benchmarked in the continuous energy mode ${ }^{6-9}$ it has not been adequately validated in the multigroup mode. Thus we present a number of MCNP multigroup neutron, photon, and criticality calculations to compare MCNP multigroup results to deterministic codes, continuousenergy MCNP, and experimental measurements.

\section{Outline}

This report is organized as follows: Section II describes applications for the MCNP multigroup/adjoint capabilities. Section III describes the treatment of multigroup cross st "tions in MCNP and presents the CRSRD computer code and instructions related to its use. A discussion on how to use multigroup data in MCNP for forward and adjoint calculations and for the generation of adjoint importance functions is provided in Section IV. Section IV also presents several examples of these capabilities. Section $\mathrm{V}$ investigates the validity of multigroup MCNP by comparing results from multigroup MCNP, continuous energy MCNP, deterministic codes (ONEDANT, ${ }^{10}$ TWODANT, ${ }^{11}$ and THREEDANT,${ }^{12}$ ) and experimental measurements for a relatively wide variety of problems. Section VI presents conclusions. Appendix A contains information related to the MCNP default multigroup cross-section library MGXSNP. MCNP input files are presented in Appendix B, providing an unambiguous description of the example problems of Section IV. Finally, A ppendix $\mathrm{C}$ contains a description of the format and contents of a multigroup cross-section file that is readable by MCNP. 


\section{Applications of Multigroup/Adjoint Capabilities}

The following is a collection of situations in which the various multigroup/adjoint capabilities can be useful.

\section{A. Code Comparisons}

It is often desirable tc compare deterministic $S_{N}$ results to Monte Carlo results to determine the adequacy of the deterministic model, and to identify potential problems associated with deterministic transport (i.e., transport through optically thick regions or voids and geometric approximations). However, to truly compare the two methods, one must use the same cross sections in both calculations. Thus, the $\mathrm{S}_{N}$ multigroup library must be processed into a format suitable for MCNP and subsequently used in a multigroup MCNP calculation. This processing can be done with the CRSRD code.

\section{B. Calculational Efficiency}

One of the inherent difficulties associated with Monte Carlo calculations is the amount of computer time required to generate statistically converged results of sufficient precision. This difficulty is especially pronounced in problems containing optically thick materials and in problems that are geometrically large. There are many ways in which a user can improve the precision of a Monte Carlo calculation. These include: (1) properly choosing the tally size and type, (2) properly implementing the applicable variance reduction techniques, (3) running additional histories, (4) executing the problem in the appropriate mode (i.e., forward or adjoint), and (5) generating and utilizing either weight windows or an adjoint importance function, where applicable.

The choice of a forward versus an adjoint calculation depends upon the relative size of the source and detector regions. It is much easier to transport particles from a small region to a large region than it is to transport particles from a large region to a small region. Forward calculations transport particles from the source region to the detector regions and are therefore preferable when the detector regions are relatively large and the source region is relatively small. On the other hand, because adjoint calculations transport particles backward (from the detector region to the source region), adjoint calculations are preferable when the source region is large and detector region is small. 
The adjoint option in MCNP can only be used in the multigroup mode. MCNP is presently not capable of continuous energy adjoint calculations. Additionally, MCNP is not presently capable of performing adjoint criticality calculations.

An accurate space-energy-dependent importance function can significantly increase the efficiency of a calculation. MCNP offers two methods of generating such

importance functions; the forward weight window generator ${ }^{13,14}$ and the multigroup adjoint transport option. The weight window generator can be used with continuous energy MCNP and generates a space and energy dependent weight window importance function for up to 15 energy intcrvals. The multigroup adjoint option, on the other hand, generates a space-dependent adjoint inportance function for each energy group in the multigroup library.

The principal problem encountered when using these generators is bad estimates of the importance function because of the statistical nature of the generator. ${ }^{14} \mathrm{Un}$ less a phase space region is sampled adequatcly, there will be cither no generator importance estimate or an unreliable one. Based on the discussion above concerning the use of forward and adjoint modes, one can determine which method of importance generation is best suited for a particular problem.

\section{Cross-Section Sensitivity Studies}

It is fairly well understood that multigroup cross sections are problem dependent and that their generation is as much an art as a science. Thus, over the years, a large number of multigroup libraries have been developed to meet the needs of different types of calculations. For example, S.AILOR, ${ }^{15}$ BUGLE, $^{16}$ and ELXSIR ${ }^{17}$ are all multigroup libraries that are applicable to pressure vessel neutron fluence calculations. ${ }^{18}$

It is an accepted practice to choose and utilize one of the many "off the shelf" multigroup cross-section libraries based on the group structure, the weighting or collapsing function used, and the intent of whoever generated the library. The majority of the "off the shelf" libraries have been thoroughly tested, and thus, this practice has, in general, produced good/arceptable results. However, one must choose the multigroup library for a particular application intelligently.

Often, due to poor documentation and/or oversights by the library creators or for reasons related to quality assurance, questions and uncertainties related to the applicability of particular libraries arise, and one would like to have the ability to 
compare the performance of a multigroup library to that of continuous energy simulation and/or other multigroup libraries. This type of analysis can be performed with the aid of the continuous energy and multigroup options in MCNP.

\section{Continuous Energy Cross-Sections Unavailable}

MCNP offers an extensive selection of continuous energy cross-sections with respect to the number of available isotopes and with respect to the origin of the data. Nevertheless, situations arise occasionally in which users require cross-section data (typically for either uncommon isotopes or matcrial homogenizations) that are not presently available within the many MCNP continuous energy libraries. For example, MCNP has only a limited tission product cross-section data set available and some important isotopes for some applications, such as germanium and iodine, are missing. To overcome this problem, the user must find an appropriate multigroup library that contains the desired cross-section data. It is currently not possible to use both continuous energy and multigroup cross-section data in a single MCNP calculation. A problem requiring cross-section data that is not available to MCNP in continuous energy form must be run using only multigroup data. Hence for this type of application, the multigroup option in MCNP is a necessity.

\section{E. Charged Particle Capability}

Although MCNP has charged particle transport for electrons, the physics is missing for other charged particles. However, charged particles can be run in MCNP provided the appropriate multigroup charged particle library is available. MCNP has a Boltzmann-Fokker-Planck treatment in its multigroup physics allowing for straight-ahead scattering and continuous slowing down in addition to Boltzmann scattering. Because all the physics of charged particle interactions is buried in the multigroup cross-section library, MCNP does the transport as if the particles were neutrons. All the printouts and summary tables appear exactly as they would for a neutron problem, and thus the charged particles are really masquerading as neutrons. To our knowledge, MCNP is the only major Monte Carlo code with an adjoint charged particle capability. The multigroup option is the only way to run charged particles other than electrons in MCNP. It is currently available as a research tool and will not be further described. Contact X-6 group for further information on this capability. The theory for this method is described in Ref. 29. 


\section{GENERATING MULTIGROUP LIBRARIES WITH CRSRD}

The CRSRD computer code was developed to read multigroup cross-section files in a variety of formats and to reformat and translate the data into a form acceptable

- to MCNP. Currently, CRSRD is able to read and process card-image data libraries written in DTF, fixed field FIDO, and the binary AMPX Working Library formats as well as the Los Alamos specific MENDF format. The code, however, is quite a bit more lengthy than one might have expected for a simple conversion utility. The reason for this length is the generality with which it was written, providing the user with many options for input. CRSRD was also written in such a way that a new user should be able to easily modify it to read another format or modify it to manipulate the data for producing the MCNP Type 1 (ASCII) cross-section file. A more detailed description of CRSRD and its input structure will be provided later in this section. First, though, a description of multigroup cross sections and how they are used within MCNP will be provided as background for the user and as insight into CRSRD. This description will be followed by a brief description of the angular treatments available in CRSRD and MCNP for handling the Legendre expansion terms in the multigroup cross-section sets.

\section{A. Multigroup Cross Sections}

Multigroup cross sections, as they are used in deterministic codes, can be defined in many different ways. This is especially true of the absorption cross section which may or may not include fission and may or may not have $(n .2 n)$ and similar reactions subtracted from it. In order to help the user better understand the CRSRD program, a discussion on multigroup cross sections will be provided.

For the purposes of this discussion we will assume that a multigroup library is available that contains only the following cross sections:

$\boldsymbol{\sigma}_{T}^{\boldsymbol{g}}$ microscopic total cross section for group $g$

$\nu * \boldsymbol{\sigma}_{\boldsymbol{F}}^{\boldsymbol{\theta}}$ microscopic fission cross section for group $g$ multiplied by $n u$ for group $g$

$\begin{aligned} & \boldsymbol{\sigma}_{\boldsymbol{A}}^{\boldsymbol{D}} \text { microscopic absorption cross section for group } g \\ & \boldsymbol{\sigma}_{\boldsymbol{S}}^{\boldsymbol{\theta} \rightarrow \boldsymbol{\theta}^{\prime}} \text { microscopic scattering cross section from group } g \text { to group } g^{\prime}\end{aligned}$

We will also assume that these cross sections were calculaied from the following reaction cross sections in a manner to be described later. 
(elastic) microscopic elastic scattering cross section from grcup $g$ to group $g^{\prime}$

$(\mathbf{n}, \boldsymbol{\gamma})$ microscopic $(n, \gamma)$ reaction cross section for group $g$; also referred to as the capture cross section

$\left(\mathbf{n}, \mathbf{n}^{\prime}\right)$ microscopic $\left(n, n^{\prime}\right)$ reaction cross section for group $g$

$(\mathbf{n}, \mathbf{2 n})$ microscopic $(n, 2 n)$ reaction cross section for group $g$

$(\mathbf{n}, \mathbf{3 n})$ microscopic $(n, 3 n)$ reaction cross section for group $g$

$(\mathbf{n}, \mathbf{f})$ microscopic fission reaction cross section for group $q$

$\left(\mathbf{n}, \mathbf{n}^{\prime} \mathbf{f}\right)$ microscopic $\left(n, n^{\prime} f\right)$ reaction cross section for group $g$

$(\mathbf{n}, \mathbf{2 n f})$ microscopic $(n, 2 n f)$ reaction cross section for group $g$

The total, fission, and scattering cross sections are defined in the following manner using the reactions listed above.

$$
\begin{gathered}
\sigma_{T}^{g}=(\text { clastic })+(n, \gamma)+\left(n, n^{\prime}\right)+(n, 2 n)+(n, 3 n)+(n, f) \\
+\left(n, n^{\prime} f\right)+(n, 2 n f) \\
\sigma_{F}^{g}=(n, f)+\left(n, n^{\prime} f\right)+(n, 2 n f) \\
\sigma_{S}^{g \rightarrow g^{\prime}}=(\text { elastic })+\left(n, n^{\prime} f\right)+2 *(n, 2 n f) \\
+\left(n, n^{\prime}\right)+2 *(n, 2 n)+3 *(n, 3 n)
\end{gathered}
$$

It is important to note that the scattering cross section includes the other modes of neutron production besides fission. This inclusion is done to combine the angular distribution data for elastic scattering with the angular distribution data for these other production processes into one cross section.

The absorption cross section can be defined in many different ways but the three most popular ways are as follows.

$$
\begin{gathered}
\sigma_{A}^{g}=(n, \gamma) \\
\sigma_{A}^{g}=(n, \gamma)-\left(n, n^{\prime} f\right)-2 *(n, 2 n f)-(n, 2 n)-2 *(n, 3 n) \\
\sigma_{A}^{g}=(n, \gamma)-\left(n, n^{\prime} f\right)-2 *(n, 2 n f)-(n, 2 n)-2 *(n, 3 n)+\sigma_{F}^{g}
\end{gathered}
$$


The latter equation can be rewritten as

$$
\sigma_{A}^{g}=(n, \gamma)-(n, 2 n)-2 *(n, 3 n)+(n, f)-(n, 2 n f)
$$

Equation 4 is the capture cross section while Eq. 5 is used to preserve cross-section balance in the sense that

$$
\sigma_{T}^{g}=\sigma_{A}^{g}+\sigma_{F}^{g}+\sigma_{S}^{g-t o t}
$$

where

$$
\sigma_{S}^{g-t o t}=\sum_{g^{\prime}=1}^{G} \sigma_{S}^{g \rightarrow g^{\prime}}
$$

Most deterministic codes and many cross-section sets only use $\nu * \sigma_{F}^{g}$. In this case the fission cross section is not available and Eq. 6, is used to preserve the balance. These different ways for defining the cross sections can create a problem for MCNP. For example, MCNP requires that $\nu$ and $\sigma_{F}^{g}$ be separate. Therefore, in the development of CRSRD certain issues had to be addressed.

1. How are $\nu$ and $\sigma_{F}^{g}$ calculated from $\nu * \sigma_{F}^{g}$ if neither is available?

2. If the absorption cross section includes fission, is this a problem and how is it resolved?

3. If the absorption cross section is negative (this can occur if absorption is defined according to Eqs. 5 or 6 ) is this a problem and how is it resolved ?

In order to answer these questions the use of multigroup cross sections within MCNP will be described so a user can better understand the mechanics of the Monte Carlo transport within MCNP. This discussion is primarily focused on forward neutron transport but is applicable to photon and possibly charged particle transport.

\section{B. MCNP Forward Multigroup Treatment}

The MCNP multigroup treatment uses only the absorption, fission, scattering, and total cross sections in the transport. In criticality calculations and when the user includes a NONU card, the fission event is treated strictly as a capture event and no new particles are produced. Capture, itself, can be handled in two fashions, 
either analog or implicit. In analog capture the particle is actually terminated if a capture event occurs. With implicit capture, the particle's weight is simply reduced by an amount equal to the original weight times the ratio of the capture cross section to the total cross section, and the particle survives. (For a more detailed discussion of anulog versus implicit capture refer to the M.ICNP manual. ${ }^{1}$ ) The combination of implicit and analog capture and the option of treating fission as capture or real results in four possible combinations that will be discussed in further detail.

During this cliscussion, the weight of a particle should be loosely interpreted as the number of particles. The important point in the transport of particles is that, on average, the number of particles emerging from all possible reactions at a given energy be correct. In other words, the outgoing weight of the particle should reflect the net increase or decrease in particles due to all possible reactions at a given energy.

In MCNP, the following events occur in the sampling of a collision.

1. Distance to collision is calculated using the total cross seciion for a material (a combination of isotopes).

2. The particle is transported to the collision site.

3. The specific isotope within which the collision occurred is sampled. The sampling is based on the macroscopic total cross section for each individual isotope and the macroscopic total cross section for the material.

4. The capture event for the chosen isotope is sampled. If analog capture is in effect, the capture is sampled, and if chosen, the particle is terminated. If capture is not chosen, then no weight change occurs. When implicit capture is in effect, then the weight of the particle is automatically reduced by the appropriate amount and transport continues.

5. If a particle survives the capture event. fission is sampled if possible.

6. If fission is not possible or is not chosen, scattering is sampled.

Table I presents the various events that occur in MCNP when analog capture is used and fission is treated as capture, as well as the associated probabilities and weight adjustments. 
TABLE I

\section{A Description of the Events that Occur}

when Analog Capture is Used and Fission is Treated as Capture

\begin{tabular}{|c|c|c|}
\hline \multicolumn{2}{|l|}{ Weight before capture } & $W G T_{\text {orig }}$ \\
\hline \multicolumn{2}{|l|}{ Probability of capture } & $\frac{\sigma_{\Lambda}^{g}+\sigma_{E}^{g}}{\sigma_{T}^{g}}$ \\
\hline \multicolumn{2}{|c|}{ Weight after capture if it survives } & $W^{\prime} G T_{\text {orig }}$ \\
\hline & Fission & Scatter \\
\hline Probability & 0 & $1-\frac{\sigma_{A}^{g}+\sigma_{E}^{g}}{\sigma_{T}^{g}}$ \\
\hline $\begin{array}{l}\text { Num. particles emerging } \\
\text { from event }\end{array}$ & 0 & $\frac{\sigma_{S}^{g-t o t}}{\sigma_{T}^{g}-\sigma_{A}^{g}-\sigma_{F}^{g}}$ \\
\hline $\begin{array}{l}\text { Weight adjustment } \\
\text { (Prob.)*(Num. particles) }\end{array}$ & 0 & $\frac{\sigma_{S}^{g-t o t}}{\sigma_{T}^{g}}$ \\
\hline
\end{tabular}

The final weight, therefore, is equivalent to the original number of particles times the net number of particles emerging from a collision of a single particle with an isotope. Consulting Eq. 3 will help assure the user that the final weight listed in Table I is correct. It is important to note here that the absorption cross section does not play a direct role in the weight emerging from the collision. However, problems will arise in the transport of particles if $\sigma_{A}^{g}+\sigma_{F}^{g}<0$. This situation can arise when the fission cross section is zero and absorption is defined according to Eq. 5 and $(n, 2 n)$ or similar reactions have higher cross sections than $(n, \gamma)$. This interpretaion is especially true in Deuterium and Beryllium at the higher energies.

In order to better understand the implications of Table I, the method used in MCNP to determine if a capture event has occurred is shown below.

$$
t m p=R N * \sigma_{T}^{g}
$$

where $\mathrm{RN}$ is a random number between 0 and 1 and $t m p$ is a dummy variable

$$
\text { if } \sigma_{A}^{g}+\sigma_{F}^{g}>\operatorname{tmp}
$$


In this case one can see that if $\sigma_{A}^{g}+\sigma_{F}^{g}<0$, then a capture event will never occur. This problem is not serious by itself. However, the next event to be sampled will be scattering, and the number of particles emerging from the scattering event will be one, according to Table I. This is because $\sigma_{A}^{y}$ is defined according to Eq. 5 and the cross-sections balance. A single particle emerging from this scattering event is incorrect, and no adjustment is made elsewhere. The result is incorrect transport of particles with no resulting fatal error, simply incorrect answers. The solution to this problem is to set the negative absorption cross section to zero to assure that $\sigma_{A}^{g}+\sigma_{F}^{g}$ is never less than zero.

The exact manner in which MCNP handles the scattering is different from that represented ir. Table I. The final result after a collision occurs is basically as represented in the table except the actual mechanics of the scattering are different. The method MCNP uses for scattering and fission does not result in any weight increase to the particles. Rather a certain number of particles are all started with the same weight, and the net effect is as presented in the table. The exact method MCNP uses for scattering is:

$$
n u m=\operatorname{int}\left(R N+\frac{\sigma_{S}^{g-t o t}}{t m p}\right)
$$

where num is the number of particles created from the scattering event all at the same weight $W G T_{\text {orig }}$ and for fission it is:

$$
t m p=R N *\left(\sigma_{T}^{g}-\sigma_{A}^{g}\right)
$$




$$
n u m=\operatorname{int}(R N+\nu)
$$

where num is the number of particles created from the fission event all at the same weight $W G T_{\text {orig }}$

Table II describes the processes that occur and their associated probabilitie; and weight adjustment for a problem run with implicit capture and fission treated as capture. In this particular case $\sigma_{A}^{g}+\sigma_{F}^{g}<0$ does not create a serious problem; however, it is of significant enough interest to warrant further discussion.

\section{TABLE II}

\section{A Description of the Events that Occur \\ when Implicit Capture is Used and Fission is Treated as Capture}

Weight before capture

$W G T_{\text {orig }}$

\begin{tabular}{lcc}
\hline Weight after implicit capture & $W G T_{n e w}=W G T_{\text {orig }} *\left(1-\frac{\sigma_{A}^{g}+\sigma_{F}^{g}}{\sigma_{T}^{g}}\right)$ \\
\hline Probability & Fission & Scatter \\
\hline $\begin{array}{l}\text { Num. particles emerging } \\
\text { from event }\end{array}$ & 0 & 1 \\
\hline $\begin{array}{l}\text { Weight adjustment } \\
\text { (Prob.)*(Num. particles) }\end{array}$ & 0 & $\frac{\sigma_{S}^{g-t o t}}{\sigma_{T}^{g}-\sigma_{A}^{g}-\sigma_{F}^{g}}$ \\
\hline \hline
\end{tabular}

Final weight

$$
\begin{aligned}
W G T_{\text {final }} & =W G T_{n e w^{\prime}} *\left(\frac{\sigma_{S}^{g-t o t}}{\sigma_{T}^{g}-\sigma_{A}^{g}-\sigma_{F}^{g}}\right) \\
& =W G T_{\text {oriy }} *\left(\frac{\sigma_{S}^{g-\operatorname{tot}}}{\sigma_{T}^{g}}\right)
\end{aligned}
$$

In order to illustrate what can happen when $\sigma_{A}^{g}+\sigma_{F}^{g}<0$ and implicit capture is performed, the following cross sections will be used. 
- $\sigma_{C}^{g}=0.5$ - capture as defined by Eq. 4

- $\sigma_{F}^{g}=0.0$

- $\sigma_{T}^{g}=10.0$

- $\sigma_{S}^{g-t o t}=400.0$

Three possible scenarios will be explored. The first is when $\sigma_{A}^{g}=\sigma_{C}^{g}$, the second has $\sigma_{A}^{g}=-390.0$, while the third scenario has $\sigma_{A}^{g}=0.0$.

Case $1 \sigma_{A}^{g}=0.5$

$W G T_{\text {new }}=W G T_{\text {orig }} * 0.99875$

Number of particles emerging $=42.1$, each with weight

$W G T_{\text {orig }} * 0.99875$

Case $2 \sigma_{A}^{g}=-390.0$

$W G T_{\text {new }}=W G T_{\text {orig }} * 40.0$

Number of particles emerging $=1.0$

Case $3 \sigma_{A}^{g}=0.0$

$W G T_{\text {new }}=W G T_{\text {orig }}$

Number of particles emerging $=40.0$, each with weight $W G T_{\text {orig }}$

It is obvious that all three of these different cases will produce the same net weight. However, a different number of particles will be generated in each case. Cases 1 and 3 will both result in the "bank" filling up very quickly and overflowing to a backup file. This overflow will not affect the answers, but the efficiency of the calculation may drastically drop compared to the Case 2 scenario. However, the Case 2 scenario will result in a large weight increase which may adversely affect the weight game if variance reduction techniques are used. Therefore, the user has been provided with the option in CRSRD to either set negative absorption cross sections to zero or leave them unaltered. If they are left unaltered, the user must NOT use analog capture as this will result in incorrect answers, and NO warning messages will be given.

In Table II a serious problem can arise if $\sigma_{A}^{g}+\sigma_{F}^{g}>\sigma_{T}$. In this particular case $W G T_{\text {new }}$ would become negative. This negative weight particle would then be terminated immediately in the weight cutoff game. The result is an incorrect representation of the scattering event because it would never occur. Again this sort 
of error would not be evident in MCNP except that the answers would be incorrect. Usually this problem will not arise; however, if $\sigma_{A}^{g}$ is defined according to Eq. 6 and $\sigma_{F}^{g}$ is non negative or $\nu * \sigma_{F}^{g}$ is inadvertently used for $\sigma_{F}^{y}$, then this problem does manifest itself.

Tables III and IV present the interactions and the associated probabilities and weight corrections for the cases of analog and implicit capture being used when fission is treated as real. Analysis of these tables indicates that problems can arise if $\sigma_{A}^{g}$ is less than zero for the analog case and if $\sigma_{A}^{g}>\sigma_{T}^{g}$ for the implicit case. The problems will manifest themselves in that the scattering interactions will not be sampled properly. These problems are basically idertical to the ones discussed for Tables I and II.

TABLE III

A Description of the Events that Occur when Analog Capture is Used and Fission is Treated as Real

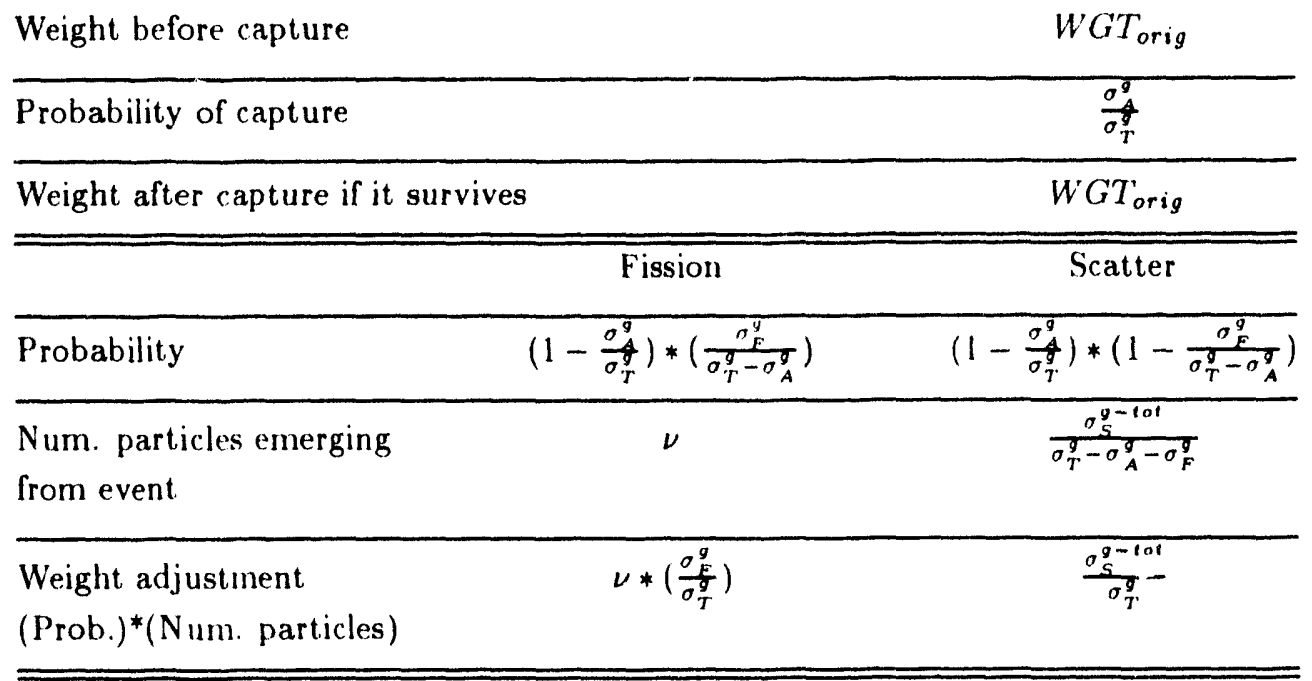

Final weight

$$
W\left(i T_{\text {orig }} *\left(\frac{\nu * \sigma_{F}^{g}+\sigma_{S}^{g-t o t}}{\sigma_{T}^{q}}\right)\right.
$$




\section{TABLE IV}

\section{A Description of the Events that Occur \\ When Implicit Capture is Used \\ and Fission is Treated as Real}

\begin{tabular}{|c|c|c|}
\hline Weight before capture & & $W G T_{\text {orig }}$ \\
\hline Weight after implicit capture & & $W G T_{\text {new }}=W G T_{\text {orig }} *\left(1-\frac{\sigma^{9}}{\sigma_{T}^{9}}\right)$ \\
\hline & Fission & Scatter \\
\hline Probability & $\frac{\sigma_{E}^{g}}{\sigma_{T}^{g}-\sigma_{A}^{g}}$ & $1-\frac{\sigma_{F}^{g}}{\sigma_{T}^{g}-\sigma_{A}^{g}}$ \\
\hline $\begin{array}{l}\text { Num. particles emerging } \\
\text { from event }\end{array}$ & $\nu$ & $\frac{\sigma_{S}^{g-10 t}}{\frac{\sigma_{T}^{g}-\sigma_{A}^{g}-\sigma_{F}^{g}}{F}}$ \\
\hline $\begin{array}{l}\text { Weight adjustment } \\
(\text { Prob.)*(Num. particles) }\end{array}$ & $\nu *\left(\frac{\sigma_{P}^{g}}{\sigma_{T}^{g}-\sigma_{A}^{g}}\right)$ & $\frac{a_{S}^{g-10 t}}{\sigma_{T}^{g}-\sigma_{A}^{g}}$ \\
\hline
\end{tabular}

Final weight

$$
\begin{aligned}
W G T_{\text {final }} & =W G T_{\text {new }} *\left(\frac{\nu * \sigma_{E}^{g}+\sigma_{S}^{g-10 t}}{\sigma_{T}^{g}-\sigma_{A}^{g}}\right) \\
& =W G T_{\text {oriy }} *\left(\frac{\nu * \sigma_{E}^{g}+\sigma_{S}^{g-t o t}}{\sigma_{T}^{g}}\right)
\end{aligned}
$$

The important point that can be derived from the tables presented is that $\nu * \sigma_{F}^{g}$, $\sigma_{S}^{g-t o t}$, and $\sigma_{T}^{g}$ are the only cross sections that are vitally important for the proper transport of particles, assuming certain conditions are met concerning $\sigma_{A}^{g}$.

\section{How CRSRD Handles Cross Section Problems}

Multigroup cross-section libraries differ significantly in both content and arrangement. CRSRD, must therefore, be able to properly handle the different ways in which it receives the data. An excellent example is that many libraries only provide $\nu * \sigma_{F}^{g}$, therefore this has to be split by CRSRD into its separate components. Also, CRSRD has to be able to determine if there are problems with the cross sections, and if so, how to correct them. As discussed earlier, problems can arise in the MCNP transport if any of the following conditions occur. 
- $\sigma_{A}^{g}+\sigma_{F}^{g}>\sigma_{T}^{g}$ for fission being treated as capture

- $\sigma_{A}^{g}+\sigma_{F}^{g}<0$ for fission being treated as capture and analog capture used

- $\sigma_{A}^{g}>\sigma_{T}^{g}$ for fission being treated as real

- $\sigma_{A}^{g}<0$ for fission being treated as real and analog capture used

CRSRD has three different methods of determining $\nu$ and $\sigma_{F}^{g}$ from $\nu * \sigma_{F}^{g}$ when the latter is the only reaction available. They are listed in the order in which they are used.

1. If $\sigma_{F}^{g}$ is available as a reaction, it is used to calculate $\nu_{t o t a l}$.

2. If $\nu_{\text {total }}$ or $\nu_{\text {prompt }}$ are provided by the user or listed as a reaction, then they are used to calculate $\sigma_{F}^{g}$ ( $\nu_{\text {total }}$ being used before $\nu_{\text {prompt }}$ )

3. A value of 2.5 is used for $\nu_{\text {total }}$ and $\sigma_{F}^{g}$ is then calculated.

CRSRD has been written to correct any of the problems mentioned above and to split $\nu * \sigma_{F}^{g}$ into its separate parts when required. Since other formats may be different in the information they contain, the user who wishes to add an additional capability of reading a different format to CRSRD must be aware of how that format is defined.

Table V illustrates how CRSRD handles the potential problems that can arise in processing multigroup cross sections.

TABLE V

\section{A Description of How CRSRD Handles Potential Cross Section Problems}

\begin{tabular}{lcc} 
Problem & Usually Occurs When & Solution \\
\hline$\sigma_{A}^{g}+\sigma_{F}^{g}>\sigma_{T}^{g}$ & $\begin{array}{c}\sigma_{F}^{g} \text { is non zero and } \\
\text { is included in } \sigma_{A}^{g}\end{array}$ & $\begin{array}{c}\text { subtract } \sigma_{F}^{g} \\
\text { from } \sigma_{A}^{g}\end{array}$ \\
\hline$\sigma_{A}^{g}+\sigma_{F}^{g}<0$ & $\sigma_{F}^{g}$ is zero and \\
$(n, 2 n)>(n, \gamma)$ & $\begin{array}{c}\text { user option to set } \\
\sigma_{A}^{g} \text { to zero }\end{array}$ \\
\hline$\sigma_{A}^{g}<0$ & $(n, 2 n)>(n, \gamma)$ & user option to set \\
& & $\sigma_{A}^{g}$ to zero
\end{tabular}




\section{Legendre Series Representation in MCNP}

The Legendre series expansion used by deterministic codes to represent the angular scattering information is not suitable for direct use in MCNP. This problem is because the scattering function, as represented with the Legendre expansion, is not everywhere positive over the range $-1 \leq \mu \leq 1$. If it were used directly, negative weight particles might be created which could adversely affect the stability of the answers. Therefore, the expansion must be converted into a form usable by MCNP. There are two methods of performing this conversion on the Legendre expansion.

The first method is to create discrete scattering angles based on a conservation of the moments. The second is to create equi-probable scattcring bins also based on a conservation of moments. The discrete angle approach has been used in other Monte Carlo codes but can result in problems for certain scattering media due to "rayeffects." ${ }^{19}$ Another disadvantage to discrete angles is that in some codes, MCNP included, point detectors do not work with this angular representation because the point detectors must be able to sample from an angular distribution. There are two algorithms for calculating the discrete angles in CRSRD. The first, and most widely used, was borrowed from MORSE and will be referred to as the MORSE method. The second algorithm is the RADAU treatment. This treatment is primarily used for heavily forward peaked scattering as can be found in charged particle transport. This treatment is only recommended for the user who is familiar with its proper use because the total cross section is adjusted when this treatment is used.

There are two methods available for calculating the equi-probable scattering bins. The first was developed by Carter and Forest and is based on conservation of the moments. The second method was developed by Baker and is referred to as the Maximum Entropy approach. ${ }^{5}$ This approach calculates a new scattering function which is everywhere positive and then uses this function to calculate 32 or less equi-probable bins.

Table VI lists the number of discrete angles or equi-probable bins that are produced from a Legendre expansion of order $L$ using each of the methods discussed.

When only P0 cross sections are present, isotropic scattering in the lab system occurs. In this case, CRSRD will not execute any of the angular distribution routines since they are not apprspriate. Rather. CRSRD will put the appropriate information on the Type 1 cross-section file indicating isotropic scattering. 


\section{TABLE VI \\ Number of Discrete Angles or Equi-Probable Bins \\ Produced by the Various Methods Available in CRSRD as a Function of Legendre Order L}

\begin{tabular}{lcc} 
Method & $\begin{array}{c}\text { Number of Angles } \\
\text { or Bins Produced }\end{array}$ & Restrictions \\
\hline MORSE & $\begin{array}{c}L \text { for } L \text { odd } \\
L+1 \text { for } L \text { even }\end{array}$ & $L \geq 1$ \\
\hline RADAU & $\begin{array}{l}L+2 \text { for } L \text { odd } \\
L+3 \text { for } L \text { even }\end{array}$ & $L \geq 1$ \\
\hline Carter-Forest & $L-1$ & $L \geq 2$ \\
\hline Maximum Entropy & $\leq 32$ & $L \geq 1$
\end{tabular}

A special situation arises when only $\mathrm{P} 0$ and $\mathrm{P} 1$ scattering cross sections are available. In this case, the MORSE treatment will produce one angle and that angle will be:

$$
\bar{\mu}=\sigma_{S-P_{1}}^{g \rightarrow g^{\prime}} / \sigma_{S \rightarrow P 0}^{g \rightarrow g^{\prime}}
$$

The RADAU treatment will produce three angles, but these are only applicable for the charged particle treatment.

Even though Table VI says that the Carter and Forest treatment only works for $L \geq 2$, it will execute with a Legendre order of one. In this case this treatment also returns $\bar{\mu}$ as its value. However, there is a fundamental difference in what MCNP will do with the $\bar{\mu}$ calculated by the MORSE treatment and the one calculated by the Carter and Forest treatment. If the Carter and Forest treatment was used, the parameter isang (refer to Appendix $\mathrm{C}$ ) in the MCNP cross-section file will be set to zero, indicating equi-probable bins are used. If the MORSE treatment was used, then isang will be equal to one, indicating that discrete angles are used for the scattering. MCNP will work fine if isang is equal to one and there is only one discrete angle present. However, the results may not be very reliable because of this crude approximation for the angular distribution from scattering. If isang is equal to zero and there is only one value present for the equi-probable bins $(\bar{\mu})$, then MCNP will use a method different from the equi-probable bins to calculate 
the scattering angle. The angle will be calculated from equations which utilize a random number as described below.

$$
\begin{gathered}
\text { if } \bar{\mu} \geq 0 \text { then } \\
\mu=1 .-2 . * R N *(1 .-\bar{\mu}) \\
\text { if } \bar{\mu}<0 \text {. then } \\
\mu=1 .+2 . * R N *(1 .+\bar{\mu})
\end{gathered}
$$

The Monte Carlo code KENO uses similar expressions to handle the case of P1 scattering. These expressions can be easily incorporated into MCNP if a user wishes to match the KENO treatment. The changes should be made in "function scat" and it should be fairly straightforward to change the above expressions to the KENO expressions listed below.

$$
\begin{gathered}
\text { if }|\bar{\mu}|>\frac{1}{3} \text { then } \\
\mu=R N *(1-|\bar{\mu}|)+\bar{\mu} \\
\text { if } \bar{\mu} \leq \frac{1}{3} \text { then } \\
\mu=\left(\sqrt{1+6 * R N * \bar{\mu}+(3 * \bar{\mu})^{2}}-1\right) /(3 * \bar{\mu})
\end{gathered}
$$

where $R N$ is a random number between -1 and 1

In general it is recommended that the Maximum Entropy approach be used for doing the angular scattering conversion from the Legendre expansion to something usable by MCNP. More importantly, though, users should be aware of what angular representation they are using and the possible ramifications. When doing multigroup transport, it is vital that users examine the results closely to assure themselves that the results are reasonable and to determine the applicability of both the cross-section library they are using and the angular representation they choose. 


\section{E. CRSRD Input}

CRSRD uses free field input with some simple restrictions. Integer values must be entered as integer; CRSRD will give a warning or fatal error if a non-integer is entered and an integer was expected. There are certain character items that must be entered and others that are optional. CRSRD will automatically convert all character items to lowercase before utilizing them. The following items, however, do not undergo a case conversion when read: file names, material identifiers, and the cfs directory name. CRSRD distinguishes one itcm from another by either a blank space, a comma, or an equal sign. Therefore, the latter two items cannot be used in a file name or material identification.

The input is broken into two or three sections depending on the cross-section file format being read. The first section contains the general information and command items. The second section (not used by all cross-section files) contains either the group boundaries or energy centers and widths. The third section contains the list of ZAIDs to be processed. The specific information for file "inp", as required by CRSRD, is discussed below.

At the end of this section there are a few examples of CRSRD input and output files. One of these is for a FIDO format coupled neutron-photon library, and another is for the Los Alamos specific MENDF format. It might be helpful to a user to refer to these examples while reading the description of the input format.

The input for CRSRD is of the form "keyword = value" with a few exceptions. Before processing of the data, CRSRD will check the consistency of the input and print any errors it finds. It may not catch all possible errors, but it should catch most. Table VII lists the data files CRSRD requires and creates. Actual file names are presented in quotes while the variable which holds the user-provided name is rot quoted.

\section{F. Input Cards}

The various keywords used in the CRSRD input are listed along with the appropriate values, their meanings, and any default values. Following each keyword, in parentheses, is the type of value required (character, real, or integer) and the cross-section formats for which this card is valid. 
TABLE VII

\section{A List of the Files Required and Created by CRSRD}

\begin{tabular}{lll} 
File Name & $\begin{array}{c}\text { User input or } \\
\text { CRSRD created }\end{array}$ & Description \\
\hline "inp" & User & $\begin{array}{l}\text { Name of the input file which } \\
\text { the user must provide }\end{array}$ \\
\hline "out" & $\begin{array}{l}\text { Name of the output file CRSRD } \\
\text { creates - this file contains } \\
\text { diagnostic information }\end{array}$ \\
\hline "mgdirl" & $\begin{array}{l}\text { Name of another output file } \\
\text { created by CRSRD - this file } \\
\text { contains diagnostic information from } \\
\text { the angular processing routines }\end{array}$ \\
\hline CRinp & $\begin{array}{l}\text { Name of the new xsdir file } \\
\text { created by CRSRD }\end{array}$ \\
\hline type1 & $\begin{array}{l}\text { Name of the cross-section data } \\
\text { file CRSRD will read - this item is } \\
\text { provided by the user in "inp" }\end{array}$ \\
& CRSRD & $\begin{array}{l}\text { Name of the Type 1 cross-section file } \\
\text { CRSRD will create - this item is } \\
\text { provided by the user in "inp" }\end{array}$ \\
\hline
\end{tabular}

\section{Section 1 - DTF, FIDO, MENDF, AMPX}

This section of the input file contains the keywords and values for optional and required information.

The first line in the input file must contain the following information

Item 1, Item 2 (character, DTF, FIDO, MENDF, AMPX)

Item 1 Name of the cross-section file to be read (10 cliar max)

Item 2 Format of the cross-section file

- DTF

- FIDO

- MENDF

- AMPX 
After the first line, all of the input is of the form "keyword = value." The following is a list of keywords and associated values.

cfs $=$ ?? (character (70 char max), DTF, FIDO, MENDF, AMPX)

?? is the CFS directory name where the user will siore the Type 1 output file (refer to the MCNP manual for more information) default $=0$

type1 = ?? (character (10 char max), D'TF, FIDO, MENDF, AMPX)

?? is the MCNP Type 1 output file name

default $=$ "Type $1 "$

xcon $=? ?($ real, DTF, FIDO, MENDF, AMPX)

?? is the Maximum Entropy convergence criteria default $=1.0 \mathrm{E}-03$

ixprnt $=$ ?? (integer, DTF, FICO, MENDF, AMPX)

?? = 0 - Error messages only from Maximum Entropy routines

?? = 1 - Error messages and corrected moments messages from Maximum Entropy routines

?? = 2 - All messages and bin boundary plot data from Maximum Entropy routines - the output for the bin boundaries will appear on a file called "maxbin" default $=0$

i2lp1 = ?? (integer, DTF, FIDO, AMPX)

$? ?=0$ - the $2 * l+1$ factor is NOT included in sigma scattering

$? ?=1-$ the $2 * l+1$ factor IS included default $=0$

NOTE: The option should probably be used when processing AMPX and ANISN formats. ANISN formats can appear as fixed field fido.

iterm $=? ?$ (integer, FIDO) 
$? ?=0$ - terminator cards are present at the end of the cross-section data for each isotope - terminator cards are " $t$ " or " $T$ "

?? = 1 - terminator cards are NOT present at the end of the cross-section data for each isotope

default $=0$

iskip = ?? (integer, DTF, FIDO)

?? is the number of lines to skip in the cross-section file before reading the actual data

default $=0$

ilen $=$ ?? (integer, DTF, FIDO)

?? is the number of cross-section data for a single group

default $=$ none

itpos = ?? (integer, DTF, FIDO)

?? is the position of the total cross section

default $=$ none

ispos = ?? (integer, DTF, FIDO)

?? is the position of the within-group scattering cross section

default $=$ none

ititl $=$ ?? (integer. DTF, FIDO, AMPX)

$? ?=0$ - title card for the isotopes in the cross-section fie is NOT present

$? ?=1$ - title card is present

?? = 2 - title cards are present but not used (further discussion under section

3)

default $=0$

iengb $=$ ?? (integer, DTF, FIDO)

$? ?=1$ - energy group boundaries are provided

?? = 2 - energy group centers followed by energy group widths are provided default $=$ none

iincp $=$ ?? (integer, DTF, FIDO, MENDF, AMPX) 
?? number of incident particles on cross-section file - maximum number is 2 Do $\mathrm{i}=1,2 *$ iincp

if(i.le.iincp) then enter the number of groups associated with particle $i$

if(i.gt.iincp) then enter the particle type of particle $i$-iincp

$$
\begin{aligned}
0 & =\text { other } \\
1 & =\text { neutron } \\
2 & =\text { photon } \\
\text { default } & =\text { none }
\end{aligned}
$$

For DTF and FIDO files, this card determines if a coupled library is to be split into separate libraries on the Type 1 file. Currently, only coupled neutron-photon libraries can be split. As an example, assume that the cross-section file is a coupled 42 group library ( 30 neutron groups and 12 photon groups). If the card looks like: incp=1 420

then the 42 groups will be treated as a single particle designated as other. If, however, the card looks like:

iincp=2 $30 \quad 1212$

then CRSRD will interpret this to mean that there are 42 groups total on the library, the first 30 groups are neutron, and the remaining 12 groups are photon, and these cross sections will be split into separate neutron and photon libraries on the Type 1 file. (see further discussion below concerning atomic weight raiios)

When processing an AMPX file, incp must equal the number of particles represented on the file, and the corresponding number of groups must be properly entered. If a user does not wish to have an AMPX file split into separate particles on the Type 1 file then the icoup card should be used.

This card has a slightly different meaning for the MENDF file format. If iincp is equal to one, then only the neutron file will be read , however, iincp is equal to 2, then the photon library will be read as well. The file .lame for the MENDF photon library is "mendf5g". This name can be changed in the CRSRD code if desired. ipn $=$ ?? (integer, DTF, FIDO)

?? is the Legendre order $\mathrm{L}$

$$
\text { default }=0
$$

iang = ?? (integer, DTF, FIDO, MENDF, AMPX) 
?? = -32 to 0 - the Maximum Entropy approach will be used to convert the Legendre expansion to equi-probable bins. If the value is less than 0 then the absolute value of that number will be the number of bins created. If the value is 0 then 32 bins will be created.

?? = 1 - MORSE discrete angle treatment

$? ?=2-$ RADAU discrete angle treatment

$? ?=3$ - Carter and Forest equi-probable bin treatment

default $=0$

ibal1 = ?? (integer, DTF, FIDO, MENDF, AMPX)

?? if this value is not equal to 0 , that indicates that a cross-section balance is to be performed and the value entered is the number of different particles represented on the cross-section file - no maximum number

Do $i=1$, ibal1 enter the number of groups associated with each particle default $=0$

If a cross-section balance is desired, then the user must enter the number of groups belonging to the different particles on the cross-section file. Entering the number of groups does not affect whether coupled libraries are split into separate libraries for each particle. This data is needed so that CRSRD can exclude scattering cross sections from one particle to another that should not be considered in the crosssection balance. As an example, assume that the cross-section file is a coupled 42 group library ( 30 neutron groups and 12 photon groups). If the card looks like:

ibal1=1 42

Then the scattering cross sections from the neutron groups to the photon groups will be incorrectly included in the balance of the neutron cross sections. However, the following card would be correct.

ibal1=2 3012

nabs = ?? (integer, DTF, FIDO, MENDF, AMPX)

$? ?=0$ - negative absorption cross sections will be set to zero

?? = 1 - negative absorption cross sections will not be altered

default $=0$

nall $=? ?($ integer, MENDF $)$ 
?? = 0 - process individual ZAIDs as listed in the input file

?? = 1 - process all ZAIDs on cross-section file/s - ZAIDs are not listed in the input file

defuult $=0$

icoup = ?? (integer, MENDF, AMPX)

$? ?=0$ - if coupled neutron-photon MENDF or AMPX libraries are being processed, then the neutron and photon crosis sections will be split into separate libraries on the Type 1 filc

?? = 1 - if coupled neutron-photon MENDF or AMPX libraries are being processed, then the neutron and photon cross sections will NOT be split into separate libraries; rather, all data will be kept on a single library and the particle type will be denoted as neutrou

default $=0$

nchi = ?? (integer, MENDF)

$? ?=0$ - total chi values will be used from the MENDF file

?? = 1 - prompt chi values will be used from the MENDF file default $=0$

iproc $=$ ?? (integer, DTF, FIDO, MENDF, AMPX)

?? = 0 - cross sections that are unbalanced will be skipped

$? ?=1$ - cross sections that are unbalanced will be processed anyway default $=0$

\section{Section 2 - DTF, FIDO}

\section{LINE 1}

"energy"

The character string "energy" (without the quotes) marks the beginning of section 2.

\section{FOLLOWING LINES}

If iengb $=1$, then the energy group boundaries are listed in free field input for particle 1. The number of entries is equal to the number of groups plus one and the values must be contered in MeV. If incp is cqual to two, then the energy group) boundaries for the next particlo begin on a new line inmediately following the group boundaries for the previous particle. 
If iengb $=2$, then the energy centers followed by the energy widths are listed in free field input for particle 1. The number of entries for the energy centers and the number of entries for the energy widths are equal to the number of groups for particle 1. If incp is equal to two, then the energy centers followed by the energy widths for the second particle begin on a new line immediately following the energy centers and widths for the previous particle.

\section{Section 3 - DTF, FIDO, MENDF, AMPX}

This section contains the list of materials to be processed from the cross-section file. Various information is needed depending on the file format being read. If the format is DTF, FIDO, or AMPX then the ZAID, atomic weight, and material id (if title cards are present and being used) are entered on a line. CRSRD knows which item is which by its location within the line. Optional information can be added on this line and extra lines as described below.

The material id (if entered) is used to locate the appropriate isotope within the cross-section file. If material ids are not used then the first ZAID in the input file will automatically correspond to the first cross section on the cross-section file, the second ZAID to the second cross section, etc. When processing AMPX libraries, the material id should be the identifier of the set being processed (this is word 19 on the nuclide directory record).

If the file format is MENDF, then only ZAIDs need to be entered. A separate ZAID must be entered on each line. The optional information is not applicable either.

The following is a description of the information which can be entered for each material to be processed. The information is displayed according to lines of input and the variables which are filled by the values on that line. Items displayed in quotes are character items that are entered literally.

\section{LINE 1}

"materials"

"materials" this entry must be present in order to mark the beginning of Section 3 .

\section{LINE 2}

matid zaid atw "ipn="?? "patw="??

matid (DTF, FIDO, AMPX) 
Material id on the cross-section file being read. This item is present only if ititl = 1. matid can have a maximum of 15 characters and must not contain blankspace, commas, or equal signs as these are used as delimiters.

zaid (DTF, FIDO, MENDF, AMPX)

User chosen ZAID of the form zzaaa.xx - must not contain characters and must be a number greater than or equal to 1000 . Refer to the MCNP manual ${ }^{1}$ for a description of ZAIDs.

atw (DTF, FIDO, AMPX)

Atomic weight for zaid - the atomic weight ratio will be calculated from this atomic weight and included in the atomic weight ratio table at the top of the XSDIR file. More information concerning the atomic weight ratios is provided later, and additional information can be found in the MCNP manual. ${ }^{1}$

"ipn="?? (DTF, FIDO)

Legendre order of this particular isotope if different from previous isotope. The ipn value entered in Section 1 is used until this item is entered on a line. This ipn value then remains in effect until changed. This item is optional.

"patw="?? (DTF, FIDO, MENDF, AMPX)

Atomic weight to be used for the photon portion of this cross section if this is a coupled neutron-photon library which is going to be split. In most cases this atomic weight should correspond to the atomic weight of the naturally occurring isotope. Only one photon atomic weight needs to be entered for each atomic number. However, if only one photon atomic weight is entered per atomic number then it must be associated with the first occurrence of that atomic number. If a photon atomic weight is not entered for a particular atomic number, then neutron atomic weight associated with the first occurrence of that atomic number will be used incorrectly as the photon atomic: weight. For more information refer to the discussion on atomic weights below. This item is optional.

NOTE: Items can not be split across lines.

LINE 3 - OPTIONAL for DTF and FIDO only

"edit" or "chi" or "nutotal" or "nuprompt" 
"edit" if present, indicates that edit reaction MT identifiers are to follow on the next line. The first identifier in the list corresponds to the first edit position withir, the data file and the second identifier to the second position and so on. If fewer than itpos -3 values are entered. then the last entry should be "end". These cdit numbers stay in effect, until changed. The MT identifiers listed in Table VIII have special meaning to CRSRD and should be used to represent the reaction that CRSRD associates with that jdentifier.

"chi" if present, indicates that chi values are to follow on the next line. igrps chi values are then listed in free field input. It is assumed that these chi values correspond to the first particle in the library. If fewer than igrps values are entered, the last entry should be "end". The remaining values will default to zero. These chi values remain in effect until changed.

"nuprompt" if present, indicates that $\nu_{\text {prompt }}$ values are to follow on the next line. igrps $\nu_{\text {prompt }}$ values are then listed in free field input. It is assumed that these $\nu_{\text {prompt }}$ values correspond to the first particle in the library. If fewer than igrps values are entered, the last entry should be "end". The remaining values will default to zero. These $\nu_{\text {prompt }}$ values remain in effect until changed.

"nutotal" if present, indicates that $\nu_{\text {total }}$ values are to follow on the next line. igrps $\nu_{\text {total }}$ values are then listed in free field input. It is assumed that these $\nu_{\text {total }}$ values correspond to the first particle in the library. If fewer than igrps values are entered, the last entry should be "end". The remaining values will default to zero. These $\nu_{\text {total }}$ values remain in effect until changed.

LINE 3 and associated data may be repeated for a given ZAID. For example, there may be edit reaction $M T$ identifiers, chi values, and $\nu$ values all listed for a single ZAID.

LINE 2 is repeated for as many isotopes as the user wishes. CRSRD will terminate when an end-of-file has been reached on the input file. If title cards are present, the order of the matid and associated data as listed in the input file does not have to correspond to the order in which the data appear in the cross-section file. 


\section{Compiling CRSRD}

CRSRD has been written in Fortran 77 and should compile easily on most platforms. CRSRD is distributed in a form similar to MCNP and therefore must be processed with the utility code PRPR before compiling. Instructions concerning the use of PRPR can be found in the MCNP manual.

The * define directives used by PRPR for CRSRD are listed below.

lanl - necessary for processing MENDF format ted files - only applicable at Los Alamos National Laboratory on CRAY UNICOS cheap - for 32-bit machines

ibm - for IBM RISC machines

carter - if the Carter-Forest angular treatment is desired

morse - if the MORSE and/or RADAU angular treatment is desired

nos - for the NOS operating system

nosve - for the NOSVE operating system

cftlib - for the LANL Cray Fortran library

fortlib - for the LLNL Fortran library

vms - for the VMS operating system

hpux - for the HPUX operating system

dec - for the DIGITAL Unix/Ultrix operating system

cos - for the COS operating system

unicos - for the UNICOS operating system

unix - for the UNIX operating system

aix - for the AIX operating system

pcdos - for IBM compatible Personal Computers

cray - for CRAY computers

When compiling with the lanl option on the LANL CRAYs, the user must link with the cftlib library.

\section{Discussion and Cautions}

a. Edit Reactions

In order to tally reaction rates in MCNP using the FM card, the requested reaction cross section must be available on the cross-section file. MCNP does not automatically use the total cross section when an MT of 1 is placed on the FM card. Rather MCNP looks at the list of available reaction cross sections for that MT value and uses the associated data if it is available. 
CRSRD has beeu written to store certain data automatically as edit reaction data on the Type 1 file. The list of MT values CRSRD uses for defining these default edit reactions are listed in Table VIII for DTF and FIDO formats. If any of these MT values appears in Section 3 of the input, then the default cross sections will not be used for that edit; rather the requested edit position within the cross-section file will be used.

Table IX lists the default edit MT values that are used for the MENDF format. These are the only edits available for the MENDF formats as CRSRD cannot currently read additional edit reaction data from another source.

TABLE VIII

A List of the Default Reaction MT Values that CRSRD Uses When Processing DTF and FIDO Formatted Files

\begin{tabular}{ll} 
MT value & $\begin{array}{l}\text { Cross sections or data } \\
\text { used for this reaction }\end{array}$ \\
\hline \hline 1 & Total \\
\hline 18 & Fission \\
\hline 901 & Chi values \\
\hline 903 & Prompt nu values \\
\hline 904 & Total nu values \\
\hline 905 & $\begin{array}{l}\text { Total P0 including scatter } \\
\text { to other particles }\end{array}$ \\
\hline
\end{tabular}


TABLE IX

\section{A List of the Default Reaction MT Values that CRSRD Uses When Processing MENDF Formatted Files}

\begin{tabular}{|c|c|}
\hline MT value & $\begin{array}{l}\text { Cross sections or data } \\
\text { used for this reaction }\end{array}$ \\
\hline 1 & Total \\
\hline 2 & Elastic scattering \\
\hline 4 & $\left(n, n^{\prime}\right)$ \\
\hline 16 & $(n, 2 n)$ \\
\hline 17 & $(n, 3 n)$ \\
\hline 18 & $\begin{array}{l}(n, F) \\
\text { sum of } 19,20, \text { and } 21\end{array}$ \\
\hline 19 & $(n, f)$ \\
\hline 20 & $\left(n, n^{\prime} f\right)$ \\
\hline 21 & $(n, 2 n f)$ \\
\hline 102 & $(n, \gamma)$ \\
\hline 103 & $(n, p)$ \\
\hline 107 & $(n, \alpha)$ \\
\hline 905 & $\begin{array}{l}\text { Absorption } \\
\text { sum of } 102,103, \text { and } 107\end{array}$ \\
\hline
\end{tabular}

\section{b. Cross-Section Incompatibility}

During setup and processing of the cross-section data, MCNP performs a check to verify that all of the requested multigroup cross-section tables of the same particle type are compatible. If they are not compatible, MCNP will terminate on a fatal error.

The following conditions must be met for cross-section tables to be compatible. 
- Number of angular distribution variables must be rqual

- Number of energy groups must be equal

- Number of upscatter groups must be equal

- Number of clownscatter groups must be equal

- Difference in energy group centers and widths between two tables must be less than 1.0E-00 times one of the values

- Number of groups for secondary particles listed in the production data must equal the number of groups on the cross-section tables for the secondary particle

- Difference in cnergy group centers and widths between those listed for the secondary particles in the production data and those listed on the crosssection tables of the secondary particle must be less than 1.0E-06 times the latter value.

The first condition listed has consequences for a user who wishes to process a cross section file that contains different Legendre orders when using the CarterForest, Morse, or Radau treatments. CRSRD will process files containing different Legendre orders without a problem if the user properly specifies the ipn values. However, in MCNP, only cross sections of $\mathrm{P} 0$ and $\mathrm{P} 1$ order can be mixed in an input file if they were processed with the Carter-Forest or Morse treatments. For higher order cross sections processed with these treatments the, Legendre order must be identical for all of the isotopes used in an MCNP run. Cross sections processed with the RADAU treatment that have different Legendre orders can not be used simultaneously within MCNP. Likewise all cross sections used in MCNP which were processed with the Maximum Entropy treatmont must have the same number of equal-probable bins. Further, all cross sections used in an MCNP run must have been processed with the same angular treatment.

c. Atomic Weight Ratios

MCNP uses the atomic weight ratios listed in the top of the XSDIR file to convert gram density to atonic density. The atomic weight ratios listed with each directory 
entry of the XSDIR file are used for various portions of the transport. In general, these two atomic woight ratios should be equivalent.

The atomic weight which the user enters in the CRSRD input file is converted to an atonic weight ratio, and this value is used in both locations within the XSDIR file. There is one problem that may arise when CRSRD writes the MGDIR1 file. The problem is that the atonic weight ratio written on the directory entry and in the top portion of the MGDIR1 file for the photon cross sections (separated from a coupled neutron-photon library) may be jucorrect.

The reason this problem arises is that MCNP can only use one photon cross section per element, even though multiple isotopes of an element may be used in the material definitions. In fact, when a user runs a coupled neutron-photon problem, the only ZAIDs specified on the material carcls ure neutron ZAIDs. MCNP automatically looks for the associated elemental photon cross sections. The photon ZAIDs, therefore, have the form of natural elements. For example, the associated photon ZAID for the neutron ZAID 92238 or 92236 would be 92000.

Due to the MCNP restrictions, CRSRD has been written to use only the first set of photon transport cross-section data for a particular atomic number. Any data for other isotopes having the same atomic number will not be used. This results in only one photon cross-section set per element. The ZAID for this photon crosssection set is derived from the ZAID for the isotope from which the cross-section data was taken. Because the photon ZAID has the form $x x 000$ where $x x$ is the atomic number, the value of the ZAID entered in the input file must be greater than 1000 .

In the input fild there can be two atomic weights associnted with each ZAID, and that atomic weight is appropriate for that isotope. Since the photon ZAIDs are for the elemental form of an isotope, the appropriate atomic weight should be that of the naturally occurring form of the clement. Since the photon ZAID is derived from the first isotope of an element, the photon atomic weight of that isotope is used for the atomic weight of the naturally occurring element. If the photon atomic weight was not entered, then the neutron atomic weight is used. The later is clearly incorrect, and therefore users should be aware of what they are doing.

The only time this would cause a problem is when a user wishes to run a photononly problem using the photon cross-section libraries derived from a coupled neutron photon library. In this case, the user would have to manually alter the atomic weight ratios in the MGDIR 1 file and on the Type 1 cross-section file if the neutron atomic wrights were used. 
Figure 1 is a portion of an MGDIR1 file that was created by CRSRD during the processing of a coupled neutron-photon library.

\section{G. Examples}

Figures 2, 3, and 4 are examples of input files to process DTF, FIDO, and MENDF formatted files, respectively. These are only examples, and additional or alternative options could be used. Figures 5 and 6 are examples of the DTF and the fixed-field FIDO formats for those users not familiar with these formats.

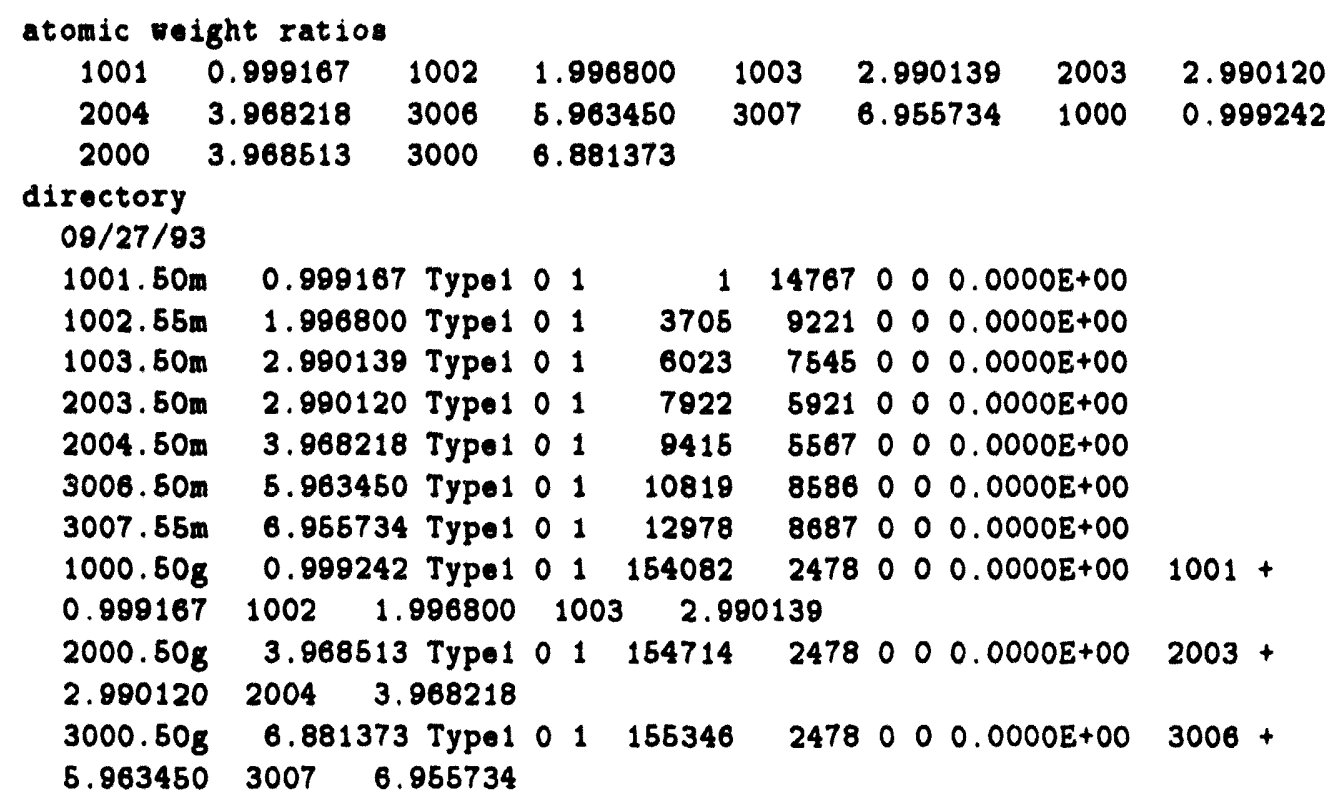

Fig. 1. This is a portion of an XSDIR file created from a coupled neutron-photon library. 


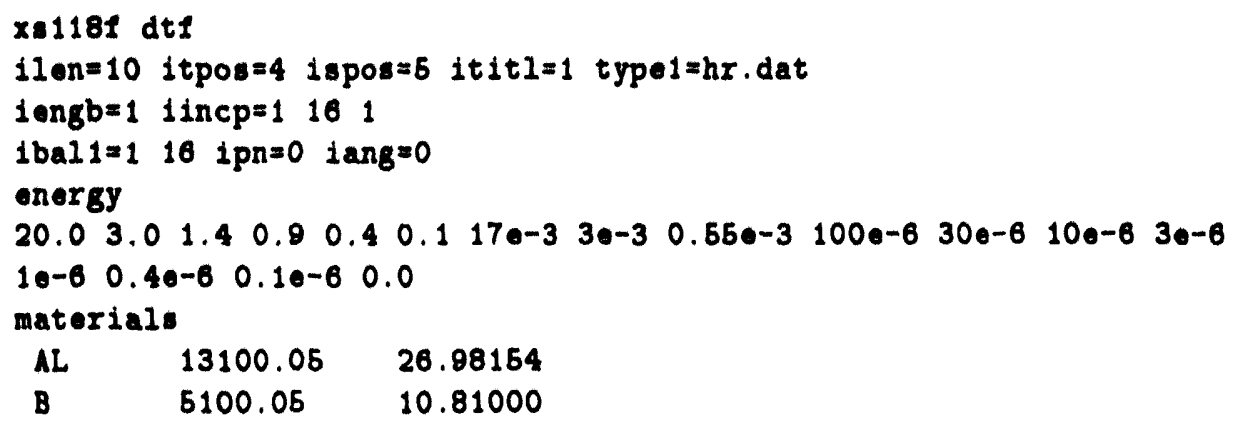

Fig. 2. This is an example of a CRSRD input file used to process a neutron cross-section file in DTF format.

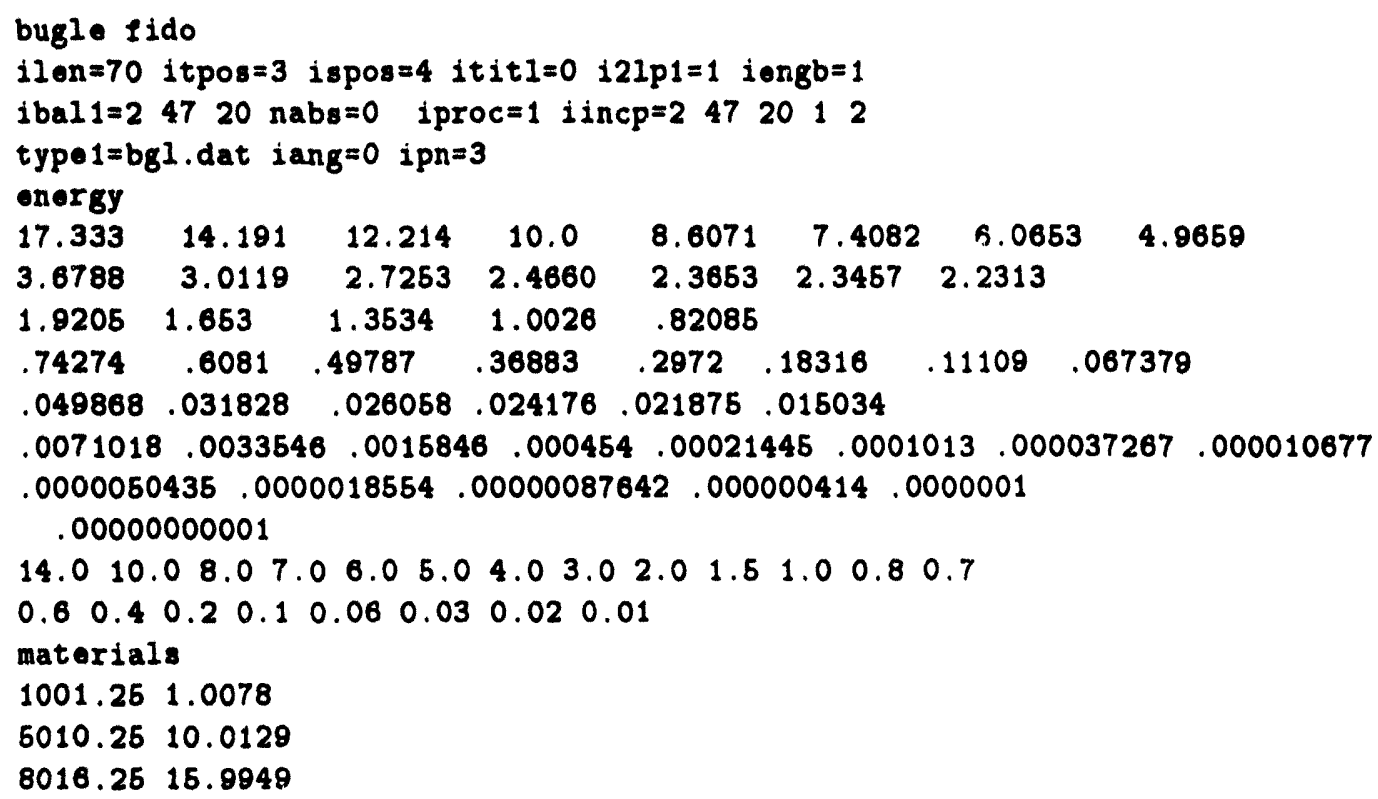

Fig. 3. This is an example of a CRSRD input file used to process a coupled neutron-photon cross-section file in FIDO format. 


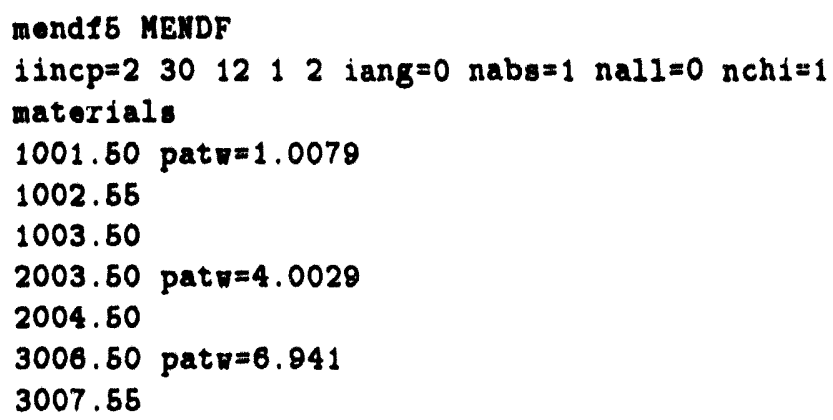

Fig. 4. This is an example of a CRSRD input file used to process a coupled neutron-photon cross-sertion file in MENDF format.

$\begin{array}{llllll}2.8853 E-05 & 0.0000 E+00 & 6.4084 E-01 & 3.7907 E-02 & 0.0000 E+00 & 0.0000 E+00 \\ 0.0000 E+00 & 0.0000 E+00 & 0.0000 E+00 & 0.0000 E+00 & 0.0000 E+00 & 0.0000 E+00 \\ 0.0000 E+00 & 0.0000 E+00 & 0.0000 E+00 & 0.0000 E+00 & 0.0000 E+00 & 0.0000 E+00 \\ 0.0000 E+00 & 0.0000 E+00 & 0.0000 E+00 & 0.0000 E+00 & 0.0000 E+00 & 0.0000 E+00 \\ 0.0000 E+00 & 0.0000 E+00 & 0.0000 E+00 & 0.0000 E+00 & 0.0000 E+00 & 0.0000 E+00 \\ 0.0000 E+00 & 0.0000 E+00 & 0.0000 E+00 & 0.0000 E+00 & 0.0000 E+00 & 0.0000 E+00 \\ 0.0000 E+00 & 0.0000 E+00 & 0.0000 E+00 & 0.0000 E+00 & 0.0000 E+00 & 0.0000 E+00 \\ 0.0000 E+00 & 0.0000 E+00 & 0.0000 E+00 & 0.0000 E+00 & 0.0000 E+00 & 0.000 E+00 \\ 0.0000 E+00 & 0.0000 E+00 & 0.0000 E+00 & 0.0000 E+00 & 0.0000 E+00 & 0.0000 E+00 \\ 0.0000 E+00 & 0.0000 E+00 & 0.0000 E+00 & 0.0000 E+00 & 0.0000 E+00 & 0.0000 E+00 \\ 0.0000 E+00 & 0.0000 E+00 & 0.0000 E+00 & 0.0000 E+00 & 0.0000 E+00 & 0.0000 E+00 \\ 0.0000 E+00 & 0.0000 E+00 & 0.0000 E+00 & 0.0000 E+00 & 3.0210 E-05 & 0.0000 E+00 \\ 7.3613 E-01 & 4.9189 E-02 & 8.1448 E-02 & 0.0000 E+00 & 0.0000 E+00 & 0.0000 E+00\end{array}$

Fig. 5. This is a portion of a DTF formatted cross-section file that has title cards.

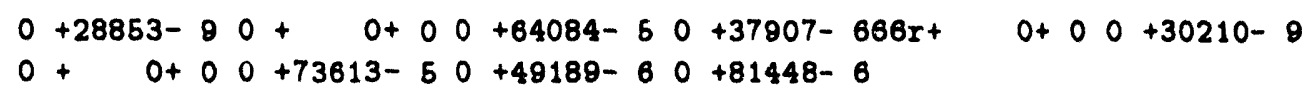

Fig. 6. This is a portion of a FIDO formatted cross-section file that does not have title cards. The data shown here is identical to the data in the previous figure. 


\section{H. MCNP Cautions}

In certain circumstances, MCNP can give fatal errors when photon cross sections that were processed with CRSRD are used.

One of these errors has to do with electron cross sections. By default, MCNP uses a thick target bremsstrahlung treatment in the continuous energy transport. When this treatment is used, MCNP must be able to find the electron cross sections through the XSDIR file. The XSDIR file (MGDIR1) created by CRSRD does not have these electron cross sections listed. Therefore, when a photon or coupled neutron-phot on problem is run with MCNP using the multigroup cross sections and the XSDIR file generated with CRSRD, a fatal error will occur. The solution to this problem is to turn off the thick target bremsstrahlung by placing the following card in the input file.

\section{PHYS:P J 1}

It should be noted that even though the electron cross sections are loaded when this card is not present, MCNP does not perform a thick target bremsstrallung treatment during multigroup transport. Therefore, the answers will be identical with or without the above mentioned card in the input file.

The second problem arises when a coupled neutron-photon problem is being run using photon cross sections generated with CRSRD that have more than 16 groups. In this situation, MCNP will print a fatal error about the febl array being too small. In order to solve this problem, a user will have to change the size of the $f e b l$ and $e b l$ arrays within MCNP and recompile. The following is a list of the locations within MCNP that must be changed.

vv4a.1, cm.62, cm4a.30, cm.173, bd.8, mg.12

These identifiers correspond to the ids listed in the MCNP source in columns 81-93 prior to running PRPR. For further information on the feblarray a user can consult the MCNP manual.

\section{UTILIZING MULTIGROUP/ADJOINT CAPABILITIES}

\section{A. Forward Multigroup}

\section{Default Multigroup Cross-Sections for MCNP}

MENDF5 $5^{20}$ is a 30-group neutron cross-section library available for use at Los Alamos National Laboratory. MENDF5G is a companion library containing 
neutron-induced photon-production data and photon-interaction data. The photon cross sections are given in 12 groups. The group boundaries corresponding to the neutron and photon libraries are listed in Tables A.I and A.II, ${ }^{21}$ respectively, of Appendix A. Although multigroup cross sections are problem dependent, there is the belief that the requirement for a large set of problems may be adequately met by using cross sections collapsed by one well-conceived weight function into one well-conceived group structure. This contention was the motivation for the development of the MENDF5 libraries. Note. that all of these cross sections are infinitely dilute; no self-shielding has been incorporated, and no upscatter groups are provided for.

Table A.III, ${ }^{22}$ of Appendix A, lists all the materials that are available on MENDF5 and MENDF5G. The ZAID identifiers and evaluated data sources are given for all 99 isotopes. From Table A.III, one may determine the source of the data and whether photon-production data are included for each cross-section set.

These MENDF5 libraries have been processed by an older version of CRSRD using the Carter Forest treatment, resulting in the default MCNP multigroup crosssection library MGXSNP. The evaluated data sources of this default library and the default continuous energy cross sections are identical for all isotopes. Additional edit reaction data were used to supplement the MENDF5 data, and prompt chi values were used in the processing of fissionable isotopes.

\section{Using Multigroup Cross Sections}

The use of the multigroup option in MCNP with the default multigroup cross sections is very straightforward. A continuous energy input deck can be converted into a forward multigroup input deck by merely performing two simple steps: (1) insert the MGOPT card followed by an $f$ (for forward) and an integer representing the total number of groups for all the kinds of particles in the problem, and (2) remove any $\mathrm{MT}$ cards $(\mathrm{S}(\alpha, \beta)$ thermal scattering treatment). When using the default multigroup cross-section library (MGXSNP), the following cards can be used for the conversion:

$$
\begin{array}{lllll}
\text { MGOPT } & F & 12 & \text { \$ MODE P } \\
\text { MGOPT } & F & 30 & \text { \$ MODE N } \\
\text { MGOPT } & F & 42 & \text { \$ MODE N P }
\end{array}
$$


Notice that when performing a coupled neutron-photon calculation, the number of neutron energy groups and the number of photon energy groups are summed and entered on the MGOPT card.

To use alternative multigroup cross-section libraries that have been processed by CRSRD, one must simply insert the MGOPT card as discussed above (recalling that your number of energy groups will most likely be different), remove any MT cards, bring the directory file MGDIR1 into your local file space, and rename MGDIR1 to XSDIR or set XSDIR = MGDIR1 on the MCNP execution line. Also, verify that the desired cross-section library is located where MGDIR1 clains it to be.

\section{Energy Group Boundaries for Tally and Source Specification}

Internally, MCNP uses the mid-point energy of each group, as defined by the group energy boundaries, as the energy value associated with the particles in each group. Therefore, in order to score particles in a given energy group within a given tally bin, the bin energy limits must bracket the median energy of the groups. As long as this condition is satisfied, the actual bin limits do not affect the tally score. However, the bin linits must not be so wide that they encompass the median energy of the adjacent energy group. Therefore, to avoid potential problems, the user is encouraged to define tally bin limits equal to the group bounclaries so that a tally energy bin spans one or severa! energy groups, and source energy bin limits such that they correspond directly to the group boundaries.

\section{Cautions}

Multigroup libraries are problem dependent. Before using any multigroup library, one should determine its applicability to the intended problem. Applicability can be determined by examining the group structure, the weighting function used for collapsing, the intended use of the library, and any assumptions/approximations used to generate the library.

As mentioned, MCNP requires slightly different information than most deterministic transport codes. Hence, the information contained in many deterministic libraries must be translated into the information that MCNP requires. The translation is not always completely possible, and thus approximations are made in some of these translations. The approximations can translate into minor discrepancies between the data that MCNP expects and the data that MCNP recoives. For example, the MENDF5 library contains only prompt $\bar{\nu}$ information. Thus, when performing criticality calculations for the purpose of code comparisons with one 
of the DANT codes (with the default multigroup library MGXSNP), it is necessary to place the following card in the input deck, TOTNU NO. ${ }^{23}$ This card will cause prompt $\bar{\nu}$ to be used for all fissionable nuclides and therefore elicit the appropriate treatment in MCNP. There is currently no way to use $\bar{\nu}$ in ONEDANT, TWODANT, or THREEDANT runs when using data from MENDF5.

In addition, the $S(\alpha, \beta)$ thermal scattering treatment is inappropriate in the multigroup mode because thermal scattering is assumed to be fully treated in the multigroup library. This thermal scattering treatment has been shown to be quite effective in predicting accurate results in the continuous energy mode. ${ }^{8}$ Therefore, the user must be cautious when attempting to solve highly moderated problems with multigroup cross sections, especially when using the default multigroup cross sections, due to the coarse thermal group structure (see Table A.I in Appendix A).

\section{B. Multigroup/Adjoint}

MCNP adjoint calculations require external calculations to be performed by the user. Thus, they are not quite as straightforward as many of the other MCNP capabilities. For this reason, it is necessary to step through the methodology and procedure for performing an adjoint calculation.

The MCAL parameter on the MGOPT (Multigroup Adjoint Transport Option) card allows the user to specify either a forward or an adjoint calculation. However, specifying an adjoint calculation by entering an $a$ for the MCAL parameter results only in an adjoint treatment of particle collisions. For a full arljoint treatment of the calculation, the user must redefine the source and tally regions accordingly. The tally characteristics in a forward run are described by the SDEF and associated cards in the adjoint run. Likewise, the source characteristics in the forward run are defined by tally cards in the adjoint run.

The source characteristics that a user may define with SDEF and associated cards are spatial, time, angular, and energy dependence. Likewise, the tally character. istics that a user may define with the $\mathbf{F}$ and associated tally cards are spatial, time, angular, and/or energy response. Hence, the problem is essentially turned around, resulting in an approximately backward Monte Carlo calculation with adjoint treatment of particle collisions. Constructing an opposite direction problem is not always possible, but the flexibility provided by MCNP in describing sources and tallies makes it possible for most problems. 
Unfortunately, replacing the source with its corresponding tally and the tally with its corresponding source will not cause the opposite direction problem (adjoint or forward) to produce correctly normalized results. In general, the product of the source densities times the response functions in the opposite direction problem should be the same as the product of the source densities times the response functions in the original problem. ${ }^{24}$ In order to satisfy this requirement, adjustments to the initial weight of the particles must be made to correct for the automatic normalization of the source densities by MCNP.

The typical user may not be familiar with the terms source density and response function since these functions are inherent characteristics of the various sources and tallies used by MCNP. For example, when a user defines a volume source with volume $V_{s}$, he/she is actually defining a uniform spatial density of $1 / V_{s}$ source particles within volume $V_{s}$. Also, unless otherwise specified, MCNP assumes the angular density to be $1 / 4 \pi$ particles per steradian. These inherent normalizations are referred to as source densities. On the other hand, if the user specifies an F4 tally for a cell of volume $V_{t}$, the result is a spatial response of $1 / l_{t}$ (1 per unit volume) and an angular response of 1 per steradian. Hence the term, response function.

The source densities are defined with parameters on the SDEF card such as

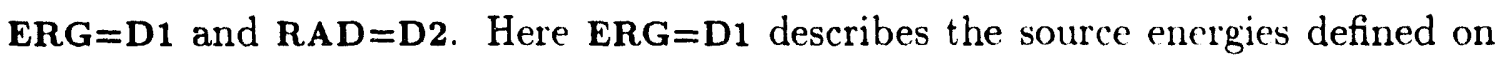
the SI1 card and $\mathbf{R A D}=\mathbf{D 2}$ designates that the radial (spatial) density of the source particles is defined with the density given on the the S12 and SP2 cards. The source densities defined with the SIn and SPn cards are automatically normalized by MCNP, and the source densities that are not defined are defaulted. To represent the source densities properly as response functions in an opposite direction problem, the user must be aware of the automatic normalization and the source default values.

Tally spatial, angular, and energy responses are determined by the number $n$ on the Fn card. However, these responses may be modified with the addition of EM, FM, CM, TM, SD, etc. cards. Except for the division by area for an $\mathbf{F 2}$ tally and the division by volume for the F4, F6, and F7 tallies, MCNP does not normally adjust the response functions defined by the user.

Table $\mathrm{X}$ shows the source and tally cards and their parameters that should replace the corresponding tally and source cards and parameters in constructing an opposite direction problem. 
TABLE X

Source and Tally Relationships for Opposite

Direction Problems

Source

Tally

SDEF (volume source)

(CEL,POS,RAD,AXS,EXT)

SDEF (surface source)

(SUR,POS,RAD,AXS,EXT)

SDEF (point source)

(POS,X,Y,Z)

SDEF (energy) $(\mathbf{E R G}=\mathrm{Dn})$

SIn, $\mathrm{SPn}$

SDEF (angle) $(D I R=D n, V E C=a b c)$

SIn, SPn

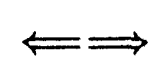

$\Longleftarrow$

F1, F2

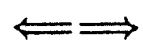

F5

$\Longleftrightarrow \quad$ FM, EM, DF

$\Longleftarrow \quad \mathrm{CM}$ (for F1 or F5 tally)

\section{Using Multigroup Adjoint Transport Option}

The procedure for setting up an adjoint problem, starting from a forward multigroup problem, will now be explained. Make a copy of the original (forward) problem input file, and redefine the source and tallies using the relationships given in Table X. Determine the source densities and the response functions for both the forward and adjoint problems. A form such as that provided in Table XI may be of assistance. The values filling the blanks depend on the characteristics of the sources and tallies that are defined in the forward and adjoint problems. After the table is complete, the product of the entries in the forward problem column is divided by the product of the entries in the adjoint problem column to obtain a normalization factor. The WGT parameter on the SDEF card, corresponding to the adjoint problem, is then set equal to this normalization factor. In addition, the MCAL parameter on the MGOPT card must be changed from $f$ to $a$, and the energy cut-off parameter on the CUT card must be set equal to the highest energy value in the forward run. If the forward problem employs cell importances, these should be removed in the adjoint problem. 


\section{TABLE XI}

\section{Normalization Form for Adjoint Problems}

\begin{tabular}{|c|c|c|}
\hline \multicolumn{2}{|c|}{ Forward Problem } & Adjoint Problem \\
\hline spatial density & & \\
\hline direction density & & \\
\hline time density & & \\
\hline energy density & & \\
\hline spatial response & & \\
\hline direction response & & \\
\hline time response & & \\
\hline energy response & & \\
\hline
\end{tabular}

\section{Examples}

The following rather simple examples will illustrate the procedure for converting forward calculations into adjoint calculations.

\section{Example 1}

The first example involves photon transport through lead. The problem consists of a 20-cm-radius spherical volume source, centered at the origin. enclosed in a 5-cm-thick spherical shell of lead. The source spectrum extends over the energy range 0.50 to $20.0 \mathrm{MeV}$ and has no defined functional description. A drawing of the configuration is given in Fig. 7. The tally consists of a single point detector located on the $\mathrm{z}$-axis, $45 \mathrm{~cm}$ from the origin. This problem is intentionally quite simplistic. The forward input file for this problem can be found in Fig. B1 of Appendix B. Note the presence of the FT, FU, and FQ tally cards. The FT and FU cards are used to output the results as a function of the order of scatter. The FQ card is used to print the information in the desired format. Analysis of the results as a function of the order of scatter can be extremely holpful when trying to identify discrepancies between forward and adjoint calculations.

To perform this calculation in the adjoint mode, the user should copy the forward input file to another file for modification. The spherical volume source must be replaced by a cell-averaged flux (F4) tally, and the point detector is transformed into a point source. The source spectrum in the forward problem becomes the energy response function in the adjoint problem, and the source spectrum in the adjoint problem is just unity because the energy response function in the forward problem is unity. Simply stated, the SP1 and EM0 cards are interchanged for the adjoint calculation. The SI 1 and E0 cards should also be interchanged; however, 
it is not necessary in this problem as they are the same. Next, the energy cutoff in the adjoint input deck is set equal to the maximum source energy (i.e., 20.0 $\mathrm{MeV}$ ), and the $f$ on the MGOPT card is replaced by an $a$. These steps conclude the transformation process except for the normalization.

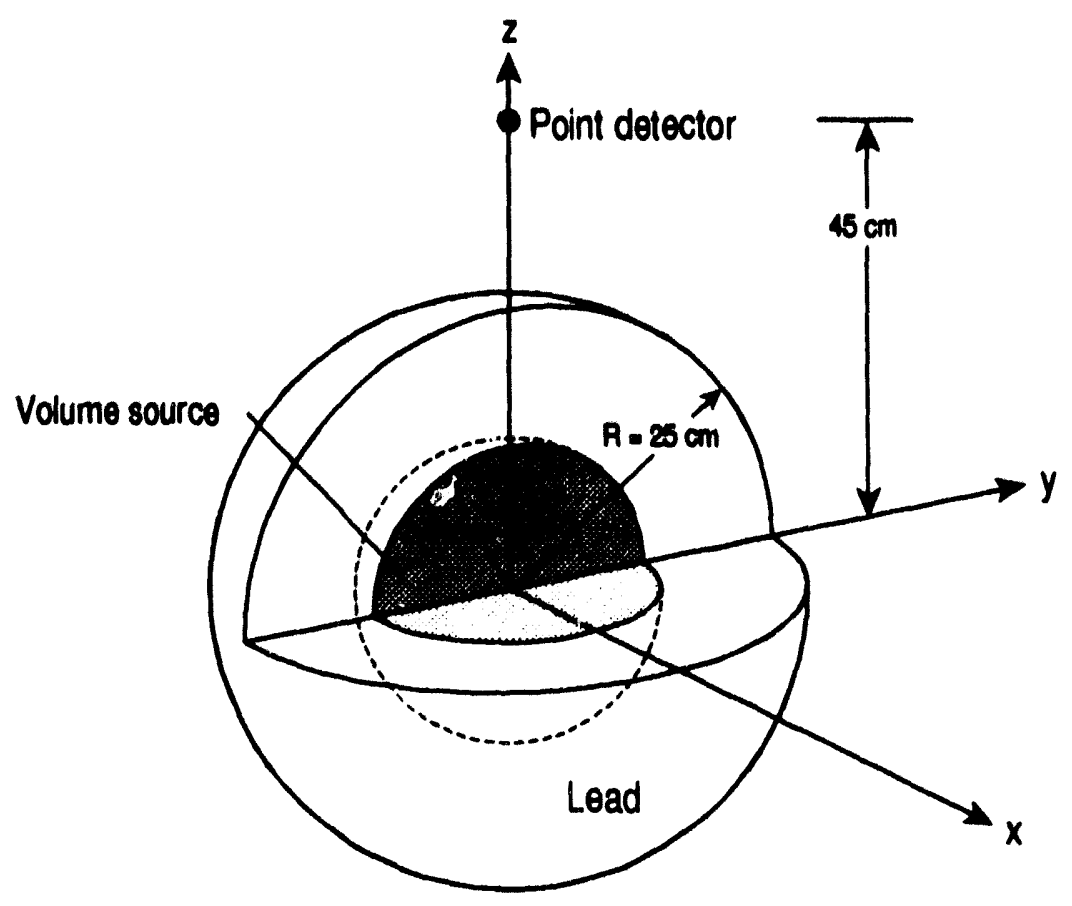

Fig. 7. Drawing of Conflguration for Example \#1.

Table XII shows a completed copy of the normalization form for this example. The values on the SP1 card of the forward run sum to 14.60, the value used for $\Sigma P_{g}$ in the normalization. The values on the EMo card of the forward run (energy response function) sum to 10.0 , the value used for the $\Sigma R_{y^{\prime}}$ in the normalization. As mentioned, the default direction density in MCNP is $1 / 4 \pi$; therefore, because the angular density is not otherwise specified, $1 / 4 \pi$ is entered in both columns. The volume of the source is entered for the spatial density in the forward problem and for the spatial response in the adjoint problem. The spatial contribution cancels out of the normalization. At this point, the product of the values in the column corresponding to the forward problem is divided by the product of the values in the 
column corresponding to the adjoint problem, to produce the desired normalization factor. This normalization factor is subsequently entered with the WGT parameter on the SDEF card in the adjoint input file.

TABLE XII

Normalization Form for Example \# 1

Forward Problem

\begin{tabular}{|c|c|c|}
\hline spatial density & $3 / 4 \pi(20)^{3}$ & 1 \\
\hline direction density & $1 / 4 \pi$ & $1 / 4 \pi$ \\
\hline time density & 1 & 1 \\
\hline energy density & $\mathrm{P}_{q} / \mathrm{P}_{q}$ & $\mathrm{R}_{q^{\prime}} / \mathrm{R}_{q^{\prime}}$ \\
\hline spatial response & 1 & $3 / 4 \pi(20)^{3}$ \\
\hline direction response & 1 & 1 \\
\hline time response & 1 & 1 \\
\hline energy response & $\mathrm{R}_{q^{\prime}}$ & $\mathrm{P}_{q}$ \\
\hline
\end{tabular}

When performing an adjoint calculation, the scores for a particular tally are not binned according to which bin of a source distribution the source particle originated in. Hence in the above problem, the energy spectrum produced by the forward and adjoint calculations will differ. This difference in the way scores are binned can be eliminated with the assistance of the SCX option on the FT card. The use of this card is demonstrated in the adjoint input file for this problem. which is located in Fig. B2 of Appendix B.

In order to verify that the adjoint calculation has been constructed and executed properly, the results as a function of the order of scatter and the spectra should be compared. These results are shown in Tables XIII and XIV, respectively. All of the relative differences listed in Table XIII, and all but two (the third and the last) of the relative differences listed in Table XIV are shown to be within the $1 \sigma$ statistical uncertainties. For example, the difference between adjoint and forward for the 10th order of scatter is $86 \%$, but the relative errors are 0.845 and $0.47 i$. Thus, the flux corresponding to the tenth order of scatter is within the $1 \sigma$ statistical uncertainties. Further, this flux is five orders of magnitude lower than the uncollided, and therefore, the $86 \%$ difference is unimportant. 


\section{TABLE XIII}

\section{Results as a Function of Order of Scatter \\ for Example \# 1}

\begin{tabular}{|c|c|c|c|c|c|}
\hline \multirow[b]{2}{*}{$\begin{array}{l}\text { Order of } \\
\text { Scattering }\end{array}$} & \multicolumn{2}{|c|}{ Forward Problem } & \multicolumn{2}{|c|}{ Adjoint Problem } & \multirow{2}{*}{ 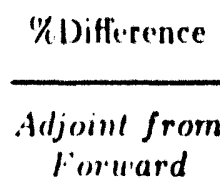 } \\
\hline & $\begin{array}{c}F / u x \\
\left(n / c m^{2}\right)\end{array}$ & $\begin{array}{c}\text { Relative } \\
\text { Error }\end{array}$ & $\begin{array}{c}\text { Flux } \\
\left(\mathrm{n} / \mathrm{cm}^{2}\right)\end{array}$ & $\begin{array}{l}\text { Relative } \\
\text { Error }\end{array}$ & \\
\hline 0 & $0.10761 \mathrm{E}-06$ & 0.002 & $0.10721 \mathrm{E}-06$ & 0.011 & 0.37 \\
\hline 1 & 0.11720 E-06 & 0.026 & $0.12012 \mathrm{E}-06$ & 0.008 & -2.48 \\
\hline 2 & $0.74523 \mathrm{E}-07$ & 0.034 & $0.73148 \mathrm{E}-07$ & 0.010 & 1.85 \\
\hline 3 & $0.34323 \mathrm{E}-07$ & 0.045 & $0.33886 \mathrm{E}-07$ & 0.017 & 1.27 \\
\hline 4 & $0.12736 \mathrm{E}-07$ & 0.070 & $0.13178 E-07$ & 0.029 & -3.47 \\
\hline 5 & $0.48983 \mathrm{E}-08$ & 0.120 & $0.48038 \mathrm{E}-08$ & 0.064 & 1.93 \\
\hline 6 & $0.15568 \mathrm{E}-08$ & 0.231 & $0.13572 \mathrm{E}-08$ & 0.106 & 12.82 \\
\hline 7 & $0.41750 \mathrm{E}-09$ & 0.359 & $0.28970 \mathrm{E}-09$ & 0.125 & 30.61 \\
\hline 8 & $0.22504 \mathrm{E}-09$ & 0.566 & $0.88059 \mathrm{E}-10$ & 0.221 & 60.87 \\
\hline 9 & $0.20841 E-10$ & 0.689 & $0.16083 \mathrm{E}-10$ & 0.345 & 22.83 \\
\hline 10 & $0.13899 \mathrm{E}-11$ & 0.845 & $0.25841 \mathrm{E}-11$ & 0.477 & -85.92 \\
\hline
\end{tabular}

TABLE XIV

Comparison of Spectra for Example \#1

\begin{tabular}{|c|c|c|c|c|c|}
\hline \multirow[b]{2}{*}{$\begin{array}{l}\text { Upper Energy } \\
\text { Bounds }\left(M e V^{\prime}\right)\end{array}$} & \multicolumn{2}{|c|}{ Forward Problem } & \multicolumn{2}{|c|}{ Adjoint Problem } & \multirow{2}{*}{ 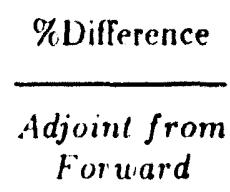 } \\
\hline & $\begin{array}{c}\text { Flux } \\
\left(\mathrm{n} / \mathrm{cm}^{2}\right)\end{array}$ & $\begin{array}{l}\text { Relative } \\
\text { Error }\end{array}$ & $\begin{array}{c}F l u x \\
\left(n / c m^{2}\right)\end{array}$ & $\begin{array}{l}\text { Relatile } \\
\text { Error }\end{array}$ & \\
\hline 1.0 & $0.85335 \mathrm{E}-07$ & 0.019 & $0.84441 E-07$ & 0.018 & 1.05 \\
\hline 2.0 & $0.71296 \mathrm{E}-07$ & 0.032 & $0.70345 \mathrm{E}-07$ & 0.012 & 1.33 \\
\hline 3.0 & $0.47757 \mathrm{E}-07$ & 0.042 & $0.51037 \mathrm{E}-07$ & 0.012 & -6.87 \\
\hline 4.0 & $0.37252 \mathrm{E}-07$ & 0.048 & $0.36246 \mathrm{E}-07$ & 0.015 & 2.70 \\
\hline 5.0 & $0.25111 \mathrm{E}-07$ & 0.059 & $0.25506 \mathrm{E}-07$ & 0.018 & -1.57 \\
\hline 6.0 & $0.24441 \mathrm{E}-07$ & 0.060 & $0.23006 \mathrm{E}-07$ & 0.021 & 5.87 \\
\hline 7.0 & $0.19595 \mathrm{E}-0 \mathrm{~T}$ & 0.035 & $0.20592 \mathrm{E}-07$ & 0.025 & -5.09 \\
\hline 8.0 & $0.18797 E-07$ & 0.050 & $0.17601 \mathrm{E}-07$ & 0.029 & 6.37 \\
\hline 9.0 & $0.14531 \mathrm{E}-07$ & 0.026 & $0.15338 \mathrm{E}-07$ & 0.031 & -5.55 \\
\hline 20.0 & $0.94019 \mathrm{E}-08$ & 0.014 & $0.99852 \mathrm{E}-08$ & 0.036 & -6.20 \\
\hline
\end{tabular}

Figure 8 lists the tally fluctuation charts for the two solutions and reveals that the Figure of Merit (FOM) corresponding to the adjoint solution is more than a factor 
of sixteen greater than the FOM for the forward problem. Further. Fig. 9 verifies that the factor, by which the adjoint FOM is larger than the forward FOM for the above problem, is approximately doubled when the thickness of lead is doubled.

In this first example the forward problem could have becn run more efficiently using an F2 tally located on a 45-cm-radius spherical surface rather than using a point detector. However, the main purpose of the example is to demonstrate the procedure for setting up an adjoint problem. Also, the angular distribution of the point source in the adjoint problem could have been restricted to the solid angle subtended by the 25-cm-radius lead sphere, which may have sligltty increased the efficiency of the adjoint problem. However, this restriction definitely would have required a different weighting factor since the adjoint source angular distribution would have been $1 / \Delta \Omega$ rather than $1 / 4 \pi$.

\section{Example 2}

The second example involves neutron transport from a 25-('m-radius disk source incident on a $10-\mathrm{cm}$ - thick slab of water. The source has a cosine angular density

and a continuous spectrum defined by the density $S(E)=\int_{E_{y}}^{E_{g^{\prime}}}(10.0-E) d E$, over the range from 0.01 to $10.0 \mathrm{MeV}$. The tally is a point detector $5 \mathrm{~cm}$ from the opposite side of the water slab with an energy response $R(E)=\left(E_{g^{\prime}}-E_{g}\right) / 2$ over the range from 0.01 to $10.0 \mathrm{MeV}$. A drawing of this configuration is provided in Fig. 10, and the forward input file for this problem is listed in Fig. B3.

To perform this calculation in the adjoint mode, the user must first change the disk source into a surface current (F1) tally with energy response $S(E)$ and change the point detector into a point source with a spectrum defined by $R(E)$. Due to the cosine angular density of the forward source, the disk source is replaced by a surface current tally, rather than by a surface flux tally. The spectrum and response function are taken care of by merely interchanging the SP2 and EMO cards for the adjoint calculation. Also, the SI2 and E0 cards need to be interchanged; although for this problem they are the same. Next, the energy cutoff is set equal to the maximum source energy, and the $f$ on the MGOPT card is repliced lyy an $a$. These steps conclude the transformation process except for the normalization. 


\section{(a). Adjoint Problem}

\begin{tabular}{|c|c|c|c|c|c|}
\hline nps & mean & $\begin{array}{l}\text { tally } \\
\text { orror }\end{array}$ & $\begin{array}{c}4 \\
\text { vor }\end{array}$ & 10pe & fom \\
\hline 612000 & 3. $6083 \mathrm{E}-07$ & 0.0269 & 0.0098 & 6.3 & 1397 \\
\hline 1024000 & 3. $6152 \mathrm{E}-07$ & 0.0192 & 0.0058 & 4.7 & 1375 \\
\hline 1536000 & $3.4594 \mathrm{E}-07$ & 0.0155 & 0.0032 & 4.6 & 1408 \\
\hline 2048000 & $3.4808 \mathrm{E}-07$ & 0.0136 & 0.0023 & 6.0 & 1385 \\
\hline 2500000 & $3.4674 E-07$ & 0.0120 & 0.0017 & 4.3 & 1413 \\
\hline 3072000 & $3.4681 \mathrm{E}-07$ & 0.0110 & 0.0014 & 4.3 & 1415 \\
\hline 3584000 & $3.4574 E-07$ & 0.0101 & 0.0011 & 4.4 & 1430 \\
\hline 4096000 & $3.4760 E-07$ & 0.0095 & 0.0009 & 3.7 & 1428 \\
\hline 4608000 & $3.4771 \mathrm{E}-07$ & 0.0089 & 0.0008 & 3.8 & 1431 \\
\hline 5120000 & $3.4920 E-07$ & 0.0086 & 0.0024 & 3.3 & 1374 \\
\hline 5632000 & $3.5041 E-07$ & 0.0083 & 0.0022 & 3.3 & 1365 \\
\hline 6144000 & 3. $5080 \mathrm{E}-07$ & 0.0079 & $0.001 \theta$ & 3.1 & 1374 \\
\hline 6656000 & $3.5045 E-07$ & 0.0076 & 0.0017 & 3.1 & 1378 \\
\hline 7168000 & $3.5182 E-07$ & 0.0073 & 0.0016 & 3.1 & 1363 \\
\hline 7680000 & 3. $6247 \mathrm{E}-07$ & 0.0071 & 0.0015 & 2.8 & 1367 \\
\hline 8192000 & $3.5326 \mathrm{E}-07$ & 0.0068 & 0.0013 & 2.8 & 1362 \\
\hline 8704000 & 3. $6341 \mathrm{E}-07$ & 0.0066 & 0.0012 & 2.7 & 1365 \\
\hline 9216000 & 3. 5336E-07 & 0.0065 & 0.0011 & 2.7 & 1360 \\
\hline 28000 & 3. $5388 \mathrm{E}-07$ & 0.0063 & 0.0012 & 2.7 & 1348 \\
\hline 00000 & $5410=-$ & 0.0082 & 0.0012 & 2.7 & 1342 \\
\hline
\end{tabular}

(b). Forward Problem

\begin{tabular}{|c|c|c|c|c|c|}
\hline nps & mean & $\begin{array}{l}\text { tally } \\
\text { orror }\end{array}$ & $\begin{array}{c}5 \\
\text { vor }\end{array}$ & slope & fom \\
\hline 512000 & $3.4510 \mathrm{E}-07$ & 0.0529 & 0.0528 & 2.2 & 106 \\
\hline 1024000 & $3.5349 E-07$ & 0.0352 & 0.0222 & 5.0 & 120 \\
\hline 1536000 & $3.6362 \mathrm{E}-07$ & 0.0336 & 0.0484 & 4.0 & 88 \\
\hline 2048000 & $3.6088 E-07$ & 0.0285 & 0.0320 & 5.5 & 92 \\
\hline 2560000 & 3. $5909 \mathrm{E}-07$ & 0.0267 & 0.0247 & 4.4 & 83 \\
\hline 3072000 & $3.6514 E-07$ & 0.0260 & 0.0369 & 4.5 & 73 \\
\hline 3584000 & 3. 6588E-07 & 0.0237 & 0.0292 & 4.5 & 75 \\
\hline 4096000 & $3.6171 \mathrm{E}-07$ & 0.0219 & 0.0252 & 4.6 & 77 \\
\hline 4608000 & $3.6306 \mathrm{E}-07$ & 0.0207 & 0.0208 & 4.6 & 77 \\
\hline 5120000 & 3. 6283E-07 & 0.0183 & 0.0183 & 4.5 & 80 \\
\hline 5632000 & 3.6230E-07 & 0.0184 & 0.0167 & 4.1 & 80 \\
\hline 6144000 & $3.6387 E-07$ & 0.0179 & 0.0151 & 4.0 & 77 \\
\hline 6656000 & $3.6058 \mathrm{E}-07$ & 0.0170 & 0.0141 & 4.4 & 79 \\
\hline 7168000 & $3.5870 E-07$ & 0.0163 & 0.0129 & 5.0 & 80 \\
\hline 7680000 & $3.5746 E-07$ & 0.0156 & 0.0118 & 5.2 & 82 \\
\hline 8192000 & 3. 5598E-07 & 0.0151 & 0.0113 & 4.7 & 81 \\
\hline 8704000 & 3. 5589E-07 & 0.0147 & 0.0103 & 5.0 & 81 \\
\hline 9216000 & 3. 5628E-07 & 0.0142 & 0.0093 & 5.8 & 81 \\
\hline 9728000 & 3. 5477E-07 & 0.0138 & 0.0088 & 5.6 & 82 \\
\hline 10000000 & $3.5362 E-07$ & 0.0136 & 0.0087 & 5.6 & 82 \\
\hline
\end{tabular}

Fig. 8. Tally Fluctuation Charts for Example \#1 (forward and adjoint). 


\section{(a). Adjoint Problem}

\begin{tabular}{|c|c|c|c|c|c|}
\hline np: & moan & $\begin{array}{l}\text { tally } \\
\text { error }\end{array}$ & $\begin{array}{c}4 \\
\text { vov }\end{array}$ & -10po & lom \\
\hline 612000 & 3. $3461 E-08$ & 0.0658 & 0.0199 & 10.0 & 225 \\
\hline 1024000 & 3. $3076 \mathrm{E}-08$ & 0.0478 & 0.0123 & 10.0 & 214 \\
\hline 536000 & 3. $3338 E-08$ & 0.0380 & 0.0074 & 10.0 & 225 \\
\hline 048000 & 3. 3753E-08 & 0.0336 & 0.0060 & 10.0 & 216 \\
\hline 2560000 & 3. $4334 E-08$ & 0.0289 & 0.0046 & 10.0 & 219 \\
\hline 3072000 & $3.4342 E-08$ & 0.0274 & 0.0039 & 10.0 & 217 \\
\hline 584000 & $3.4678 E-08$ & 0.0261 & 0.0033 & - & 222 \\
\hline 4098000 & 3. $5033 E-08$ & 0.0236 & 0.0029 & 10.0 & 220 \\
\hline 4608000 & 3. $5218 E-08$ & 0.0222 & 0.0025 & 10.0 & 221 \\
\hline 5120000 & 3. $5220 \mathrm{E}-08$ & 0.0211 & 0.0023 & 10.0 & 220 \\
\hline 5632000 & 3. $6207 \mathrm{E}-08$ & 0.0200 & 0.0021 & 10.0 & 222 \\
\hline 6144000 & 3. $5140 \mathrm{E}-08$ & 0.0192 & 0.0019 & 10.0 & 222 \\
\hline 6656000 & 3. $5196 \mathrm{E}-08$ & 0.0184 & 0.0018 & 10.0 & 223 \\
\hline 7000000 & 3. $5363 E-08$ & 0.0180 & 0.0017 & 10.0 & 222 \\
\hline
\end{tabular}

\section{(b). Forward Problem}

\begin{tabular}{|c|c|c|c|c|c|}
\hline nps & mean & $\begin{array}{l}\text { tally } \\
\text { orror }\end{array}$ & $\begin{array}{c}6 \\
\text { vov }\end{array}$ & slope & fom \\
\hline 512000 & $3.5108 E-08$ & 0.1642 & 0.2212 & 1.7 & 11 \\
\hline 1024000 & 4. 1201E-08 & 0.1656 & 0.1987 & 1.8 & $5.4 E+00$ \\
\hline $153 A 000$ & $4.0658 E-08$ & 0.1342 & 0.1436 & 2.0 & $5.6 E+00$ \\
\hline 2048000 & $4.0154 E-08$ & 0.1172 & 0.1186 & 2.0 & 5. $4 E+00$ \\
\hline 2560000 & 3.8787E-08 & 0.1016 & 0.1010 & 2.1 & $6.8 E+00$ \\
\hline 3072000 & $3.7602 E-08$ & 0.0902 & 0.0897 & 2.2 & $6.1 E+00$ \\
\hline 3584000 & $3.7044 E-08$ & 0.0807 & 0.0806 & 2.2 & $6.5 E+00$ \\
\hline 4086000 & 3. $6040 \mathrm{E}-08$ & 0.0748 & 0.0732 & 2.2 & $6.7 E+00$ \\
\hline 4608000 & $3.5809 E-08$ & 0.0687 & 0.0663 & 2.3 & $7.0 \mathrm{E}+00$ \\
\hline 5120000 & $3.5943 E-08$ & 0.0637 & 0.0588 & 2.4 & 7. $3 E+00$ \\
\hline 5632000 & $3.6545 \mathrm{E}-08$ & 0.0684 & 0.0777 & 2.3 & $6.1 E+00$ \\
\hline 6144000 & $3.6615 E-08$ & 0.0627 & 0.0681 & 2.4 & $6.3 E+00$ \\
\hline 685 & $8006 E$ & 0.0585 & 0.0662 & 2.7 & $6.5 E+00$ \\
\hline & $969 \mathrm{k}$ & & 0800 & 2 . & $6.5 E+00$ \\
\hline
\end{tabular}

Fig. 9. Tally Fluctuation ('harts for Example \#1 with Doubled Laid Thickness (forward and adjoint). 


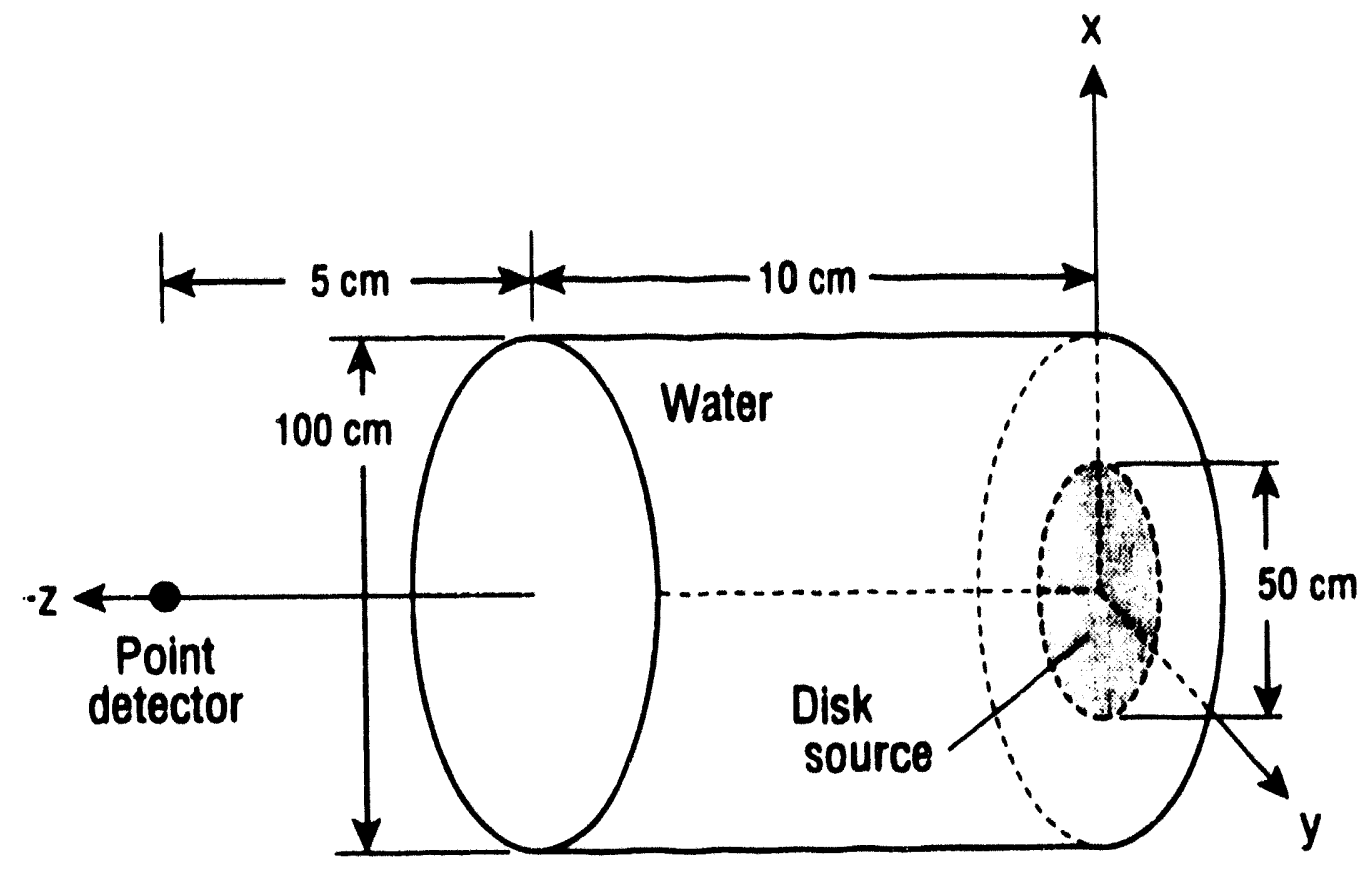

Fig. 10. Drawing of Conflguration for Example \#2.

Table XV shows a completed copy of the normalization form for this example. The values on the SP2 card of the forward run sum to 49.908s, the value nord for $\Sigma P_{g}$ in the normalization. The values on the EMO card of the forward run sum to 32.6410 , the value used for the $\Sigma R_{g^{\prime}}$ in the normalization. The values used for the direction densities on the normalization form for the forward and adjoint problems are readily apparent. At this point, the product of the values in the column corresponding to the forward problem is divided by the product of the values in the column corresponding to the adjoint problem, to produce the desired normalization factor. This normalization factor is subsequently entered with the WGT parameter on the SDEF card in the adjoint input file. The adjoint input file is provided in Fig. B4. 
TABLE XV

Normalization Form for Example \# 2

\begin{tabular}{|c|c|c|}
\multicolumn{1}{c}{ Forward Problem } & Adjoint Problem \\
\hline spatial density & $1 / \pi(25)^{2}$ & 1 \\
\hline direction density & $\mu / \pi$ & $1 / 2 \pi$ \\
\hline time density & 1 & 1 \\
\hline energy density & $\mathrm{P}_{g} / \Sigma \mathrm{P}_{g}$ & $\mathrm{R}_{g^{\prime}} / \Sigma \mathrm{R}_{q^{\prime}}$ \\
\hline spatial response & 1 & $1 / \pi(25)^{2}$ \\
\hline direction response & 1 & $\mu$ \\
\hline time response & 1 & 1 \\
\hline crergy response & $\mathrm{R}_{q^{\prime}}$ & $\mathrm{P}_{g}$ \\
\hline
\end{tabular}

Results from the two input files are shown in Tables XVI and XVII. The relative differences in Table XVI are shown to be within the $1 \sigma$ statistical uncertainties for all but one (the sixth) of the values listed. Similarly, all but one (the fifth) of the relative difference values in Table XVII are within the statistical uncertainties. Figure 11 presents the relevant tally fluctuation charts and reveals that the FOM corresponding to the adjoint solution is roughly a factor of three greater than the FOM for the forward problem. Thus, for this problem, the adjoint is capable of producing the same result as the forward three times more efficiently.

\section{Cautions}

Particles which clownscatter in a forward problem, upscatter in an adjoint problem; and adjoint fission is more probable at high energies where the fission spectrum is high resulting in low energy particles being emitted where $\nu \sigma_{f}$ values are high. In the reversed world of adjoint particles, these particles originate in the detector, Hy backwards in time, and upscatter in energy towards the physical source. In a sense, tracking adjoint particles is like backtracking forward particles. In fact, in one-group calculations, it is exactly equivalent to backtracking forward particles. However, in multigroup calculations, the analogy breaks down. This breakdown follows from the fact that, given an incident particle energy, the average number of particles emerging from an adjoint collision does not necessarily equal the average number of particles emerging from a forward collision. Furthermore, this multiplicity factor can vary greatly for adjoint collisions even when it is relatively constant for forward collisions. Since MCNP allows only one particle to emerge from each adjoint collision, a weight correction factor proportional to the multiplicity factor must be applied. 


\section{TABLE XVI}

\section{Results as a Function of Order of Scatter \\ for Example \# 2}

\begin{tabular}{|c|c|c|c|c|c|}
\hline \multirow[b]{2}{*}{$\begin{array}{l}\text { Order of } \\
\text { Scattering }\end{array}$} & \multicolumn{2}{|c|}{ Forward Problem } & \multicolumn{2}{|c|}{ Adjoint Problem } & \multirow{2}{*}{$\begin{array}{c}\text { \%Difference } \\
\begin{array}{c}\text { Adjoint from } \\
\text { Forward }\end{array}\end{array}$} \\
\hline & $\begin{array}{c}F l u x \\
\left(n / c m^{2}\right)\end{array}$ & $\begin{array}{c}\text { Relative } \\
\text { Error }\end{array}$ & $\begin{array}{c}\text { Flux } \\
\left(n / \mathrm{cm}^{2}\right)\end{array}$ & $\begin{array}{l}\text { Relative } \\
\text { Error }\end{array}$ & \\
\hline 0 & $0.19661 \mathrm{E}-03$ & 0.002 & $0.19642 \mathrm{E}-03$ & 0.007 & 0.10 \\
\hline 1 & $0.13463 \mathrm{E}-03$ & 0.011 & $0.13606 \mathrm{E}-03$ & 0.008 & -1.07 \\
\hline 2 & 0.64817 E-04 & 0.016 & $0.64811 \mathrm{E}-04$ & 0.010 & 0.01 \\
\hline 3 & $0.27310 \mathrm{E}-04$ & 0.025 & $0.27068 \mathrm{E}-04$ & 0.012 & ().89 \\
\hline 4 & $0.11079 \mathrm{E}-04$ & 0.034 & $0.10685 \mathrm{E}-04$ & 0.015 & 3.56 \\
\hline 5 & $0.42696 \mathrm{E}-05$ & 0.039 & $0.45860 \mathrm{E}-05$ & 0.019 & -7.41 \\
\hline 6 & $0.18434 \mathrm{E}-05$ & 0.050 & $0.19335 \mathrm{E}-05$ & 0.021 & .4 .89 \\
\hline 7 & $0.97173 \mathrm{E}-06$ & 0.074 & $0.88547 \mathrm{E}-06$ & 0.030 & 8.88 \\
\hline 8 & $0.38539 \mathrm{E}-06$ & 0.060 & $0.41607 \mathrm{E}-06$ & 0.030 & $-\tau .96$ \\
\hline 9 & $0.21909 \mathrm{E}-06$ & 0.086 & $0.19639 \mathrm{E}-06$ & 0.036 & 10.36 \\
\hline 10 & $0.10049 \mathrm{E}-06$ & 0.111 & $0.98838 \mathrm{E}-07$ & 0.049 & 1.64 \\
\hline 11 & $0.46844 \mathrm{E}-07$ & 0.104 & $0.48058 \mathrm{E}-07$ & 0.050 & .2 .59 \\
\hline 12 & $0.21422 E-07$ & 0.112 & 0.23270 E- 07 & 0.067 & -8.63 \\
\hline 13 & $0.11433 \mathrm{E}-07$ & 0.169 & $0.13100 \mathrm{E}-07$ & 0.089 & -14.58 \\
\hline 14 & $0.52448 \mathrm{E}-08$ & 0.212 & $0.62997 \mathrm{E}-08$ & 0.100 & .20 .11 \\
\hline 15 & $0.23269 \mathrm{E}-08$ & 0.260 & $0.26568 \mathrm{E}-08$ & 0.159 & -14.18 \\
\hline
\end{tabular}

This factor works well for many situations, but it can cause problems if $\Delta E$ is large (low $\mathrm{Z}$ materials), $\Sigma_{T}$ varies significantly over small energy ranges (resonance regions), and/or the medium is fissionable and/or highly scattering. Since the weight correction factor is applied at each collision, the weight correction after $n$ collisions is the product of the correction for each of the $n$ collisions. The variance of this product increases as $n$ increases. Therefore, once again, it is a good idea to compare forward and adjoint results as a function of the order of scatter and as a function of energy. Comparisons, similar to those for the example problems, will reveal any problems related to scattering. In general, adjoint calculations may not perform well for problems involving high-order scattering. 


\section{TABLE XVII}

\section{Comparison of Spectra for Example \# 2}

\begin{tabular}{|c|c|c|c|c|c|}
\hline \multirow[b]{2}{*}{$\begin{array}{l}\text { Upper Energy } \\
\text { Bounds (MeV') }\end{array}$} & \multicolumn{2}{|c|}{ Forward Problem } & \multicolumn{2}{|c|}{ Adjoint Problem } & \multirow{2}{*}{$\begin{array}{c}\% \text { Difference } \\
\begin{array}{c}\text { Adjoint from } \\
\text { Forward }\end{array}\end{array}$} \\
\hline & $\begin{array}{c}\text { Flux } \\
\left(n / c m^{2}\right)\end{array}$ & $\begin{array}{l}\text { Relative } \\
\text { Error }\end{array}$ & $\begin{array}{c}\text { Flux } \\
\left(n / c m^{2}\right)\end{array}$ & $\begin{array}{c}\text { Relative } \\
\text { Error }\end{array}$ & \\
\hline 0.0248 & $0.70030 \mathrm{E}-07$ & 0.034 & $0.67788 \mathrm{E}-07$ & 0.015 & 3.20 \\
\hline 0.0676 & $0.21753 \mathrm{E}-06$ & 0.025 & $0.22136 \mathrm{E}-06$ & 0.014 & -1.76 \\
\hline 0.1840 & $0.86455 \mathrm{E}-06$ & 0.023 & $0.84808 \mathrm{E}-06$ & 0.013 & 1.91 \\
\hline 0.3030 & $0.12374 \mathrm{E}-05$ & 0.030 & $0.12111 \mathrm{E}-05$ & 0.013 & 2.13 \\
\hline 0.5000 & $0.25254 \mathrm{E}-05$ & 0.024 & $0.26348 \mathrm{E}-05$ & 0.012 & -4.33 \\
\hline 0.8230 & $0.66881 \mathrm{E}-05$ & 0.020 & $0.66800 \mathrm{E}-05$ & 0.011 & 0.12 \\
\hline 1.3530 & $0.13162 \mathrm{E}-04$ & 0.019 & $0.12982 \mathrm{E}-04$ & 0.011 & 1.37 \\
\hline 1.7380 & $0.13493 \mathrm{E}-04$ & 0.026 & $0.13518 \mathrm{E}-04$ & 0.010 & -0.18 \\
\hline 2.2320 & $0.20419 \mathrm{E}-04$ & 0.021 & $0.20973 \mathrm{E}-04$ & 0.010 & -2.71 \\
\hline 2.8650 & $0.35713 \mathrm{E}-04$ & 0.017 & $0.35925 \mathrm{E}-04$ & 0.010 & -0.59 \\
\hline 3.6800 & $0.46419 \mathrm{E}-04$ & 0.015 & $0.47357 \mathrm{E}-04$ & 0.010 & -2.02 \\
\hline 6.0700 & $0.13520 \mathrm{E}-03$ & 0.009 & $0.13628 \mathrm{E}-03$ & 0.010 & -0.81 \\
\hline 7.7900 & $0.10485 \mathrm{E}-03$ & 0.011 & $0.10270 \mathrm{E}-03$ & 0.009 & 2.05 \\
\hline 10.0000 & $0.61465 \mathrm{E}-04$ & 0.012 & $0.61848 \mathrm{E}-04$ & 0.010 & -0.62 \\
\hline
\end{tabular}

Based on the above information, it is easy to understand why the two example problems produced such good results. Example problem one transported photons through lead, which is optically thick and involves very little scattering, and is thus very well suited for an adjoint calculation. Example problcm two simulates the transport of high energy neutrons through water. Due to the energy of the neutrons and the corresponding scattering cross section of water at these energies, high orders of scattering are not observed. Thus, based on geometric considerations more than any other, this problem was also well suited for adjoint application.

In order to determine applicability, the adjoint behavior in highly scattering media must be investigated. To this end, the input files for the first example problem have been modified to investigate neutron transport in two different materials. The modifications consist of doubling the thickness of material that must be transversed and enlarging the energy range to span the entire default 30-group neutron library. The two materials under investigation are water, which is highly scattering at lower energies, and iron, which has a large inelastic scattering cross section over a large portion of the energy range. Although the input files are very similar to those of example one, they are included in Appendix B (Figs. B5 through B8) for clarity. 


\section{(a). Adjoint Problem}

$\begin{array}{rccccr}\text { nps } & \text { mean } & \begin{array}{c}\text { tally } \\ \text { error }\end{array} & \begin{array}{c}1 \\ \text { vov }\end{array} & \begin{array}{c}\text { slope } \\ \text { fom }\end{array} \\ 128000 & 4.4042 E-04 & 0.0166 & 0.0007 & 10.0 & 9704 \\ 192000 & 4.4156 E-04 & 0.0117 & 0.0004 & 10.0 & 9762 \\ 256000 & 4.4213 E-04 & 0.0083 & 0.0002 & 10.0 & 9695 \\ 320000 & 4.4239 E-04 & 0.0074 & 0.0001 & 10.0 & 9741 \\ 384000 & 4.4223 E-04 & 0.0068 & 0.0001 & 10.0 & 9738 \\ 448000 & 4.4380 E-04 & 0.0063 & 0.0001 & 10.0 & 9745 \\ 512000 & 4.4412 E-04 & 0.0059 & 0.0001 & 10.0 & 9738 \\ 576000 & 4.4337 E-04 & 0.0055 & 0.0 n 01 & 10.0 & 9728 \\ 640000 & 4.4187 E-04 & 0.0053 & 0.000: & 10.0 & 9698 \\ 704000 & 4.4278 E-04 & 0.0050 & 0.0001 & 10.0 & 9742 \\ 768000 & 4.4284 E-04 & 0.0048 & 0.0001 & 10.0 & 9740 \\ 832000 & 4.4319 E-04 & 0.0046 & 0.0001 & 10.0 & 9734 \\ 896000 & 4.4323 E-04 & 0.0044 & 0.0001 & 10.0 & 9744 \\ 960000 & 4.4273 E-04 & 0.0043 & 0.0000 & 10.0 & 9741 \\ 1000000 & 4.4325 E-04 & 0.0042 & 0.0000 & 10.0 & 9743\end{array}$

(b). Forward Problem

$\begin{array}{rccccr}\text { nps } & \text { mean } & \begin{array}{c}\text { tally } \\ \text { error }\end{array} & \begin{array}{c}5 \\ \text { vov }\end{array} & \text { slope } & \text { fom } \\ 64000 & 4.3937 E-04 & 0.0182 & 0.0290 & 4.1 & 3644 \\ 128000 & 4.4464 E-04 & 0.0147 & 0.0426 & 3.4 & 2788 \\ 192000 & 4.4911 E-04 & 0.0123 & 0.0249 & 2.9 & 2655 \\ 256000 & 4.4832 E-04 & 0.0106 & 0.0172 & 3.0 & 2680 \\ 320000 & 4.4714 E-04 & 0.0095 & 0.0128 & 3.5 & 2677 \\ 384000 & 4.4722 E-04 & 0.0086 & 0.0100 & 3.9 & 2710 \\ 448000 & 4.4479 E-04 & 0.0078 & 0.0083 & 4.3 & 2813 \\ 512000 & 4.4495 E-04 & 0.0073 & 0.0071 & 4.3 & 2866 \\ 576000 & 4.4477 E-04 & 0.0068 & 0.0061 & 4.6 & 2897 \\ 640000 & 4.4472 E-04 & 0.0065 & 0.0057 & 4.1 & 2889 \\ 704000 & 4.4415 E-04 & 0.0061 & 0.0051 & 4.5 & 2910 \\ 768000 & 4.4314 E-04 & 0.0059 & 0.0047 & 3.9 & 2924 \\ 832000 & 4.4148 E-04 & 0.0056 & 0.0043 & 3.9 & 2957 \\ 896000 & 4.4097 E-04 & 0.0054 & 0.0039 & 4.1 & 3005 \\ 960000 & 4.4191 E-04 & 0.0052 & 0.0036 & 4.0 & 2979 \\ 1000000 & 4.4232 E-04 & 0.0051 & 0.0033 & 4.2 & 2981\end{array}$

Fig. 11. Tally Fluctuation Charts for Example \#2 (forward and adjoint). 
The results as a function of order of scatter and as a function of energy are given for both water and iron in Tables XVIII and XIX and Tables XX and XXI, respectively. These tables show that the adjoint results compare well to the forward results. It is interesting to note the behavior of the relative error in Tables XIX and XXI, and observe how the adjoint results converge in a somewhat smooth manner from high energies to lower energies whereas the relative errors for the forward results converge in a more jagged manner.

The input files for example problem \#2 (the water cylinder of Fig. 10) have been used to compare the adjoint and forward results for a variety of different materials. Table XXII lists the materials used, the calculated total flux values, and the relative differences. The relative differences are shown to be within the $1 \sigma$ statistical uncertainties for all materials except Boron and the fissionable materials with fission treated as capture. However, it is important to note that this table compares total fluxes, and that discrepancies in the spectra at low energies, where the magnitude of the flux is small with respect to the group fluxes at higher energies. will not be apparent in this type of comparison.

Table XXII demonstrates the ineffectiveness of the NONU card (an input card that forces fission to be treated as capture) in multigroup/adjoint MCNP. Therefore, problems involving a fixed source and a multiplying medium with the NONU card are not compatible with the multigroup/adjoint option. However, problems involving a fixed source in a multiplying medium in which the user would like to have fission treated properly are compatible with the multigroup/adjoint option (refer to the last eight rows of Table XXII). It is worth noting that the number of applications affected by this apparent bug are few and that manual cross-section adjustments can be performed to accommodate these applications.

The cautions listed in section IV.A.4 should be considered a subset of the cautions for adjoint MCNP, because all adjoint calculations must be performed in the multigroup mode. Therefore, when preparing to perform an adjoint calculation, consider the multigroup cautions as well as the adjoint cautions discussed above. 
TABLE XVIII

Results as a Function of Order of Scatter

for Material Test with Water

\begin{tabular}{|c|c|c|c|c|c|}
\hline \multirow[b]{2}{*}{$\begin{array}{l}\text { Order of } \\
\text { Scattering }\end{array}$} & \multicolumn{2}{|c|}{ Forward Problem } & \multicolumn{2}{|c|}{ Adjoint Problem } & \multirow{2}{*}{ 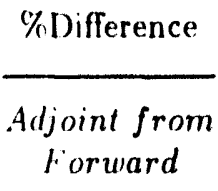 } \\
\hline & $\begin{array}{c}\text { Flux } \\
\left(n / \mathrm{cm}^{2}\right)\end{array}$ & $\begin{array}{c}\text { Relative } \\
\text { Error }\end{array}$ & $\begin{array}{c}\text { Flux } \\
\left(n / \mathrm{cm}^{2}\right)\end{array}$ & $\begin{array}{c}\text { Relative } \\
\text { Error }\end{array}$ & \\
\hline 0 & $0.86074 \mathrm{E}-06$ & 0.003 & $0.89377 \mathrm{E}-06$ & 0.020 & -3.84 \\
\hline 1 & $0.10268 \mathrm{E}-05$ & 0.022 & $0.10073 \mathrm{E}-05$ & 0.015 & 1.90 \\
\hline 2 & $0.84072 \mathrm{E}-06$ & 0.027 & $0.78891 \mathrm{E}-06$ & 0.015 & 6.16 \\
\hline 3 & $0.56110 \mathrm{E}-06$ & 0.031 & $0.57124 \mathrm{E}-06$ & 0.016 & -1.81 \\
\hline 4 & $0.38112 \mathrm{E}-06$ & 0.036 & $0.38941 \mathrm{E}-06$ & 0.018 & -2.18 \\
\hline 5 & $0.27526 \mathrm{E}-06$ & 0.046 & $0.27098 \mathrm{E}-06$ & 0.021 & 1.56 \\
\hline 6 & $0.19785 \mathrm{E}-06$ & 0.052 & $0.19018 \mathrm{E}-06$ & 0.025 & 3.88 \\
\hline 7 & $0.14142 \mathrm{E}-06$ & 0.054 & $0.14258 \mathrm{E}-06$ & 0.028 & -0.82 \\
\hline 8 & $0.12175 \mathrm{E}-06$ & 0.070 & $0.11890 \mathrm{E}-06$ & 0.030 & 2.34 \\
\hline 9 & $0.91905 \mathrm{E}-07$ & 0.073 & $0.96015 \mathrm{E}-07$ & 0.034 & -4.47 \\
\hline 10 & $0.90956 \mathrm{E}-07$ & 0.086 & $0.82585 \mathrm{E}-07$ & 0.037 & 9.20 \\
\hline 11 & $0.71044 \mathrm{E}-07$ & 0.069 & $0.78456 \mathrm{E}-07$ & 0.037 & -10.43 \\
\hline 12 & $0.75655 \mathrm{E}-07$ & 0.073 & $0.71108 \mathrm{E}-07$ & 0.039 & 6.01 \\
\hline 13 & $0.65673 E-07$ & 0.079 & $0.69275 \mathrm{E}-07$ & 0.038 & -5.49 \\
\hline 14 & $0.55080 \mathrm{E}-07$ & 0.082 & $0.64530 \mathrm{E}-07$ & 0.038 & -17.16 \\
\hline 15 & $0.66553 E-07$ & 0.093 & $0.62908 \mathrm{E}-07$ & 0.042 & 5.48 \\
\hline 16 & $0.54285 \mathrm{E}-07$ & 0.081 & $0.61584 \mathrm{E}-07$ & 0.039 & -13.45 \\
\hline 17 & $0.54238 \mathrm{E}-07$ & 0.089 & $0.55294 \mathrm{E}-07$ & 0.039 & -1.95 \\
\hline 18 & $0.63385 \mathrm{E}-07$ & 0.090 & $0.54061 \mathrm{E}-07$ & 0.040 & 14.71 \\
\hline 19 & $0.44759 \mathrm{E}-07$ & 0.081 & $0.52357 \mathrm{E}-0 \mathrm{~T}$ & 0.044 & -16.98 \\
\hline 20 & $0.51802 \mathrm{E}-07$ & 0.087 & $0.49688 \mathrm{E}-07$ & 0.044 & 4.08 \\
\hline 21 & $0.42700 \mathrm{E}-07$ & 0.080 & $0.45033 \mathrm{E}-07$ & 0.045 & -5.46 \\
\hline 22 & $0.47110 \mathrm{E}-07$ & 0.086 & $0.45387 \mathrm{E}-07$ & 0.044 & 3.66 \\
\hline 23 & $0.41831 \mathrm{E}-07$ & 0.086 & $0.40389 \mathrm{E}-07$ & 0.045 & 3.45 \\
\hline 24 & $0.39736 \mathrm{E}-07$ & 0.082 & $0.42659 \mathrm{E}-07$ & 0.048 & -7.36 \\
\hline 25 & $0.47454 \mathrm{E}-07$ & 0.078 & $0.41650 \mathrm{E}-07$ & 0.053 & 12.23 \\
\hline
\end{tabular}


TABLE XIX

Comparison of Spectra for Material Test

with Water

\begin{tabular}{|c|c|c|c|c|c|}
\hline \multirow[b]{2}{*}{$\begin{array}{l}\text { Upper Energy } \\
\text { Bounds }(\mathrm{MeV})\end{array}$} & \multicolumn{2}{|c|}{ Forward Problem } & \multicolumn{2}{|c|}{ Adjoint Problem } & \multirow{2}{*}{ 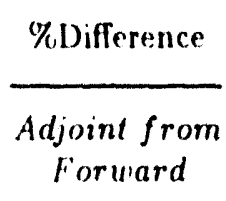 } \\
\hline & $\begin{array}{c}F / u x \\
\left(\mathrm{n} / \mathrm{cm}^{2}\right)\end{array}$ & $\begin{array}{l}\text { Relative } \\
\text { Error }\end{array}$ & $\begin{array}{c}\text { Flux } \\
\left(n / \operatorname{con}^{2}\right)\end{array}$ & $\begin{array}{c}\text { Relative } \\
\text { Error }\end{array}$ & \\
\hline $0.1520 \mathrm{E}-06$ & $0.48139 \mathrm{E}-05$ & 0.009 & $0.42810 \mathrm{E}-05$ & 0.184 & 11.07 \\
\hline $0.4140 \mathrm{E}-06$ & $0.67621 \mathrm{E}-07$ & 0.098 & $0.65315 \mathrm{E}-07$ & 0.054 & 3.41 \\
\hline $0.1130 \mathrm{E}-05$ & $0.72074 \mathrm{E}-07$ & 0.085 & $0.65398 \mathrm{E}-07$ & 0.054 & 9.26 \\
\hline $0.3060 \mathrm{E}-05$ & $0.66020 \mathrm{E}-07$ & 0.086 & $0.55125 \mathrm{E}-07$ & 0.054 & 16.50 \\
\hline $0.8320 \mathrm{E}-05$ & $0.61480 \mathrm{E}-07$ & 0.090 & $0.67129 \mathrm{E}-07$ & 0.053 & -9.19 \\
\hline $0.2260 \mathrm{E}-04$ & $0.65381 \mathrm{E}-07$ & 0.102 & $0.67746 \mathrm{E}-07$ & 0.053 & -3.62 \\
\hline $0.6140 \mathrm{E}-04$ & $0.72270 \mathrm{E}-07$ & 0.086 & $0.67957 \mathrm{E}-07$ & 0.053 & 5.97 \\
\hline $0.1670 \mathrm{E}-03$ & $0.53799 \mathrm{E}-07$ & 0.082 & $0.63015 \mathrm{E}-07$ & 0.053 & -17.13 \\
\hline $0.4540 \mathrm{E}-03$ & $0.66644 \mathrm{E}-07$ & 0.101 & $0.74737 E-07$ & 0.051 & -12.14 \\
\hline $0.1235 \mathrm{E}-02$ & $0.75266 \mathrm{E}-07$ & 0.123 & $0.70846 \mathrm{E}-07$ & 0.055 & 5.87 \\
\hline $0.3350 \mathrm{E}-02$ & $0.79044 \mathrm{E}-07$ & 0.089 & $0.74386 \mathrm{E}-07$ & 0.051 & 5.89 \\
\hline $0.9120 \mathrm{E}-02$ & $0.80428 \mathrm{E}-07$ & 0.086 & $0.82601 \mathrm{E}-07$ & 0.050 & -2.70 \\
\hline $0.2480 \mathrm{E}-01$ & $0.10545 \mathrm{E}-06$ & 0.079 & $0.90227 \mathrm{E}-07$ & 0.048 & 14.43 \\
\hline $0.6760 \mathrm{E}-01$ & $0.11602 \mathrm{E}-06$ & 0.078 & $0.10310 \mathrm{~F}-06$ & 0.044 & 11.14 \\
\hline $0.1840 \mathrm{E}+00$ & $0.13845 \mathrm{E}-06$ & 0.058 & $0.14028 \mathrm{E}-06$ & 0.043 & -1.32 \\
\hline $0.3030 \mathrm{E}+00$ & $0.10949 E-06$ & 0.080 & $0.11779 \mathrm{E}-06$ & 0.042 & -7.59 \\
\hline $0.5000 \mathrm{E}+00$ & $0.14008 \mathrm{E}-06$ & 0.063 & $0.14295 \mathrm{E}-06$ & 0.038 & -2.05 \\
\hline $0.8230 \mathrm{E}+00$ & $0.22870 \mathrm{E}-06$ & 0.056 & $0.22 \overline{3} 52 \mathrm{E}-06$ & 0.034 & 1.39 \\
\hline $0.1353 E+01$ & $0.29279 \mathrm{E}-06$ & 0.043 & $0.28813 \mathrm{E}-06$ & 0.033 & 1.59 \\
\hline $0.1738 \mathrm{E}+01$ & $0.21397 \mathrm{E}-06$ & 0.057 & $0.20440 \mathrm{E}-06$ & 0.032 & 4.47 \\
\hline $0.2232 \mathrm{E}+01$ & $0.26751 \mathrm{E}-06$ & 0.050 & $0.26010 \mathrm{E}-06$ & 0.029 & 2.77 \\
\hline $0.2865 \mathrm{E}+01$ & $0.34134 \mathrm{E}-06$ & 0.040 & $0.32935 \mathrm{E}-06$ & 0.029 & 3.51 \\
\hline $0.3680 \mathrm{E}+01$ & $0.35261 \mathrm{E}-06$ & 0.039 & $0.33018 \mathrm{E}-06$ & 0.029 & 6.36 \\
\hline $0.6070 \mathrm{E}+01$ & $0.63119 \mathrm{E}-06$ & 0.023 & $0.66092 \mathrm{E}-06$ & 0.028 & -4.71 \\
\hline $0.7790 \mathrm{E}+01$ & $0.58429 \mathrm{E}-06$ & 0.027 & $0.60830 \mathrm{E}-06$ & 0.027 & -4.11 \\
\hline $0.1000 \mathrm{E}+02$ & $0.51424 \mathrm{E}-06$ & 0.025 & $0.52786 \mathrm{E}-06$ & 0.029 & -2.65 \\
\hline $0.1200 E+02$ & $0.15804 \mathrm{E}-06$ & 0.063 & $0.15644 \mathrm{E}-06$ & 0.023 & 1.01 \\
\hline $0.1350 \mathrm{E}+02$ & $0.14661 \mathrm{E}-06$ & 0.059 & $0.14027 E-06$ & 0.025 & 4.32 \\
\hline $0.1500 \mathrm{E}+02$ & $0.79089 \mathrm{E}-07$ & 0.066 & $0.70903 \mathrm{E}-07$ & 0.025 & 10.35 \\
\hline $0.1700 \mathrm{E}+02$ & $0.58405 \mathrm{E}-07$ & 0.055 & $0.60652 \mathrm{E}-07$ & 0.027 & $-3.8 j$ \\
\hline total & $0.10052 \mathrm{E}-04$ & 0.008 & $0.94927 \mathrm{E}-05$ & 0.083 & 5.57 \\
\hline
\end{tabular}




\section{TABLE XX}

\section{Results as a Function of Order of Scatter for Material Test with Iron}

\begin{tabular}{|c|c|c|c|c|c|}
\hline \multirow[b]{2}{*}{$\begin{array}{l}\text { Order of } \\
\text { Scattering }\end{array}$} & \multicolumn{2}{|c|}{ Forward Problem } & \multicolumn{2}{|c|}{ Adjoint Problem } & \multirow{2}{*}{$\frac{\text { \%Difference }}{\begin{array}{c}\text { Adjoint from } \\
\text { Forward }\end{array}}$} \\
\hline & $\begin{array}{c}F l u x \\
\left(n / c m^{2}\right)\end{array}$ & $\begin{array}{c}\text { Relative } \\
\text { Error }\end{array}$ & $\begin{array}{c}F l u x \\
\left(n / \mathrm{cm}^{2}\right)\end{array}$ & $\begin{array}{c}\text { Relative } \\
\text { Error }\end{array}$ & \\
\hline 0 & $0.12346 \mathrm{E}-04$ & 0.001 & $0.12350 \mathrm{E}-04$ & 0.006 & -0.03 \\
\hline 1 & $0.96587 \mathrm{E}-05$ & 0.004 & $0.96774 \mathrm{E}-05$ & 0.006 & -0.19 \\
\hline 2 & $0.57447 \mathrm{E}-05$ & 0.004 & $0.57363 \mathrm{E}-05$ & 0.007 & 0.14 \\
\hline 3 & $0.32984 \mathrm{E}-05$ & 0.005 & $0.33809 \mathrm{E}-05$ & 0.009 & -2.50 \\
\hline 4 & $0.20779 E-05$ & 0.005 & $0.21075 \mathrm{E}-05$ & 0.011 & -1.43 \\
\hline 5 & $0.14137 \mathrm{E}-05$ & 0.005 & $0.14286 \mathrm{E}-05$ & 0.012 & -1.06 \\
\hline 6 & $0.10353 \mathrm{E}-05$ & 0.006 & $0.10463 \mathrm{E}-05$ & 0.012 & -1.07 \\
\hline 7 & $0.79742 \mathrm{E}-06$ & 0.006 & $0.79625 \mathrm{E}-06$ & 0.013 & 0.15 \\
\hline 8 & $063035 \mathrm{E}-06$ & 0.007 & $0.64917 \mathrm{E}-06$ & 0.014 & -2.99 \\
\hline 9 & $0.51046 \mathrm{E}-06$ & 0.008 & $0.51776 \mathrm{E}-06$ & 0.013 & -1.43 \\
\hline 10 & $0.42047 \mathrm{E}-06$ & 0.008 & $0.41743 \mathrm{E}-06$ & 0.014 & 0.72 \\
\hline 11 & $0.34524 \mathrm{E}-06$ & 0.009 & $0.34756 \mathrm{E}-06$ & 0.016 & $-(0.67$ \\
\hline 12 & $0.28953 \mathrm{E}-06$ & 0.010 & $0.28736 \mathrm{E}-06$ & 0.016 & 0.75 \\
\hline 13 & $0.24342 \mathrm{E}-06$ & 0.011 & $0.24736 \mathrm{E}-06$ & 0.017 & -1.62 \\
\hline 14 & $0.20414 \mathrm{E}-06$ & 0.012 & $0.20152 \mathrm{E}-06$ & 0.019 & 1.28 \\
\hline 15 & $0.17087 \mathrm{E}-06$ & 0.013 & $0.17261 \mathrm{E}-06$ & 0.020 & -1.01 \\
\hline 16 & $0.14378 \mathrm{E}-06$ & 0.014 & $0.14380 \mathrm{E}-06$ & 0.023 & $-(0.01$ \\
\hline 17 & $0.12034 \mathrm{E}-06$ & 0.015 & $0.11903 \mathrm{E}-06$ & 0.024 & 1.09 \\
\hline 18 & $0.10116 \mathrm{E}-06$ & 0.016 & $0.10226 \mathrm{E}-06$ & 0.025 & -1.08 \\
\hline 19 & $0.86432 \mathrm{E}-07$ & 0.017 & $0.87147 \mathrm{E}-07$ & 0.028 & -0.83 \\
\hline 20 & $0.71037 \mathrm{E}-07$ & 0.019 & $0.71273 \mathrm{E}-07$ & 0.030 & -0.33 \\
\hline 21 & $0.61215 E-07$ & 0.020 & $0.60150 \mathrm{E}-07$ & 0.035 & 1.74 \\
\hline 22 & $0.53035 \mathrm{E}-07$ & 0.022 & $0.51479 \mathrm{E}-07$ & 0.037 & 2.93 \\
\hline 23 & $0.44052 \mathrm{E}-07$ & 0.023 & $0.45363 \mathrm{E}-07$ & 0.041 & -2.98 \\
\hline 24 & $0.37206 \mathrm{E}-(07$ & 0.026 & $0.36984 \mathrm{E}-07$ & 0.043 & 0.60 \\
\hline 25 & $0.32798 \mathrm{E}-07$ & 0.028 & $0.31132 \mathrm{E}-07$ & 0.048 & 5.08 \\
\hline
\end{tabular}


TABLE XXI

Comparison of Spectra for Material Test with Iron

\begin{tabular}{|c|c|c|c|c|c|}
\hline \multirow[b]{2}{*}{$\begin{array}{l}\text { ('pper Energy } \\
\text { Bounds }(\mathrm{MeV})\end{array}$} & \multicolumn{2}{|c|}{ Forward Problem } & \multicolumn{2}{|c|}{ Adjoint Problem } & \multirow{2}{*}{$\frac{\text { \%1ifference }}{\begin{array}{c}\text { Adjoint from } \\
\text { Forward }\end{array}}$} \\
\hline & $\begin{array}{c}\text { Flux } \\
\left(n / \mathrm{cm}^{2}\right)\end{array}$ & $\begin{array}{l}\text { Relative } \\
\text { Error }\end{array}$ & $\begin{array}{c}F / u x \\
\left(n / \mathrm{cm}^{2}\right)\end{array}$ & $\begin{array}{l}\text { Relative } \\
\text { Error }\end{array}$ & \\
\hline $0.1520 \mathrm{E}-06$ & $0.37751 \mathrm{E}-06$ & 0.012 & $0.37251 \mathrm{E}-06$ & 0.022 & 1.32 \\
\hline $0.414 J \mathrm{E}-06$ & $0.61394 E-06$ & 0.011 & $0.63359 \mathrm{E}-06$ & 0.021 & -3.20 \\
\hline $0.1130 \mathrm{E}-05$ & $0.73906 \mathrm{E}-06$ & 0.011 & $0.73946 \mathrm{E}-06$ & 0.021 & -0.05 \\
\hline $0.3060 \mathrm{E}-05$ & $0.82546 \mathrm{E}-06$ & 0.011 & $0.78568 \mathrm{E}-06$ & 0.022 & 4.82 \\
\hline $0.8320 \mathrm{E}-05$ & $0.88115 \mathrm{E}-06$ & 0.011 & $0.86002 \mathrm{E}-06$ & 0.022 & 2.40 \\
\hline $0.2260 \mathrm{E}-04$ & $0.91545 \mathrm{E}-06$ & 0.011 & $0.93417 \mathrm{E}-06$ & 0.022 & -2.04 \\
\hline $0.6140 \mathrm{E}-04$ & $0.93681 \mathrm{E}-06$ & 0.011 & $0.95525 \mathrm{E}-06$ & 0.022 & -1.97 \\
\hline $0.1670 \mathrm{E}-03$ & $0.94588 \mathrm{E}-06$ & 0.011 & $0.92731 \mathrm{E}-06$ & 0.022 & 1.96 \\
\hline $0.4540 \mathrm{E}-03$ & $0.91530 \mathrm{E}-06$ & 0.011 & $0.95130 \mathrm{E}-06$ & 0.021 & -3.93 \\
\hline $0.1235 \mathrm{E}-02$ & $0.85619 \mathrm{E}-06$ & 0.011 & $0.85359 \mathrm{E}-06$ & 0.020 & 0.30 \\
\hline $0.3350 \mathrm{E}-02$ & $0.93273 \mathrm{E}-06$ & 0.010 & $0.95942 \mathrm{E}-06$ & 0.019 & -2.86 \\
\hline $0.9120 \mathrm{E}-02$ & $0.91407 \mathrm{E}-06$ & 0.011 & $0.96758 \mathrm{E}-06$ & 0.021 & -5.85 \\
\hline $0.2480 \mathrm{E}-01$ & $0.92578 \mathrm{E}-06$ & 0.007 & 0.89899 E-06 & 0.017 & 2.89 \\
\hline $0.6760 \mathrm{E}-01$ & $0.10244 \mathrm{E}-05$ & 0.012 & $0.10266 \mathrm{E}-05$ & 0.023 & -0.22 \\
\hline $0.1840 \mathrm{E}+00$ & $0.15556 \mathrm{E}-05$ & 0.007 & $0.15674 \mathrm{E}-05$ & 0.020 & -0.76 \\
\hline $0.3030 \mathrm{E}+00$ & $0.12296 \mathrm{E}-05$ & 0.007 & $0.12305 \mathrm{E}-05$ & 0.018 & -0.08 \\
\hline $0.5000 \mathrm{E}+00$ & $0.17610 \mathrm{E}-05$ & 0.006 & $0.17507 \mathrm{E}-05$ & 0.020 & 0.59 \\
\hline $0.8230 \mathrm{E}+00$ & $0.25809 \mathrm{E}-05$ & 0.005 & $0.26040 \mathrm{E}-05$ & 0.018 & -0.89 \\
\hline $0.1353 \mathrm{E}+01$ & $0.29728 E-05$ & 0.004 & $0.29518 \mathrm{E}-05$ & 0.019 & 0.71 \\
\hline $0.1738 \mathrm{E}+01$ & $0.20498 \mathrm{E}-05$ & 0.006 & $0.21264 \mathrm{E}-05$ & 0.018 & -3.74 \\
\hline $0.2232 \mathrm{E}+01$ & $0.24770 \mathrm{E}-05$ & 0.006 & $0.25019 \mathrm{E}-05$ & 0.017 & -1.01 \\
\hline $0.2865 \mathrm{E}+01$ & $0.22920 \mathrm{E}-05$ & 0.006 & $0.22406 \mathrm{E}-05$ & 0.017 & 2.24 \\
\hline $0.3680 \mathrm{E}+01$ & $0.20126 \mathrm{E}-05$ & 0.007 & $0.19988 \mathrm{E}-05$ & 0.017 & 0.69 \\
\hline $0.6070 \mathrm{E}+01$ & $0.28945 \mathrm{E}-05$ & 0.007 & $0.29323 E-05$ & 0.016 & -1.31 \\
\hline $0.7790 \mathrm{E}+01$ & $0.24897 \mathrm{E}-05$ & 0.009 & $0.25511 \mathrm{E}-05$ & 0.016 & -2.47 \\
\hline $0.1000 \mathrm{E}+02$ & $0.24620 \mathrm{E}-05$ & 0.010 & $0.24471 \mathrm{E}-05$ & 0.016 & 0.61 \\
\hline $0.1200 \mathrm{E}+02$ & $0.50461 \mathrm{E}-06$ & 0.021 & $0.51304 \mathrm{E}-06$ & 0.016 & -1.67 \\
\hline $0.1350 \mathrm{E}+02$ & $0.51417 \mathrm{E}-06$ & 0.023 & $0.50739 \mathrm{E}-06$ & 0.016 & 1.32 \\
\hline $0.1500 \mathrm{E}+02$ & $0.27664 \mathrm{E}-06$ & 0.043 & $0.25533 \mathrm{E}-06$ & 0.016 & 7.70 \\
\hline $0.1700 \mathrm{E}+02$ & $0.24298 \mathrm{E}-06$ & 0.027 & $0.24470 \mathrm{E}-06$ & 0.016 & -0.71 \\
\hline total & $0.40120 \mathrm{E}-04$ & 0.002 & $0.40289 \mathrm{E}-04$ & 0.004 & -0.42 \\
\hline
\end{tabular}

\section{Adjoint Importance Functions}

The main difficulty associated with using an importance generator (either the weight window generator or the adjoint importance function generator) comes from 
the poor estimates of the importance function caused by the statistical nature of the generator. In other words, if a phase-space region is not properly sampled, either an unreliable importance estimate or no importance estimate will be generated. Also, both generators tend to require a crude approximation of the importance function in order to estimate a better one for subsequent calculations. Thus the use of either generator is an iterative process which ideally converges to an optimum importance function.

TABLE XXII

Comparison of Forward and Adjoint Results for Different Materials

\begin{tabular}{|c|c|c|c|c|c|c|c|}
\hline \multirow[b]{2}{*}{ Material } & \multicolumn{3}{|c|}{ Forward Problem } & \multicolumn{3}{|c|}{ Adjoint Problem } & \multirow{2}{*}{$\frac{\text { \%ifference }}{\begin{array}{c}\text { Forward from } \\
\text { Adjoint }\end{array}}$} \\
\hline & $\underset{\left(\mathrm{n} / \mathrm{cm}^{2}\right)}{F / u x}$ & $\begin{array}{l}\text { Relative } \\
\text { Error }\end{array}$ & FOM & $\begin{array}{c}\text { Flux } \\
\left(n / c m^{2}\right)\end{array}$ & $\begin{array}{c}\text { Relative } \\
\text { Error }\end{array}$ & FO.M & \\
\hline $\mathrm{H}_{2} \mathrm{O}$ & $0.25022 \mathrm{E}-05$ & 0.057 & 55.0 & $0.25518 \mathrm{E}-05$ & 0.021 & 1583.0 & 1.94 \\
\hline $\mathrm{D}_{2} \mathrm{O}$ & $0.36494 \mathrm{E}-05$ & 0.038 & 93.0 & $0.38448 \mathrm{E}-05$ & 0.020 & 1573.0 & 5.08 \\
\hline B & $0.59416 \mathrm{E}-06$ & 0.050 & 39.0 & $0.68849 \mathrm{E}-06$ & 0.038 & 469.0 & 13.70 \\
\hline C & $0.10682 \mathrm{E}-04$ & 0.015 & 253.0 & $0.10875 \mathrm{E}-04$ & 0.016 & 21210 & 1.77 \\
\hline Al & $0.11978 \mathrm{~F}-04$ & 0.012 & 115.0 & $0.11780 \mathrm{E}-04$ & 0.016 & 1903.0 & -1.68 \\
\hline $\mathrm{Fe}$ & $0.31449 \mathrm{E}-05$ & 0.032 & 18.0 & $0.29966 \mathrm{E}-05$ & 0.031 & 351.0 & -4.95 \\
\hline $\mathrm{Zr}$ & $0.64043 \mathrm{E}-05$ & 0.024 & 32.0 & $0.66182 \mathrm{E}-05$ & 0.020 & 850.0 & 3.23 \\
\hline $\mathrm{Pb}$ & $0.10374 \mathrm{E}-04$ & 0.017 & 93.0 & $0.10057 \mathrm{E}-04$ & 0.023 & 581.0 & -3.15 \\
\hline $\mathrm{Th}^{\dagger}$ & $0.57365 \mathrm{E}-05$ & 0.025 & 34.0 & $0.69178 \mathrm{E}-05$ & 0.024 & 622.0 & 17.08 \\
\hline Th & $0.70622 \mathrm{E}-05$ & 0.025 & 31.0 & $0.69178 \mathrm{E}-05$ & $0.0^{\prime} 24$ & 628.0 & -2.09 \\
\hline$U^{238 \dagger}$ & $0.55269 \mathrm{E}-06$ & 0.057 & 5.0 & $0.13962 \mathrm{E}-05$ & 0.044 & 136.0 & 60.41 \\
\hline$U^{238}$ & $0.14086 \mathrm{E}-05$ & 0.053 & 3.6 & $0.13962 \mathrm{E}-05$ & 0.044 & 137.0 & -0.89 \\
\hline $\mathrm{U}\left(2 \%^{\dagger}\right)^{\dagger}$ & $0.69636 \mathrm{E}-06$ & 0.129 & 1.0 & $0.14342 \mathrm{E}-05$ & 0.056 & 36.0 & 51.45 \\
\hline$U\left(2 \%^{\ddagger}\right)$ & $0.14392 \mathrm{E}-05$ & 0.059 & 2.1 & $0.14342 \mathrm{E}-05$ & 0.056 & 36.0 & -0.35 \\
\hline$U\left(4 \%^{\dagger}\right)^{\dagger}$ & $0.67353 E-06$ & 0.132 & 1.0 & $0.13728 \mathrm{E}-05$ & 0.058 & 23.0 & 50.94 \\
\hline $\mathrm{U}\left(4 \%^{1}\right)$ & $0.15087 \mathrm{E}-05$ & 0.062 & 1.4 & $0.13728 \mathrm{E}-05$ & 0.058 & 23.0 & -9.90 \\
\hline
\end{tabular}

tResults do not include fission (i.e., NONU card present in input file).

$\ddagger \mathrm{U}^{235}$ enrichment.

While the weight window generator and the adjoint importance generator both produce space-energy-dependent importance functions that are used for splitting and Russian roulette, they differ in several ways. The weight window generator is limited to generating space-dependent importance functions for a maximum of 15 energy intervals. In comparison, the adjoint importance generator is limited only 
by the total number of groups in the multigroup library (typically greater than 15). However, the adjoint importance function generator does not allow the user the freedom to select the number of energy intervals desired. The user is forced to employ the energy intervals corresponding to the group structure of the multigroup library. For some applications, this can be a significant disadvantage. The weight window generator has the advantage of continuous energy simulation, whereas the adjoint generator can only be used in the multigroup mode. The adjoint importance function can be used in a forward multigroup run which can subsequently produce a new importance function to be used in the adjoint mode, and so on. The importance function from the weight window generator, on the other hand, can only be used in the forward mode. Weight window and adjoint importance functions can both be used either just like weight windows or as energy-dependent cell importances, when used with the multigroup option. Finally, the adjoint importance function generator utilizes a compression technique, which is presently not available to the weight window generator, to smooth out statistical fluctuations in the importance estimates.

\section{Generating Multigroup/Adjoint Importance Functions}

Generating importance functions with the MGOPT card is fairly straightforward. However, generating an optimum importance function with any generator requires patience and experience. As mentioned, the MGOPT card can bo used to generate importance functions for subsequent forward and adjoint calculations.

The generation of an adjoint importance function, to be utilized in a later forward run, will now be discussed. The converse situation is completely analogous. Beginning with a properly constructed adjoint input file, an initial run should be performed to obtain enough information (analyzing the "tracks entering" column of print table 126) to manually select spatial importances for the IMP card. These inportances, crude as they may be, can significantly reduce the number of iterations required to produce the optimum importance function. Next, the user must choose appropriate values for the following MGOPT parameters; ICW. FNW, and RIM. ICW identifies the reference cell (tally cell), FNW defines the normalization value for the generated weight windows (the value of the weight window lower bound in the most important energy group in cell ICW is set to FNW), and RIM sets the compression limit for smoothing the importance function. Beforc generated weight windows are printed, the weight windows in each group are separately checked to 
see that the ratio of the highest to the lowest is less than R.M. If not, they are compressed.

MCNP will produce a table of space-energy-dependent weight windows (located under print table 198). The user should thoroughly analyze the'se numbers for consistency, and manually adjust spurious values accordingly. The information related to importance function quality, listed in print table 120 of the subsequent run, can be useful in this analysis. These weight window values should be renoved from the output file and substituted into the forward input file. The lonling ten spaces of each line and the extraneous space between $W W N$ and the intrger identifying the first nine weight windows must be removed. At this point, the value of the IPLT parameter on the MGOPT card should be set equal to either 1 or 2. depending on the desired treatment of the importance function.

The aforementioned steps may lead to iterations betwe'n adjoint and forward calculations in a quest for the optimum importance function. Some degree of experience and a knowledge of the physics of the problem may be helpful for this process.

In the course of using adjoint importance functions and investigating their usefulness and applicability, an error in the formulation used to calculate these functions (in MCNP version 4.2) has been discovered. The formulation in MCNP version 4.2 does not divide the importance values by the energy group width $\Delta E$ or the cell volume. Thus the adjoint importance function, as listed in print table 198, is incorrect. However, the adjoint importance function can be easily corrected by dividing the group importances by their associated $\Delta E$ and dividing the cell importances by the cell volume. The adjoint importance function formulation is correct in MCNP version $4 \mathrm{~A}$.

\section{Examples}

As mentioned, generating adjoint importance functions is fairly straightforward. However in an effort to be complete and to demonstrate the usefulness of the adjoint importance functions, an example will now be discussed.

This example problem is similar to example problem \#2, with the following exception: the material to be transversed is $60 \mathrm{~cm}$ of lead as opposed to $10 \mathrm{~cm}$ of water. This problem simulates deep penetration and therefore is fairly computationally intensive. Thus, an accurate importance function would be advantageous for increasing the calculational efficiency of this problem. 
After appropriately modifying the input files for example problem \#2 to account for the aforementioned material and geometric size change, both problems (forward and adjoint) were executed to generate information for manually assigning geomet. ric importances (this information is listed in the "tracks entering" column of print table 126). Once these relatively crude importance values were entered into the input files, and the tracks entering each cell were found to be fairly constant, the files were adjusted to facilitate the generation of importance functions (i.e., weight window generator in the forward problem and adjoint importance function generator in the adjoint problem). The adjustments for the adjoint problem involved entering the cell importances and assigning values to the last five parameters on the MGOPT card. The adjustment to the forward problem consisted merely of adding the WWG and WWGE cards, and their corresponding parameters. In order to compare the adjoint importance function and the weight window generator, the values listed on the WWGE card were set to the multigrouj) (nergy bounduries. The forward and adjoint input files used to generate the import ance functions are listed in Figs. B9 and B10 of Appendix B.

At this point, both problems were used to calculate the desired importances. Due to a significant difference in the FOM values for the forward and adjoint problems ( 65 and 169 , respectively), the computer time required to generate the adjoint importances was much les than the computer time required to generate the weight window importances. The weight window and adjoint importances, which are printed in the output in the exact same format, were then extracted from the output files, adjusted, and entered in identical, but separate, forward input files. The aforementioned adjustments consisted of deleting the leading ten spaces, deleting the space directly after the WWN for the first nine WWN cards, and minor smoothing of the weight window importances. These two input files, one using the weight window importances and the other using the adjoint importances, were then used to repeat the calculations. Both input files generated the same results (within the statistical uncertainties), however, the calculation utilizing the adjoint importance function required approximately one third the computer time required by the original forward run (FOM values are 65 and 222 for the results corresponding to the use of the manually calculated importances and the adjoint importances, respectively), whereas the efficiency of the forward run using the weight window importances did not improve. Note that the dramatic increase in ctficiency associated with the adjoint importance function for this problem is most likely not representative of the increase in efficiency for all problems. At this point, the importance 
function generated in the forward run that utilized the adjoint importances was appropriately modified and entered into the adjoint input file. The subsequent adjoint FOM was observed to increase from 169 to 341 , thus doubling the original adjoint FOM.

Although the two methods used to generate importance functions are quite different, tho importance functions that they generate are very similar. A typical plot of the normalized adjoint and weight window importance values for this problem, along with the tally fluxes $\left(\mathrm{n} / \mathrm{cm}^{2}\right)$ from the forward run, is provided in Fig. 12. The importance values in Fig. 12 correspond to the geometric colls and to the energy group bounded by 1.738 and $2.232 \mathrm{MeV}$. The behavior shown is fairly representative of all energy groups. Figure 13 presents a plot of the normalized importances as a function of energy, along with the spectrum $\left(\mathrm{n} / \mathrm{cm}^{2} / \mathrm{Mr} \mathrm{V}^{\circ}\right)$ from the forward run, for cell number 10 (approximately one-half way through the lead) and is rep)resentative of the other cells in the problem. Tegether, Figs. 12 and 13 show the similarity in behavior between the adjoint and weight vindow importances.

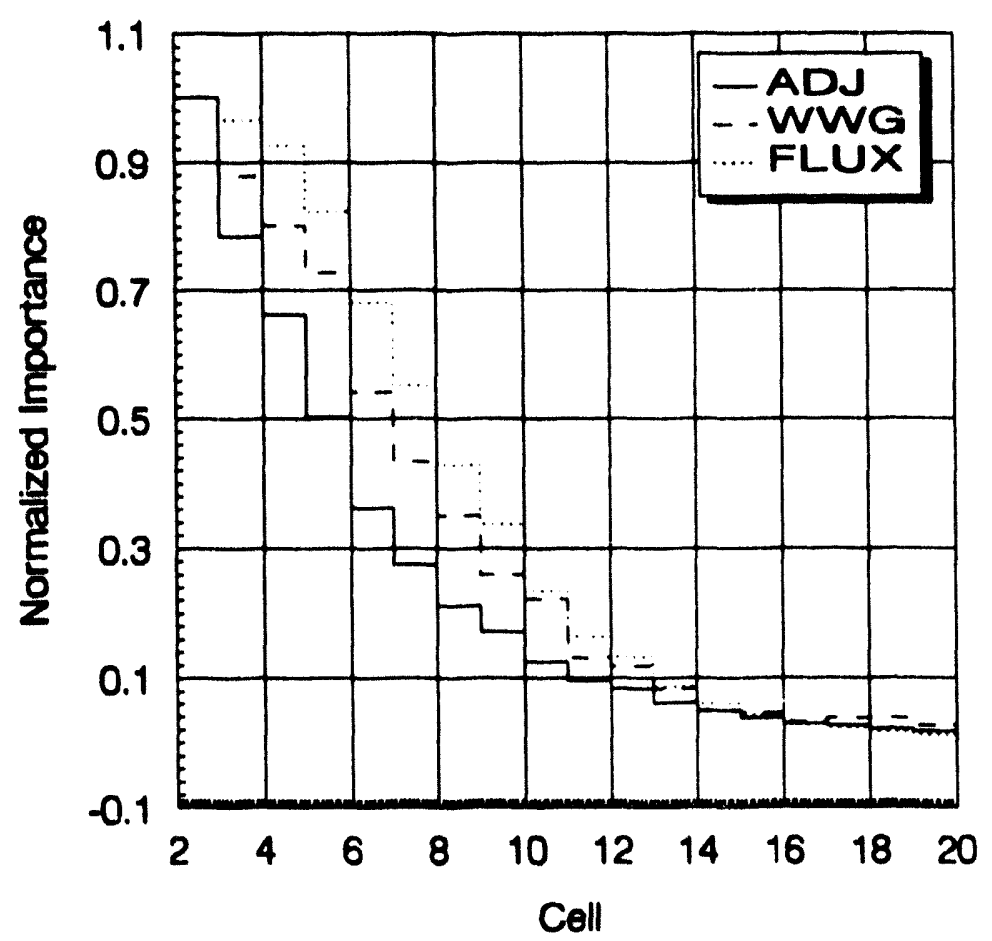

Fig. 12. Normalized Importance Values as a Function of Problem Cells. 


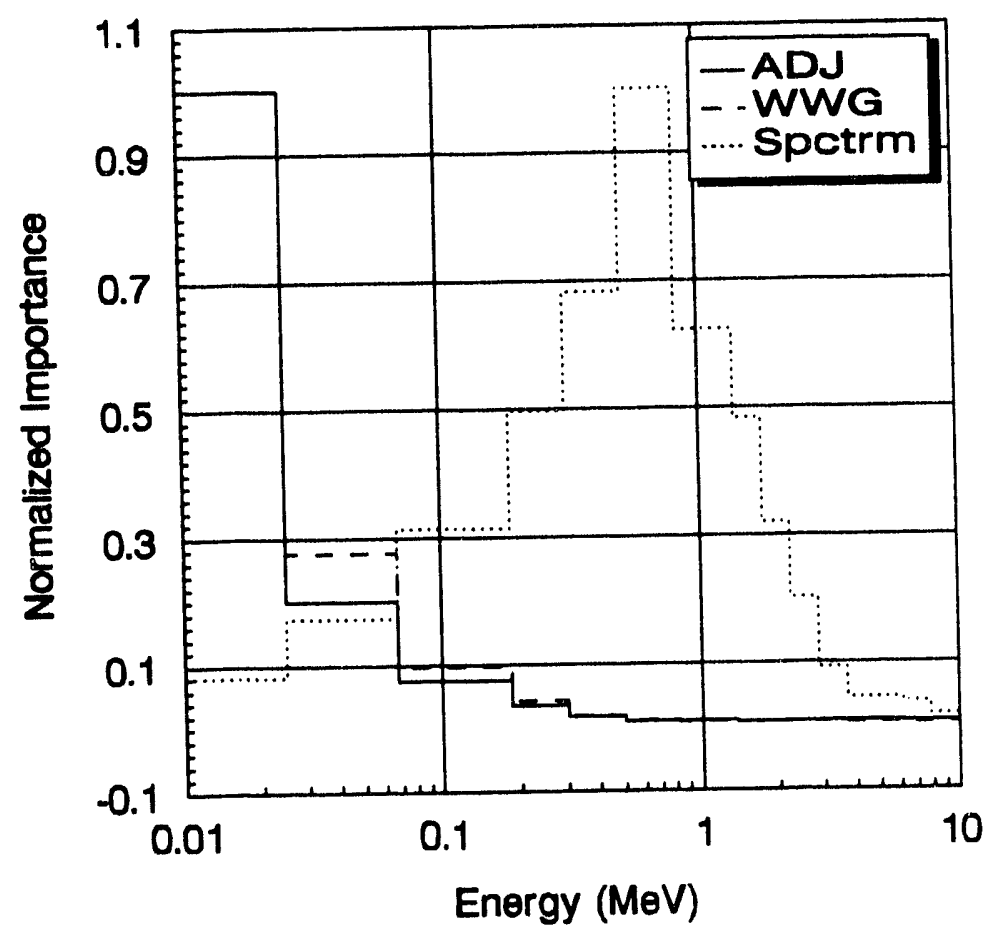

Fig. 13. Normalized Importance Values as a Function of Energy for Cell 10.

\section{Cautions}

The generation of the adjoint importance function is done in the multigroup/adjoint mode. Therefore, all previously mentioned cautions related to multigroup/adjoint calculations are applicable. However, these cautions are of less concern for this application, because a good approximation of the importance function is quite satisfactory to improve calculational efficiency and because the subsequent forward calculation can be performed in the continuous energy mode.

\section{VALIDATION OF MULTIGROUP CAPABILITIES}

A wide variety of problems has been run to validate the MCNP multigroup option by comparing MCNP multigroup results to MCNP continuous energy results, results generated by deterministic transport codes (ONEDANT, TWODANT, and THREEDANT) using the same multigroup cross-section library, and by comparison 
to experimental measurements. All MCNP results were generated with version $4 \mathrm{~A}$, and the multigroup MCNP results utilized a multigroup library based on MENDF5 as processed by CRSRD.

\section{A. Neutron Benchmark Problems}

The problems in this section are a subset of the "MCNP: Neutron Benchmark Problems," LA-12212 (Ref. 7). Table XXIII reproduces the information in Table 3 of the aforementioned report and compares multigroup MCNP results to continuous energy MCNP and experimental results for the Lawrence Livermore pulsed sphere problems ${ }^{26}$ Columns three through six list the ratios of MCNP results to the experimental results corresponding, approximately, to the cilergy ranges of 12 $16 \mathrm{MeV}$ and 2-16 MeV. The last two colurnns list the multigroup and continuous energy ratios. These columns demonstrate that multigroup MC'NP can match the continuous energy results for the pulsed sphere problems reasonatbly well.

Table XXIV compares $k_{\text {eff }}$ values from experiment, multigroup and continuous energy MCNP, and deterministic $\operatorname{codes}^{27}$ for the nine criticality problems in LA12212. The ninth problem was slightly modified by eliminating the presence of tin in two of the materials, because MGXSNP does not contain cross-section data for tin. This modification should not affect the calculated $k_{i f f}$ value since the amount of tin in the mixtures is less than $0.3 \%$. Table XXIV demonstrates that multigroup MCNP can successfully predict $k_{e f f}$ values provided the appropriate cross-section libraries are used. The disagreement between continuous energy and multigroup MCNP for problems 7 and 8 can be attributed to the MENDF5 libraries' inadequate thermal group structure for highly moderated systems (refer to Table A.I of Appendix A for MENDF5 neutron energy group structure) and failure to account for upscatter. Further, the deterministic results, which utilized the same multigroup cross-sections, agree with the multigroup MCNP results to within $0.5 \%$. The relative differences between continuous encrgy and multigroup MCNP for the rest of the problems are within $1 \%$. 
TABLE XXIII

Ratio of Calculated to Experimental Values for the Number of Neutrons Detected in Each Energy Range

\begin{tabular}{|c|c|c|c|c|c|c|c|}
\hline \multirow[b]{2}{*}{ Material } & \multirow[b]{2}{*}{$M F P$} & \multicolumn{2}{|c|}{$\mathrm{MCNP}_{c e}$} & \multicolumn{2}{|c|}{$\mathrm{MCNP}_{m g}$} & \multicolumn{2}{|c|}{ Ratio (mg/ce) } \\
\hline & & $\begin{array}{c}12-16^{\star} \\
(\mathrm{MeV})\end{array}$ & $\begin{array}{l}2-16^{\dagger} \\
(\mathrm{MeV})\end{array}$ & $\begin{array}{c}12-16^{\star} \\
(\mathrm{MeV})\end{array}$ & $\begin{array}{l}2-16^{\dagger} \\
(\mathrm{MeV})\end{array}$ & $\begin{array}{l}12-16^{\star} \\
\left(M \subset V^{\prime}\right)\end{array}$ & $\begin{array}{l}2-16^{\dagger} \\
(\mathrm{MeV})\end{array}$ \\
\hline \multirow[t]{2}{*}{${ }^{6} \mathrm{Li}$} & 0.5 & 1.035 & 0.986 & 1.013 & 0.973 & 0.979 & 0.987 \\
\hline & 1.6 & 1.136 & 1.045 & 1.092 & 1.022 & 0.962 & 0.978 \\
\hline \multirow[t]{2}{*}{${ }^{7} \mathrm{Li}$} & 0.5 & 1.052 & 0.994 & 1.030 & 0.977 & 0.979 & 0.983 \\
\hline & 1.6 & 1.149 & 1.029 & 1.104 & 1.001 & (). .961 & 0.973 \\
\hline \multirow[t]{2}{*}{ Al } & 0.9 & 1.018 & 0.979 & 1.020 & 0.975 & 1.002 & 0.996 \\
\hline & 2.6 & 0.847 & 0.851 & 0.837 & 0.838 & 0.989 & 0.985 \\
\hline $\mathrm{Be}$ & 0.8 & 0.977 & 1.000 & 0.949 & 0.980 & 0.972 & 0.980 \\
\hline \multirow[t]{2}{*}{$\mathrm{C}$} & 0.5 & 1.019 & 1.006 & 1.040 & 1.009 & 1.020 & 1.003 \\
\hline & 2.9 & 0.977 & 0.968 & 1.027 & 0.925 & 1.052 & 0.956 \\
\hline \multirow{2}{*}{$\mathrm{D}_{2} \mathrm{O}$} & 1.2 & 0.917 & 0.918 & 0.887 & 0.905 & 0.968 & 0.986 \\
\hline & 2.1 & 1.047 & 1.020 & 1.009 & 1.002 & 0.964 & 0.982 \\
\hline \multirow[t]{2}{*}{$\mathrm{Fe}$} & 0.9 & 1.047 & 1.006 & 1.038 & 0.982 & 0.991 & 0.976 \\
\hline & 4.8 & 0.989 & 0.945 & 0.997 & 0.911 & 1.008 & 0.963 \\
\hline \multirow[t]{2}{*}{$\mathrm{H}_{2} \mathrm{O}$} & 1.1 & 0.960 & 0.976 & 0.933 & 0.960 & 0.973 & 0.983 \\
\hline & 1.9 & 1.516 & 1.325 & 1.453 & 1.291 & 0.958 & 0.974 \\
\hline \multirow[t]{2}{*}{$\mathrm{Mg}$} & 0.7 & 1.097 & 1.042 & 1.095 & 1.041 & 0.998 & 0.999 \\
\hline & 1.9 & 1.060 & 0.962 & 1.053 & 0.950 & 0.994 & 0.988 \\
\hline \multirow[t]{2}{*}{$\mathrm{N}$} & 1.1 & 0.940 & 0.968 & 0.927 & 0.950 & 0.986 & 0.981 \\
\hline & 3.1 & 0.889 & 0.987 & 0.882 & 0.946 & 0.992 & 0.958 \\
\hline $\mathrm{O}$ & 0.7 & 0.975 & 0.999 & 0.983 & 0.997 & 1.009 & 0.998 \\
\hline $\mathrm{Pb}$ & 1.4 & 0.928 & 0.841 & 0.871 & 0.786 & 0.938 & 0.934 \\
\hline \multirow[t]{2}{*}{$\mathrm{Ti}$} & 1.2 & 1.118 & 0.990 & 1.069 & 0.937 & 0.956 & 0.947 \\
\hline & 3.5 & 1.148 & 0.929 & 1.077 & 0.863 & 0.938 & 0.929 \\
\hline \multirow[t]{2}{*}{$\mathrm{CH}_{2}$} & 0.8 & 1.044 & 1.017 & 1.026 & 1.005 & 0.983 & 0.988 \\
\hline & 3.5 & 1.029 & 1.009 & 0.994 & 0.935 & 0.966 & 0.927 \\
\hline \multirow[t]{2}{*}{$\mathrm{CF}_{2}$} & 0.9 & 1.050 & 1.012 & 1.053 & 1.008 & 1.003 & 0.996 \\
\hline & 2.9 & 0.823 & 0.795 & 0.821 & 0.783 & 0.997 & 0.985 \\
\hline
\end{tabular}

$\star 12-16 \mathrm{MeV}$ range is approximate and corresponds to time-of-flight range of 139.0-161.0 ns. $\dagger 2-16 \mathrm{MeV}$ range is approximate and corresponds to time-of-flight range of 139.0-391.0 ns. 
TABLE XXIV

\section{Comparison of $k_{\text {eff }}$ Values for the Neutron Benchmark Criticality Problems}

\begin{tabular}{|c|c|c|c|c|c|c|c|c|}
\hline \multirow[b]{2}{*}{$\begin{array}{l}\text { Problem } \\
\text { Number }\end{array}$} & \multicolumn{2}{|c|}{$\operatorname{MCNP}^{\dagger}(\mathrm{ce})$} & \multicolumn{2}{|c|}{$\operatorname{MCNP}^{\dagger}(\mathrm{mg})$} & \multirow{2}{*}{$\frac{\text { Deterministic }}{k_{e f f}}$} & \multicolumn{3}{|c|}{ \%Difference } \\
\hline & $k_{c e}$ & $\begin{array}{c}\text { Relative } \\
\text { Error }\end{array}$ & $k_{m g}$ & $\begin{array}{l}\text { Relative } \\
\text { Error }\end{array}$ & & $\begin{array}{c}m g \text { from } \\
\text { ce }\end{array}$ & $\underset{S_{N}}{m g}$ from & $\begin{array}{l}\text { mg from } \\
\text { exp. }\end{array}$ \\
\hline 1 & 0.9973 & 0.0008 & 0.9918 & 0.0008 & $0.9931^{t}$ & -0.55 & -0.13 & -0.83 \\
\hline 2 & 1.0021 & 0.0008 & 1.0013 & 0.0008 & - & -0.08 & - & 0.13 \\
\hline 3 & 1.0075 & 0.0008 & 1.0047 & 0.0008 & - & -0.28 & - & 0.47 \\
\hline 4 & 1.0006 & 0.0007 & 0.9909 & 0.0008 & $0.9892^{\star}$ & -0.99 & 0.18 & -0.92 \\
\hline 5 & 0.9985 & 0.0007 & 0.9927 & 0.0008 & $0.9898^{\star}$ & -0.58 & 0.29 & -0.73 \\
\hline 6 & 0.9885 & 0.0009 & 0.9854 & 0.0008 & $0.9835^{t}$ & -0.31 & 0.20 & -1.48 \\
\hline 7 & 0.9952 & 0.0010 & 1.0227 & 0.0010 & $1.0183^{!}$ & 2.69 & 0.43 & 2.22 \\
\hline 8 & 1.0215 & 0.0013 & 0.9941 & 0.0012 & - & -2.76 & - & -0.60 \\
\hline 9 & 1.0022 & 0.0017 & 1.0001 & 0.0016 & - & -0.21 & - & -0.01 \\
\hline
\end{tabular}

†Values reported are for the covariance-weighted combined estimator. $\ddagger$ Calculated by ONEDANT (One-Dimensional Discrete Ordinates Code).

$\star$ Calculated by TWODANT (Two-Dimensional Discrete Ordinates Code).

\section{B. Photon Benchmark Problems}

The results listed in this section correspond to various problems discussed in the "MCNP: Photon Benchmarks," LA-12196 (Ref. 6). The values listed in Tables 3.1 and 3.2 of the photon benchmark report have been calculated with both continuous energy and multigroup MCNP. These computed values are given in Tables XXV and XXVI. The energy buildup values associated with a $1 \mathrm{MeV}$ source reveal that the lower energy group structure, in the default multigroup photon data, is inadequate for this particular application (refer to Table A.II of Appendix A for MENDF5 photon energy group structure). On the other hand, it is clear that the group structure is applicable to the problems with a $10 \mathrm{MeV}$ source. These values are quite good up until the point where the lower energy group structure becomes important (i.e., 4 and 7 MFP values). 
TABLE XXV

Energy Buildup $\left(B_{e}\right.$ ) of Gamma Rays from a Point Source in an Infinite Medium of $\mathrm{Al}$ at 1.0 and $10.0 \mathrm{MeV}$

\begin{tabular}{|c|c|c|c|c|c|}
\hline $\begin{array}{c}\text { Source } \\
\text { Energy } \\
(\mathrm{MeV})\end{array}$ & $\begin{array}{c}\text { Mean Free } \\
\text { Path } \\
\text { (MFP) }\end{array}$ & Analytic & $\begin{array}{c}\text { MCNP } \\
\text { (ce) }\end{array}$ & $\begin{array}{c}\text { MCNP } \\
(\mathrm{mg})\end{array}$ & $\begin{array}{c}\text { Ratio } \\
\text { (mg/ce) }\end{array}$ \\
\hline \multirow[t]{4}{*}{1} & 1 & 2.01 & $2.019 \pm 0.010$ & $2.860 \pm 0.005$ & 1.417 \\
\hline & 2 & 3.29 & $3.290 \pm 0.018$ & $6.113 \pm 0.005$ & 1.858 \\
\hline & 4 & 6.52 & $6.576 \pm 0.038$ & $17.412 \pm 0.006$ & 2.648 \\
\hline & 7 & 12.95 & $13.554 \pm 0.077$ & $62.356 \pm 0.006$ & 4.601 \\
\hline \multirow[t]{4}{*}{10} & 1 & 1.22 & $1.268 \pm 0.006$ & $1.230 \pm 0.005$ & 0.970 \\
\hline & 2 & 1.45 & $1.499 \pm 0.009$ & $1.416 \pm 0.006$ & 0.945 \\
\hline & 4 & 1.91 & $1.975 \pm 0.015$ & $1.781 \pm 0.007$ & 0.902 \\
\hline & 7 & 2.64 & $2.667 \pm 0.023$ & $2.394 \pm 0.008$ & 0.897 \\
\hline
\end{tabular}

TABLE XXVI

Energy Buildup $\left(\mathrm{B}_{e}\right)$ of Gamma Rays from a Point Source in an Infinite Medium of $\mathrm{Pb}$ at 1.0 and $10.0 \mathrm{MeV}$

\begin{tabular}{cccccc}
\hline $\begin{array}{c}\text { Source } \\
\text { Energy } \\
(\mathrm{MeV})\end{array}$ & $\begin{array}{c}\text { Mean Free } \\
\text { Path } \\
(\mathrm{MFP})\end{array}$ & Analytic & $\begin{array}{c}\text { MCNP } \\
(\mathrm{ce})\end{array}$ & $\begin{array}{c}\text { MCNP } \\
(\mathrm{mg})\end{array}$ & $\begin{array}{c}\text { Ratio } \\
(\mathrm{mg} / \mathrm{ce})\end{array}$ \\
\hline \multirow{2}{*}{1} & 1 & 1.35 & $1.365 \pm 0.006$ & $1.473 \pm 0.004$ & 1.080 \\
& 2 & 1.66 & $1.652 \pm 0.010$ & $2.056 \pm 0.006$ & 1.244 \\
& 4 & 2.21 & $2.192 \pm 0.016$ & $3.857 \pm 0.007$ & 1.760 \\
& 7 & 2.95 & $2.829 \pm 0.024$ & $9.538 \pm 0.008$ & 3.371 \\
& & & & & \\
10 & 1 & 1.09 & $1.132 \pm 0.006$ & $1.138 \pm 0.005$ & 1.005 \\
& 2 & 1.19 & $1.238 \pm 0.008$ & $1.230 \pm 0.006$ & 0.994 \\
& 4 & 1.46 & $1.528 \pm 0.012$ & $1.472 \pm 0.008$ & 0.963 \\
& 7 & 2.16 & $2.320 \pm 0.019$ & $2.104 \pm 0.008$ & 0.907 \\
& & & & & \\
\hline
\end{tabular}




\section{Criticality Benchmark Problems}

Table XXVII compares continuous energy and multigroup MCNP, deterministic, ${ }^{28}$ and experimental results for a subset of the 25 criticality safety problems cited in "MCNP: Criticality Safety Benchmark Problems," LA-12415 (Ref. 8) and Ref. 28. Comparisons are not made for all 25 problems, as some of the problems are identical. Results for those problems that are unique are listed. Table XXVII verifies that multigroup MCNP compares well (within 1\%) with continuous energy MCNP for all problems that are not highly moderated. The discrepancies in the results for problems 3,5,15, and 21 can be largely attributed to the lack of an adequate number of thermal energy groups and upscatter in the MENDF5 library. The deterministic results for problems 15 and 21 support these conclusions and are within $0.35 \%$ of the multigroup MCNP results.

\section{CONCLUSIONS}

The MCNP multigroup/adjoint option is valuable for many reasons: comparisons with deterministic transport codes; running adjoint problems; generating adjoint importance functions; cross-section sensitivity studies; problems for which there are no continuous energy cross-sections available; and transport of charged particles.

An auxiliary code, CRSRD, is available to generate multigroup cross sections from several widely used deterministic multigroup library dat a formats. CRSRD is fairly easy to use as was described in Section III.

As described in Section IV, running multigroup problems in MCNP is simple and straightforward once the multigroup library is available. Adjoint problems, on the other hand, can be intimidating at first, although the adjoint capability is a powerful method. Adjoint importance functions can be of value in forward multigroup or continuous-energy MCNP calculations.

A wide variety of calculations has been made to compare multigroup MCNP to continuous-energy MCNP, the deterministic codes, and experimental measurements. Results of these calculations are presented in Section V. They indicate that the multigroup method is reliable and robust, provided an appropriate multigroup cross-section library is available in MCNP format. 
TABLE XXVII

Comparison of $k_{e f f}$ Values for the Criticality Safety

Benchmark Problems

\begin{tabular}{|c|c|c|c|c|c|c|c|c|}
\hline \multirow[b]{2}{*}{$\begin{array}{l}\text { Problem } \\
\text { Number }\end{array}$} & \multicolumn{2}{|c|}{$\operatorname{MCNP}{ }^{\dagger}(c e)$} & \multicolumn{2}{|c|}{$M\left(N P^{\dagger}(\mathrm{mg})\right.$} & \multirow{2}{*}{$\frac{\text { Deterministic }}{k_{\text {es }}}$} & \multicolumn{3}{|c|}{ \%Diffrence } \\
\hline & $k_{c e}$ & $\begin{array}{c}\text { Relative } \\
\text { Error }\end{array}$ & $k_{m g}$ & $\begin{array}{l}\text { Relative } \\
\text { Error }\end{array}$ & & $\begin{array}{c}m g \text { from } \\
\text { ce }\end{array}$ & $m g$ from & $\begin{array}{c}\text { mg from } \\
\text { exp. }\end{array}$ \\
\hline 1 & 0.9999 & 0.0009 & 0.9926 & 0.0008 & - & -0.73 & - & -0.74 \\
\hline 2 & 0.9999 & 0.0009 & 0.9926 & 0.0008 & - & -0.73 & - & -0.74 \\
\hline 3 & 0.9990 & 0.0011 & 1.0128 & 0.0011 & - & 1.37 & - & 1.28 \\
\hline 5 & 0.9995 & 0.0027 & 1.0143 & 0.0028 & - & 1.46 & - & 1.43 \\
\hline 6 & 0.7461 & 0.0010 & 0.7405 & 0.0008 & $0.7417^{\star}$ & -0.76 & -0.16 & $*$ \\
\hline 7 & 0.9993 & 0.0009 & 0.9949 & 0.0008 & - & -0.44 & - & -0.51 \\
\hline 8 & 0.9401 & 0.0009 & 0.9336 & 0.0009 & - & -0.70 & - & $*$ \\
\hline 9 & 2.2935 & 0.0004 & 2.2800 & 0.0005 & - & -0.59 & - & * \\
\hline 12 & 0.9986 & 0.0012 & 0.9966 & 0.0013 & $0.9966^{\circ}$ & -0.20 & $-(0.01$ & -0.34 \\
\hline 13 & 0.9942 & 0.0009 & 0.9923 & 0.0009 & - & -0.18 & - & -0.77 \\
\hline 14 & 0.9991 & 0.0009 & 0.9946 & 0.0009 & - & -0.46 & - & -0.54 \\
\hline 15 & 1.0025 & 0.0010 & 1.0243 & 0.0009 & $1.0208^{*}$ & 2.12 & 0.34 & 2.43 \\
\hline 16 & 0.9887 & 0.0008 & 1.0075 & 0.0009 & - & 1.87 & - & $*$ \\
\hline 17 & 1.0029 & 0.0014 & 0.9809 & 0.0014 & - & -2.24 & - & * \\
\hline 18 & 1.0287 & 0.0013 & 1.0636 & 0.0012 & - & 3.28 & - & * \\
\hline 20 & 0.9981 & 0.0014 & 0.9936 & 0.0014 & $0.9991^{\circ}$ & -0.44 & .0 .56 & -0.64 \\
\hline 21 & 0.9948 & 0.0009 & (0.8299 & 0.0010 & $0.8290^{t}$ & -19.86 & 0.11 & -17.01 \\
\hline
\end{tabular}

tValues reported are for the covariance-weighted combined estimator.

$\ddagger$ Calculated by ONEDANT (One-Dimensional Discrete Ordinates (Code).

* Calculated by TWODANT (Two-Dimensional Discrete Ordinates (Code).

- Calculated by THREEDANT (Three-Dimensional Discrete Ordinates Code).

* Experimental values of $k_{e f f}$ could not be located for these problems. 


\section{ACKNOWLEDGMENTS}

John Wagner would like to acknowledge the extensive assistance of Dave Collins in matters related to adjoint calculations; and D. Kent Parsons for providing the input files, as well as assistance, used to generate all the deterministic results.

\section{REFERENCES}

1. J. F. Briesmeister, Editor, "MCNP - A General Monte Carlo N-Particle Transport Code, Version 4A," Los Alamos National Laboratory report LA-12625 (1993).

2. J. F. Briesmeister, Editor, "MCNP - A General Monte Carlo Code for Neutron and Photon Transport, Version 3A," Los Alamos National Laboratory report LA-7396-M, Rev. 2 (1986).

3. G. P. Estes, R. E. Seamon, R. D. O'Dell, W. T. Urban, R. C. Little, R. A. Forster, "MCNP/ONEDANT Comparisons," Los Alamos National Laboratory internal memoraridum X-6:GPE-88-416 (1988).

4. R. S. Baker, "MCNP/ONEDANT Comparisons," Los Alamos National Laboratory internal memorandum X-6:RSB-91-128 (1991).

5. R. S. Baker, "XREP Module," Los Alamos National Laboratory internal memorandum X-6:RSB-93-208 (Mar. 1993).

6. D. J. Whalen, D. E. Hollowell, and J. S. Hendricks, "MCNP: Photon Benchmark Problems," Los Alamos National Laboratory report LA-12196 (1991).

7. D. J. Whalen, D. A. Cardon, J. L. Uhle, and J. S. Hendricks, "MCNP: Neutron Benchmark Problems," Los Alamos National Laboratory report LA-12212 (1991).

8. J. C. Wagner, J. E. Sisolak, G. W. McKinney, "MCNP: Criticality Safety Benchmark Problems," Los Alamos National Laboratory report LA-12415 (1992).

9. S. Sitaraman, "MCNP: Light Water Reactor Critical Benchmarks," GE Nuclear Energy report NEDO-32028 (Mar. 1992). 
10. R. D. O'Dell, F. W. Brinkley, Jr., D. R. Marr, R. E. Alcouffe. "Revised User's Manual for ONEDANT: A Code Package for One-Dimensional, Diffusion Accelerated, Neutral-Particle Transport," Los Alamos National Laboratory Report LA-9184-M, Rev. (Dec. 1989).

11. R. E. Alcouffe, F. W. Brinkley, Jr., D. R. Marr, R. D. O'Dell, "User's Guide () TWODANT: A Code Package for Two-Dimensional, Diffusion Accelerated, Neutral-Particle Transport," Los Alamos National Laboratory Report LA-10049M, Rev. 1, (Oct. 1984).

12. R. D. O'Dell, F. W. Brinkley, Jr., D. R. Marr, R. E. Alcouffe, "Revised User's Manual for ONEDANT: A Code Package for One-Dimensional, Diffusion Accelerated, Neutral-Particle Transport," Los Alamos National Laboratory Report LA-9184-M, Rev. (Dec. 1989) (THREEDANT manual is forthcoming).

13. T. E. Booth, "A Sample Problem in Variance Reduction in MCNP," Los Alamos National Laboratory report LA-10363-MS (1985).

14. T. E. Booth, J. S. Hendricks, "Importance Estimation in Forward Monte Carlo Calculations," Nucl. Tech./Fusion, 5, 90-100, (1984).

15. G. L. Simmons, R. Roussin, "SAILOR - A Coupled Cross-Section Library for Light Water Reactors," DLC-76, Oak Ridge National Laboratory, Radiation Shielding Information Center (Mar. 1983).

16. "BUGLE-80, Coupled 47 Neutron, 20 Gamma, $P_{3}$ Cross-Section Library for LWR Shielding Calculations," DLC-75, Oak Ridge National Laboratory, Radiation Shielding Information Center (1980).

17. R. E. Maerker, W. E. Ford, "The ELXSIR Cross Section Library for LWR Pressure Vessel Irradiation Studies: Part of the LEPRICON Computer Code System," EPRI NP3654, Electric Power Research Institute (Sept. 1984).

18. A. Haghighat R. Veerasingam, "Transport Analysis of Several Cross-Section Libraries Used for Reactor Pressure Vessel Fluence Calculations," Nucl. Tech, 101, 237-243, (Feb. 1993). 
19. E. E. Lewis, W. F. Miller, Computational Methods of Neutron Transport, John Wiley \& Sons, New York (1984).

20. R. C. Little, R. E. Seamon, "New MENDF5 and MENDF5G," Los Alamos National Laboratory internal memorandum X-6:RCL-86-412 (Sept. 1986).

21. R. C. Little, "Neutron and Photon Multigroup Data Tables for MCNP3B," Los Alamos National Laboratory internal memorandum X-6:RCL-87-225 (Apr. 1987).

22. R. C. Little, "Replacement of Public Multigroup Libraries," Los Alamos National Laboratory internal memorandum X-6:RCL-87-642 (Dec. 1987).

23. R. E. Seamon, "Comparing Cross Sections for MCNP and ONEDANT," Los Alamos National Laboratory internal memorandum X-6:RES-88-445 (Oct. 1988).

24. D. G. Collins, "Normalization of Forward and Adjoint MCNP Runs," Los Alamos National Laboratory internal memorandum DGC-87-187 (Mar. 1987).

25. D. G. Collins, "Use of Multigroup Cross Section in MCNP," Los Alamos National Laboratory internal memorandum DGC-87-164 (Mar. 1987).

26. C. Wong, J. D. Anderson, P. Brown, L. F. Hansen, J. L. Kammerdiener, C. Logan, B. Pohl, "Lawrence Livermore Pulsed Sphere Program: Program Summary Through July 1971," Lawrence Livermore National Laboratory report UCRL-51144, Rev. 1 (1972).

27. D. K. Parsons, R. E. Alcouffe, D. R. Marr, F. W. Brinkley, "Recent Developments in the TWODANT System of Codes for Criticality Safety," 1993 Topical Meeting of the American Nuclear Society, Nashville, TN, (Sept. 1993), to be published.

28. Gregg W. McKinney, John C. Wagner, James E. Sisolak, "MCNP/KENO Criticality Comparison," Proceedings of the Topical Meeting on Physics and Methods in Criticality Safety, Nashville, Tennessee, September 19-23, American Nuclear Society, Order 700186, p. 207 (September 1993) 
29. J. E. Morel, W. M. Taylor, L. J. Lorence, Jr., J. W. Vandenburg, D. P. Sloan, "A Hybrid Multigroup/Continuous-Energy Monte Carlo Method for Solving the Boltzmann-Fokker-Planck Equation," to be submitted to Nucl. Science and Engineering. 


\section{APPENDIX A: \\ MULTIGROUP CROSS-SECTION DATA}


TABLE A.I

MENDF5 Neutron Energy Group Boundaries

\begin{tabular}{cccc} 
Group & $\begin{array}{c}\text { Upper Energy Group } \\
\text { Boundaries (MeV) }\end{array}$ & Group & $\begin{array}{c}\text { Upper Energy Group } \\
\text { Boundaries (MeV) }\end{array}$ \\
\hline 1 & 17.000 & 16 & 0.1840 \\
2 & 15.000 & 17 & 0.0676 \\
3 & 13.500 & 18 & 0.0248 \\
4 & 12.000 & 19 & 0.00912 \\
5 & 10.000 & 20 & 0.00335 \\
6 & 7.790 & 21 & 0.001235 \\
7 & 6.070 & 22 & $4.54 \mathrm{E}-04$ \\
8 & 3.680 & 23 & $1.67 \mathrm{E}-04$ \\
9 & 2.865 & 24 & $6.14 \mathrm{E}-05$ \\
10 & 2.232 & 25 & $2.26 \mathrm{E}-05$ \\
11 & 1.738 & 26 & $8.32 \mathrm{E}-06$ \\
12 & 1.353 & 27 & $3.06 \mathrm{E}-06$ \\
13 & 0.823 & 28 & $1.13 \mathrm{E}-06$ \\
14 & 0.500 & 29 & $4.14 \mathrm{E}-07$ \\
15 & 0.303 & 30 & $1.52 \mathrm{E}-07$
\end{tabular}

thower energy of group 30 is $1.39 \mathrm{E}-10 \mathrm{MeV}$.

TABLE A.II

MENDF5 Photon Energy Group Boundaries

Group Upper Energy Group
Boundaries $(\mathrm{MeV})^{\dagger}$

\begin{tabular}{cc}
\hline 1 & 20.0 \\
2 & 9.0 \\
3 & 8.0 \\
4 & 7.0 \\
5 & 6.0 \\
6 & 5.0 \\
7 & 4.0 \\
8 & 3.0 \\
9 & 2.0 \\
10 & 1.0 \\
11 & 0.5 \\
12 & 0.1
\end{tabular}

†lower energy of group 12 is $0.01 \mathrm{MeV}$. 


\begin{tabular}{|c|c|c|c|}
\hline Isotope & $Z A I D$ & Source & $\begin{array}{l}\text { Photon } \\
\text { Production }\end{array}$ \\
\hline H & 1001.50 & ENDF/B-V & Yes \\
\hline D & 1002.55 & Group T-2 & Yes \\
\hline $\mathrm{T}$ & 1003.50 & ENDF $/ \mathrm{B}-\mathrm{V}$ & No \\
\hline $\mathrm{He}-3$ & 2003.50 & ENDr/B-V & No \\
\hline He-4 & 2004.50 & ENDF/B-V & No \\
\hline $\mathrm{Li}-6$ & 3006.50 & ENDF/B-V & Yes \\
\hline $\mathrm{Li}-7$ & 3007.55 & Group T-2 & Yes \\
\hline Be-7 & 4007.50 & ENDL85 & No \\
\hline Be -9 & 4009.50 & ENDF/B-V & Yes \\
\hline B- 10 & 5010.50 & ENDF/B-V & Yes \\
\hline B-11 & 5011.56 & Group T-2 & Yes \\
\hline $\mathrm{C}$ & 6000.50 & ENDF/B-V & Yes \\
\hline $\mathrm{C}-12$ & $\mathrm{c}(012.50$ & ENDF/B-V & Yes \\
\hline$N-14$ & 7014.50 & ENDF/B-V & Yes \\
\hline $\mathrm{N}-15$ & 7015.55 & Group T-2 & Yes \\
\hline $0-16$ & 8016.50 & ENDF/B-V & Yes \\
\hline F-19 & 9019.50 & ENDF/B-V & Yes \\
\hline $\mathrm{Na}-23$ & 11023.50 & ENDF/B-V & Yes \\
\hline $\mathrm{Mg}$ & 12000.50 & ENDF/B-V & Yes \\
\hline $\mathrm{Al}-27$ & 13027.50 & ENDF/B-V & Yes \\
\hline $\mathrm{Si}$ & 14000.50 & ENDF / B-V & Yes \\
\hline P-31 & 15031.50 & ENDF/B-V & Yes \\
\hline S-32 & 16032.50 & ENDF/B-V & Yes \\
\hline $\mathrm{Cl}$ & 17000.50 & ENDF/B-V & Yes \\
\hline Ar & 18000.35 & ENDL85 & Yes \\
\hline K & 19000.50 & ENDF/B-V & Yes \\
\hline $\mathrm{Ca}$ & 20000.50 & ENDF/B-V & Yes \\
\hline $\mathrm{Ti}$ & 22000.50 & ENDF/B-V & Yes \\
\hline V & 23000.50 & ENDF/B-V & Yes \\
\hline $\mathrm{Cr}$ & 24000.50 & ENDF/B-V & Yes \\
\hline
\end{tabular}


TABLE A.III (continued)

Materials Available on MENDF5 and MENDF5G

\begin{tabular}{|c|c|c|c|}
\hline Isotope & ZAID & Source & $\begin{array}{l}\text { Photon } \\
\text { Production }\end{array}$ \\
\hline $\mathrm{Mn}-55$ & 25055.50 & ENDF/B-V & Yes \\
\hline $\mathrm{Fe}$ & 26000.55 & Group T-2 & Yes \\
\hline Co-59 & 27059.50 & ENDF/B-V & Yes \\
\hline $\mathrm{Ni}$ & 28000.50 & ENDF/B-V & Yes \\
\hline $\mathrm{Cu}$ & 29000.50 & ENDF/B-V & Yes \\
\hline $\mathrm{Ga}$ & 31000.50 & ENDF/B-V & Yes \\
\hline As- 75 & 33075.35 & ENDL85 & Yes \\
\hline $\mathrm{Kr}-78$ & 36078.50 & ENDF/B-V & No \\
\hline $\mathrm{Kr}-80$ & 36080.50 & ENDF/B-V & No \\
\hline $\mathrm{Kr}-82$ & 36082.50 & ENDF/B-V & No \\
\hline $\mathrm{Kr}-83$ & 36083.50 & ENDF/B-V & No \\
\hline $\mathrm{Kr}-84$ & 36084.50 & ENDF/B-V & No \\
\hline $\mathrm{Kr}-86$ & 36086.50 & ENDF/B-V & No \\
\hline Y-98 & 39089.50 & ENDF/B-V & No \\
\hline $\mathrm{Zr}$ & 40000.50 & ENDF/B-V & No \\
\hline $\mathrm{Nb}-93$ & 41093.50 & ENDF/B-V & Yes \\
\hline Mo & 42000.50 & ENDF/B-V & Yes \\
\hline Rh-103 & 45103.50 & ENDF/B-V & No \\
\hline U235 FP & 45117.90 & Group T-2 & Yes \\
\hline Pu239 FP & 46119.90 & Group T-2 & Yes \\
\hline $\mathrm{Ag}$ & 47000.55 & ENDF/B-V & Yes \\
\hline Ag- 107 & 47107.50 & ENDF/B-V & No \\
\hline $\mathrm{Ag}-109$ & 47109.50 & ENDF/B-V & No \\
\hline $\mathrm{Cd}$ & 48000.50 & ENDF/B-V & No \\
\hline Avg FP & .50120 .35 & ENDL85 & Yes \\
\hline FPP & 50998.99 & PERMFILE & No \\
\hline FPA & 50999.99 & PERMFILE & No \\
\hline $\mathrm{Xe}$ & 54000.35 & ENDL85 & Yes \\
\hline Ba-138 & 56138.50 & ENDF/B-V & Yes \\
\hline Eu & 63000.35 & ENDL85 & Yes \\
\hline Eu-151 & 63151.55 & Group T-2 & Yes \\
\hline Eu-153 & 63153.55 & Group T-2 & Yes \\
\hline Gd & 64000.35 & ENDL85 & Yes \\
\hline Ho- 165 & 67165.55 & Group T-2 & Yes \\
\hline Tm-169 & 67169.55 & Group T-2 & No \\
\hline
\end{tabular}


TABLE A.III (continued)

Materials Available on MENDF5 and MENDF5G

\begin{tabular}{|c|c|c|c|}
\hline Isotope & ZAID & Source & $\begin{array}{l}\text { Photon } \\
\text { Production }\end{array}$ \\
\hline Ta-181 & 73181.50 & ENDF/B-V & Yes \\
\hline W & 74000.55 & Group T-2 & Yes \\
\hline W-182 & 74182.55 & Group T-2 & Yes \\
\hline W-183 & 74183.55 & Group T-2 & Yes \\
\hline W-184 & 74184.55 & Group T-2 & Yes \\
\hline W-186 & 74186.55 & Group T-2 & Yes \\
\hline Re-185 & 75185.50 & ENDF/B-V & No \\
\hline Re- 187 & 75187.50 & ENDF/B-V & No \\
\hline Ir & 77000.55 & Group T-2 & No \\
\hline $\mathrm{Pt}$ & 78000.35 & ENDL85 & Yes \\
\hline $\mathrm{Au}-197$ & 79197.56 & Group T-2 & Yes \\
\hline $\mathrm{Pb}$ & 82000.50 & ENDF/B-V & Yes \\
\hline $\mathrm{Bi}-209$ & 83209.50 & ENDF/B-V & Yes \\
\hline Th-232 & 90232.50 & ENDF/B-V & Yes \\
\hline $\mathrm{Pa}-233$ & 91233.50 & ENDF/B-V & No \\
\hline U-233 & 92233.50 & ENDF/B-V & No \\
\hline $\mathrm{U}-234$ & 92234.50 & ENDF/B-V & No \\
\hline U-235 & 92235.50 & ENDF/B-V & Yes \\
\hline U-236 & 92236.50 & ENDF $/ B-V$ & No \\
\hline U-237 & 92237.50 & ENDF/B-V & Yes \\
\hline U-238 & 92238.50 & ENDF/B-V & Yes \\
\hline U-239 & 92239.35 & ENDL85 & Yes \\
\hline Np-237 & 93237.55 & Group T-2 & No \\
\hline $\mathrm{Pu}-237$ & 94237.35 & ENDL86 & Yes \\
\hline Pu-238 & 94238.50 & ENDF/B-V & No \\
\hline Pu-239 & 94239.55 & Group T-2 & Yes \\
\hline $\mathrm{Pu}-240$ & 94240.50 & ENDF/B-V & Yes \\
\hline $\mathrm{Pu}-241$ & 94241.50 & ENDF /B-V & Yes \\
\hline Pu-242 & 94242.50 & ENDF/B-V & Yes \\
\hline Am-241 & 95241.50 & ENDF/B-V & No \\
\hline$A m-242 m$ & 95242.50 & ENDF/B-V & No \\
\hline Am-243 & 95243.50 & ENDF / B-V & No \\
\hline $\mathrm{Cm}-242$ & 96242.50 & ENDF/B-V & No \\
\hline $\mathrm{Cm}-244$ & 96244.50 & ENDF/B-V & No \\
\hline
\end{tabular}




\section{APPENDIX B:}

MCNP INPUT FILES 


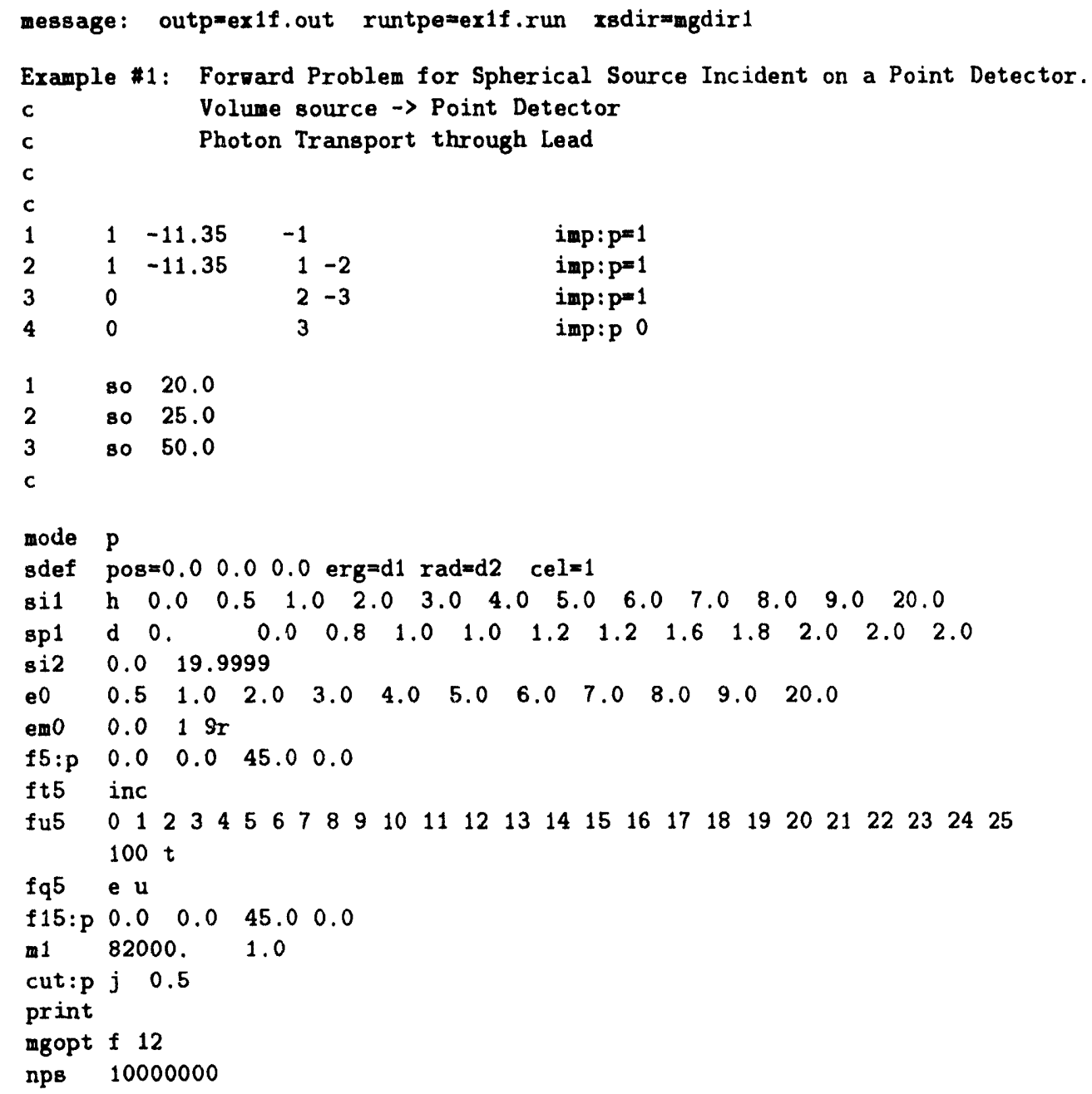

Fig. B1. Forward Input File for Example 1 




Fig. B2. Adjoint Input File for Example 1 


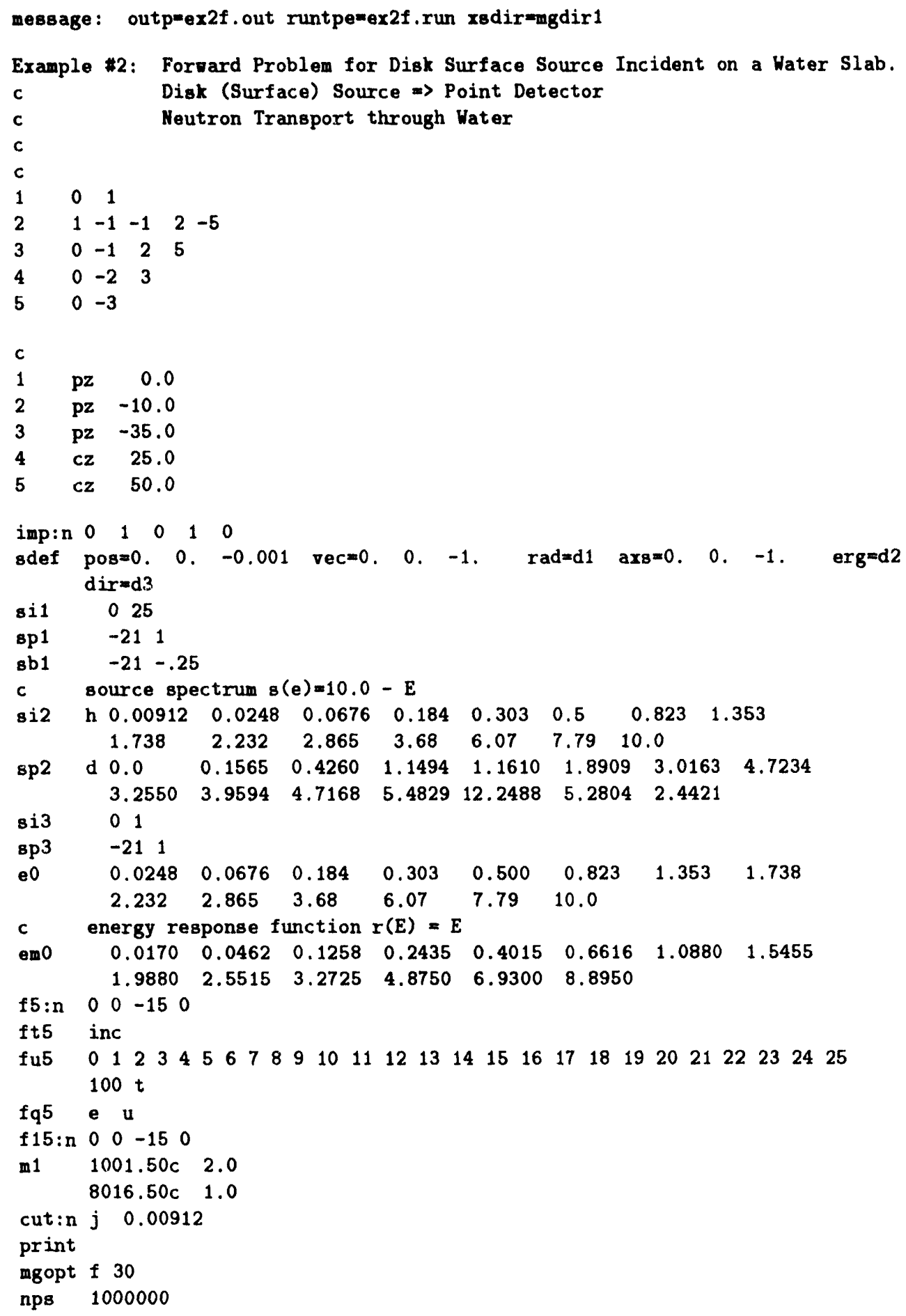

Fig. B3. Forward Input File for Example 2 


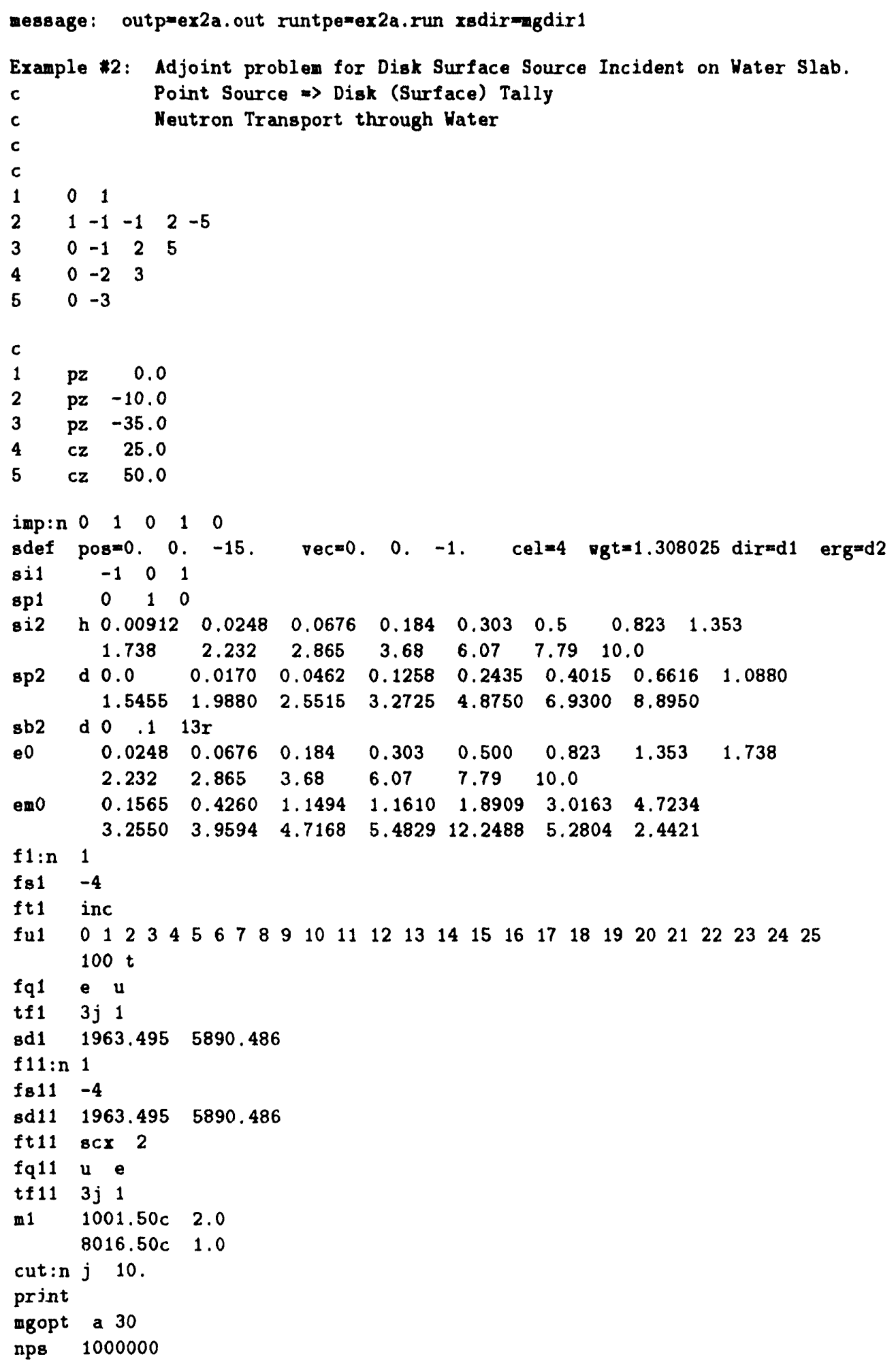

Fig. B4. Adjoint Input File for Example 2 


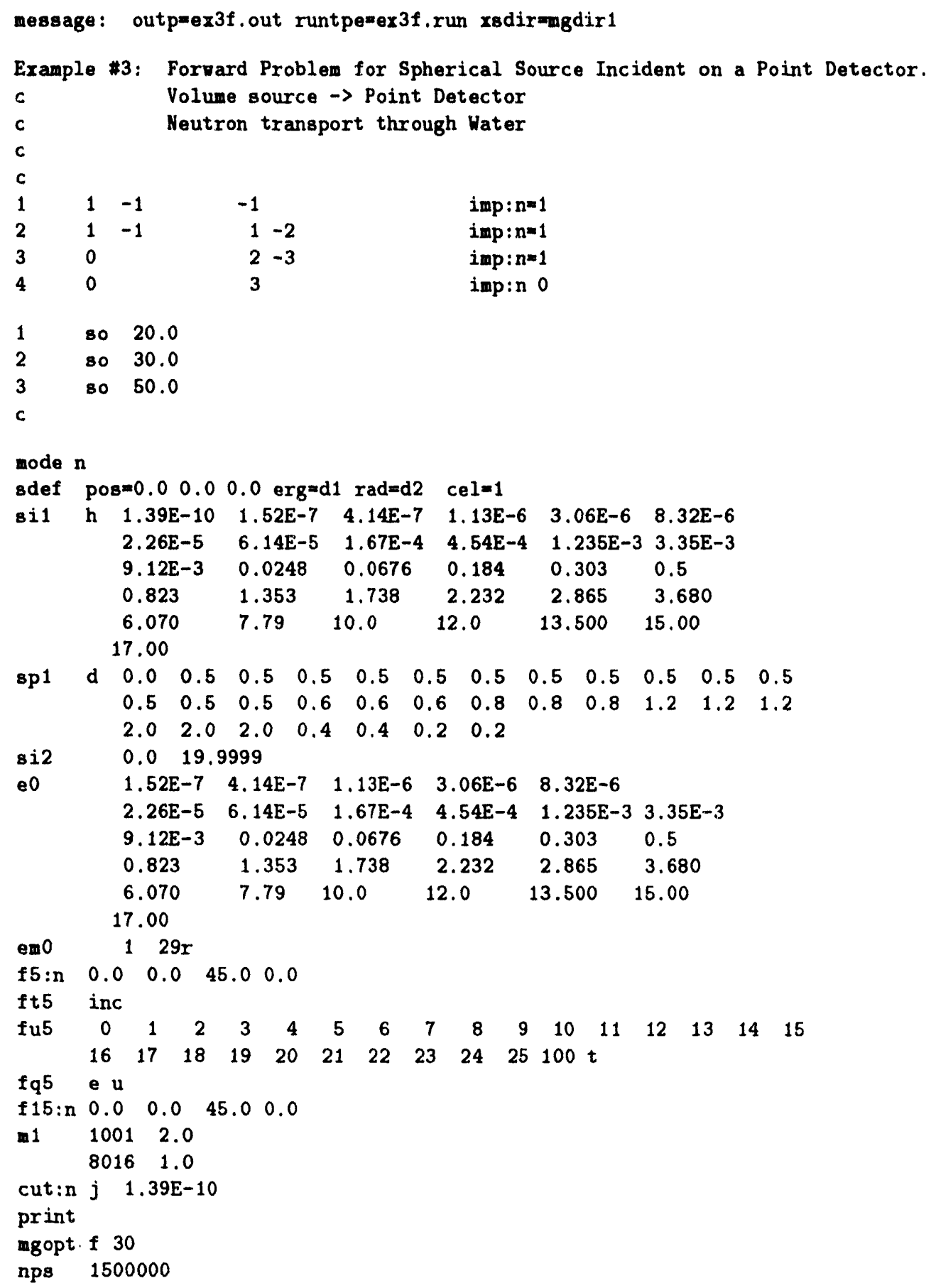

Fig. B5. Forward Input File for Material Test with Water 


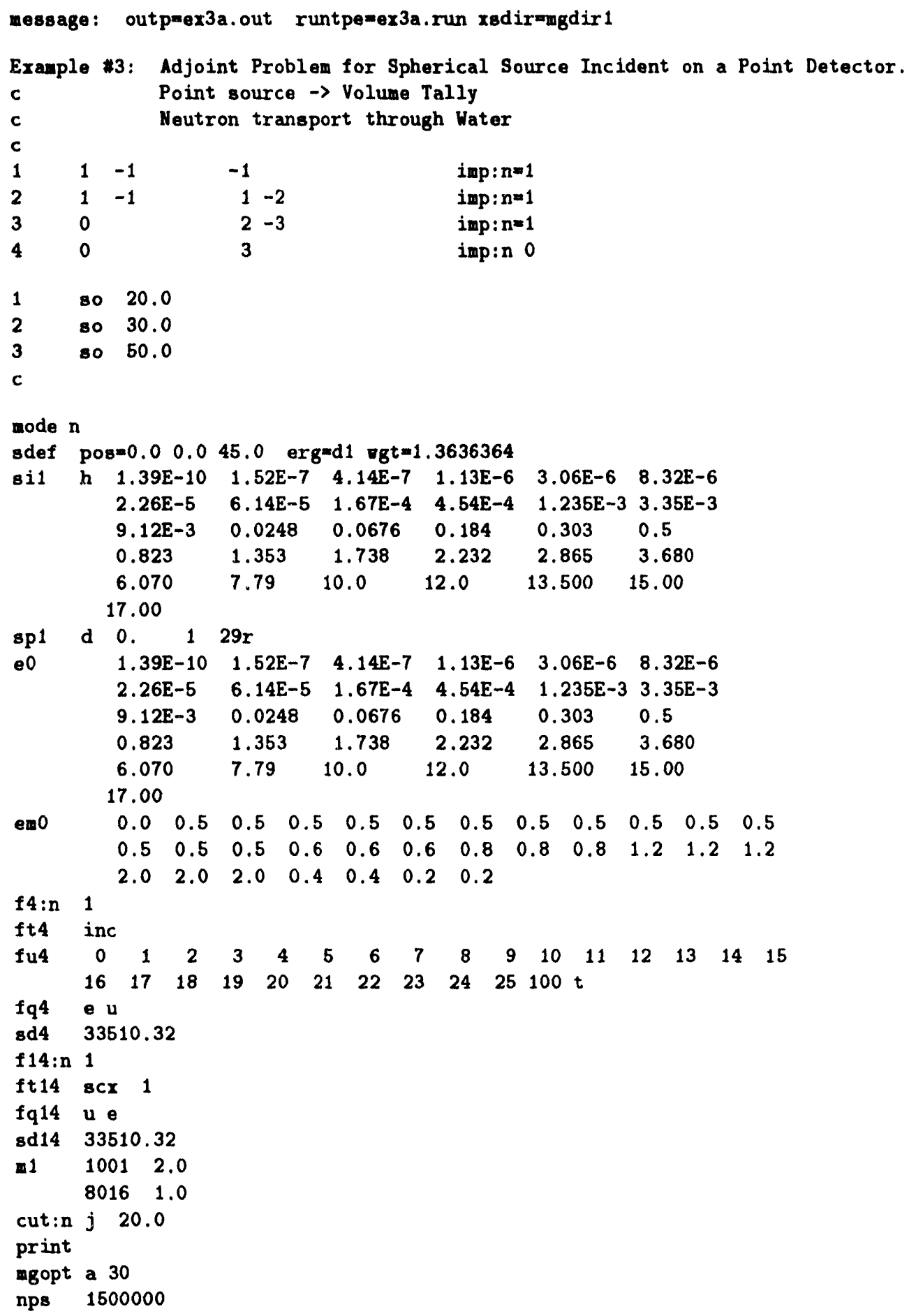

Fig. B6. Adjoint Input File for Material Test with Water 


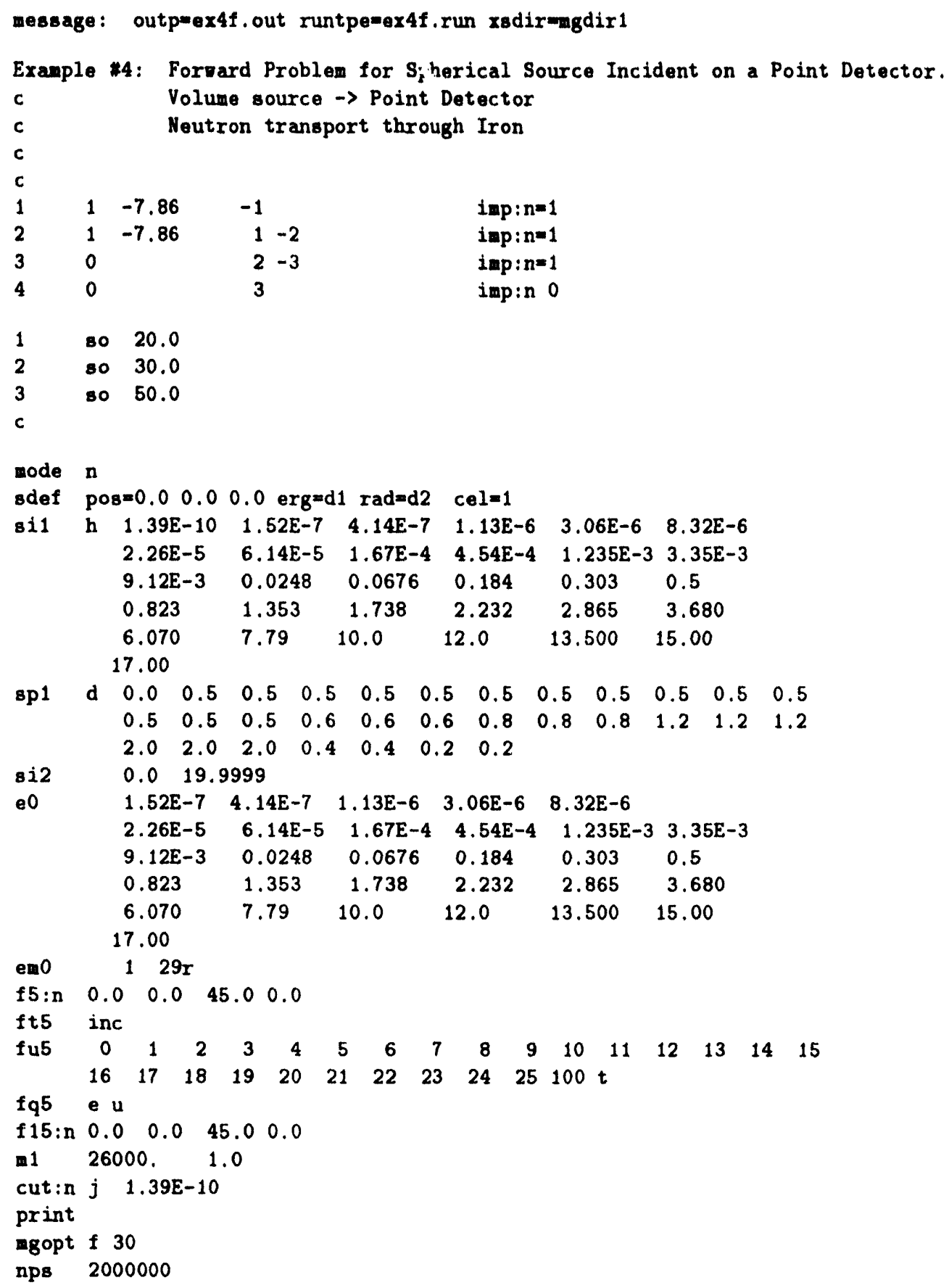

Fig. B7 Forward Input File for Material Test with Iron 




Fig. B8. Adjoint Input File for Material Test with Iron. 




Fig. B9. Forward Input File for Generating Weight Window Importance Functions. 


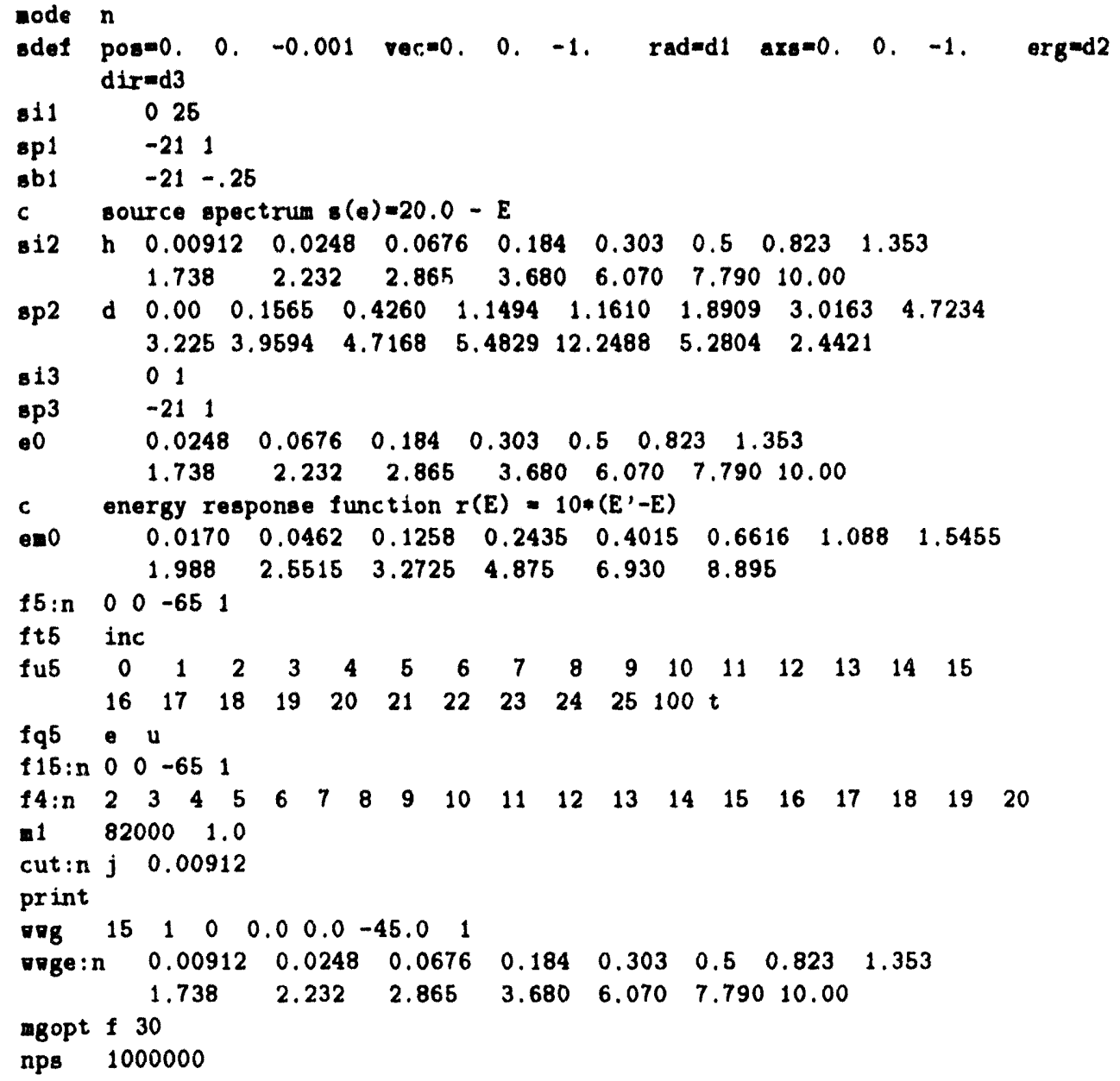

Fig. B9. Forward Input File for Generating Weight Window Importance Functions (continued). 


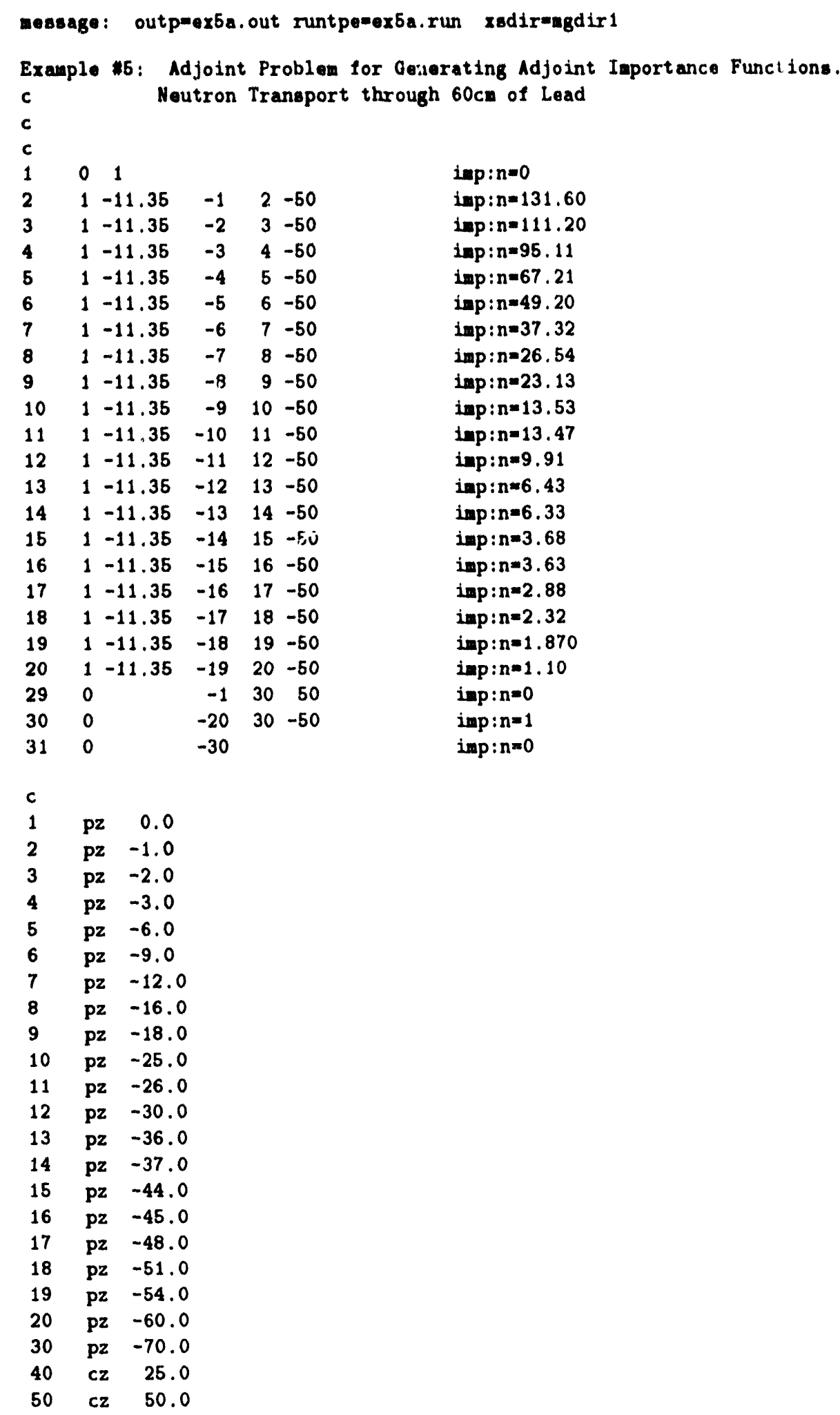

Fig. B10. Adjoint Input File for Generating Adjoint Importance Functions. 






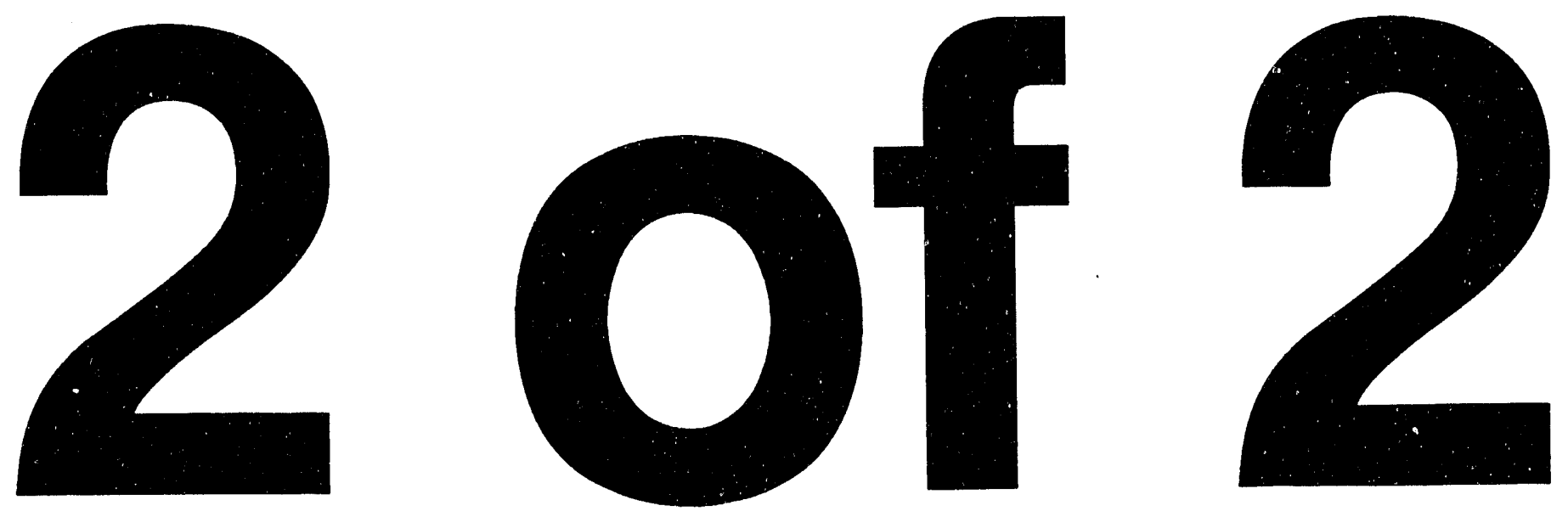




Fig. B10. Adjoint Input File for Generating Adjoint Importance Functions (continued). 
APPENDIX C:

MCNP MULTIGROUP DATA FORMATS 


\section{TABLE C.I}

\section{NXS ARRAY}

Parameter

$\mathrm{NXS}(1)$

$\mathrm{NXS}(2)$

$\mathrm{NXS}(3)$

$\mathrm{NXS}(4)$

$\mathrm{NXS}(5)$

$\mathrm{NXS}(6)$

$\operatorname{NXS}(7)$

$\mathrm{NXS}(8)$

$\operatorname{NXS}(9)$

NXS(10)

NXS(11)

NXS(12)
LDB

ZA

NLEG

NEDIT

NGRP

NUS

NDS

NSEC

ISANG

NNUBAR

IBFP

IPT
Description

Length of second block of data

$1000^{*} \mathrm{Z}+\mathrm{A}$

Number of angular distribution variables

Number of edit reactions

Number of groups

Number of upscatter groups

Number of downscatter groups

Number of secondary particles

Angular distribution type

ISANG $=0$ for equi-probable cosine bins ISANG $=1$ for discrete cosines

Number of nubars given

Boltzmann-Fokker-Planck indicator $\mathrm{IBFP}=0$ for Boltzmann only

IBFP $=1$ for Boltzmann-Fokker-Planck $\mathrm{IBFP}=2$ for Fokker-Planck only

Identifier for incident particle

IPT $=1$ for neutrons

$\mathrm{IPT}=2$ for photons

$\mathrm{IPT}=0$ for other particles (temporary)

NXS(13)-NXS(16) are presently unused

All data in the NXS Array is appropriate for the incident particle only. 


\section{TABLE C.II}

\section{JXS ARRAY}

Parameter

$\mathrm{JXS}(1)$

$\mathrm{JXS}(2)$

$\mathrm{JXS}(3)$

$\mathrm{JXS}(4)$

$\mathrm{JXS}(5)$

$\mathrm{JXS}(6)$

$\operatorname{JXS}(7)$

$\operatorname{JXS}(8)$

$\operatorname{JXS}(9)$

JXS(10)

JXS(11)

JXS(12)

JXS(13)

JXS(14)

JXS(15)

JXS(16)

$\operatorname{JXS}(17)$

JXS(18)

JXS(19)

$\operatorname{JXS}(20)$
LERG

LTOT

LFISS

LNU

$\mathrm{LCHI}$

LABS

LSTOP

LMOM

LMTED

LXSED

LIPT

LERG2L

LPOL

LSANG2

LNLEG2

LXPNL

LPNL

LSIGMA

LSIGSC

LSIGSCS

\section{Description}

Location of incident particle group structure $=1$

Location of total cross sections

Location of fission cross sections

Location of nubar data

Location of fission chi data

Location of absorption cross sections

Location of stopping powers

Location of momentum transfers

Location of edit reaction numbers

Location of edit cross sections

Location of secondary particle types

Location of secondary group structure locators

Location of PO locators

Location of secondary angular distribution types

Location of number of angular distribution variables for secondaries

Location of $X P_{N}$ locators

Location of $P_{N}$ locators

Location of SIGMA Block locators

Location of cumulative P0 scattering cross sections

Location of cumulative P0 scattering cross sections to secondary particle

Notes: JXS(18)-JXS(20) are calculated and used internally in MCNP.

These parameters have a value of 0 on the cross-section file.

$\mathrm{JXS}(21)-\mathrm{JXS}(32)$ are presently unused. 
TABLE C.III

\section{ERG BLOCK}

\begin{tabular}{|c|c|c|}
\hline Location & Parameter & Description \\
\hline $\mathrm{JXS}(1)$ & $\operatorname{ECENT}(1)$ & $\begin{array}{l}\text { Center energy of group } 1 \\
\text {. } \\
\text {. }\end{array}$ \\
\hline $\mathrm{JXS}(1)+\mathrm{NXS}(5)-1$ & $\operatorname{ECENT}(\mathrm{NXS}(5))$ & Center energy of Group NXS(5) \\
\hline $\mathrm{JXS}(1)+\mathrm{NXS}(5)$ & $\operatorname{EWID}(1)$ & Width of Group 1 \\
\hline . & . & \\
\hline$J X S(1)+2^{*} N X S(5)-1$ & $\operatorname{EWID}(\mathrm{NXS}(5))$ & Width of Group NXS(5) \\
\hline $\mathrm{JXS}(1)+2^{*} \mathrm{NXS}(5)$ & GMASS $(1)$ & Mass of Group-1 particle \\
\hline . & . & . \\
\hline $\mathrm{JXS}(1)+3^{*} \mathrm{NXS}(5)-1$ & GMASS(NXS(5)) & Mass of Group-NXS(5) particle \\
\hline
\end{tabular}

Notes: Group masses are given only if NXS(12) $=0$.

All entries are in $\mathrm{MeV}$.

Group energies are descending, unless $\operatorname{NXS}(12)=0$, in which case there may be discontinuities.

Length: $2^{*} \mathrm{NXS}(5)$ if $\mathrm{NXS}(12) \neq 0 ; 3^{*} \mathrm{NXS}(5)$ if $\mathrm{NXS}(12)=0$

Exists: Always 


\section{TABLE C.IV}

\section{TOT BLOCK}

\begin{tabular}{llll}
\multicolumn{1}{c}{ Location } & \multicolumn{1}{c}{ Parameter } & & Description \\
\cline { 1 - 1 } & $\operatorname{SIGTOT}(1)$ & & Total cross section in Group 1 \\
$\cdot$ & $\cdot$ & $\cdot$ \\
$\cdot$ & $\cdot$ & $\cdot$ \\
$\cdot$ & $\cdot$ & $\cdot$ \\
JXS(2)+NXS(5)-1 & SIGTOT $(\mathrm{NXS}(5))$ & Total cross section in Group NXS(5) \\
Length: $\mathrm{NXS}(5)$ & &
\end{tabular}

Exists: If $\mathrm{JXS}(2) \neq 0$ 


\section{TABLE C.V}

\section{FISS BLOCK}

\begin{tabular}{|c|c|c|}
\hline Location & Parameter & Description \\
\hline $\mathrm{JXS}(3)$ & SIGFIS(1) & Fission cross section in Group 1 \\
\hline$\cdot$ & . & . \\
\hline . & · & · \\
\hline . & . & . \\
\hline $\mathrm{JXS}(3)+\mathrm{NXS}(5)-1$ & SIGFIS(NXS(5)) & Fission cross section in Group NXS(5) \\
\hline Length: NXS(5) & & \\
\hline Exists: If $\mathrm{JXS}(3) \neq c$ & & \\
\hline
\end{tabular}


TABLE C.VI

\section{NU BLOCK}

Location

JXS(4)

.

.

JXS(4)+NXS(10)*NXS(5)-1 NUBAR(NXS(10)*NXS(5)) See below

Note: If $\operatorname{NXS}(10)=1$, then one set of nubars is given NUBAR $(1) \rightarrow$ NUBAR $(\mathrm{NXS}(5))$. The nubars may be either prompt or total. If $\mathrm{NXS}(10)=2$, then both prompt and total nubars are given. In this case, NUBAR(1) $\rightarrow$ NUBAR(NXS(5)) are prompt nubars and NUBAR(NXS(5)+1) $\rightarrow$ NUBAR $(2 * \mathrm{NXS}(5))$ are total nubars.

Length: $\mathrm{NXS}(5) * \mathrm{NXS}(10)$

Exists: If $\mathrm{JXS}(3) \neq 0$ 


\section{TABLE C.VII}

\section{CHI BLOCK}

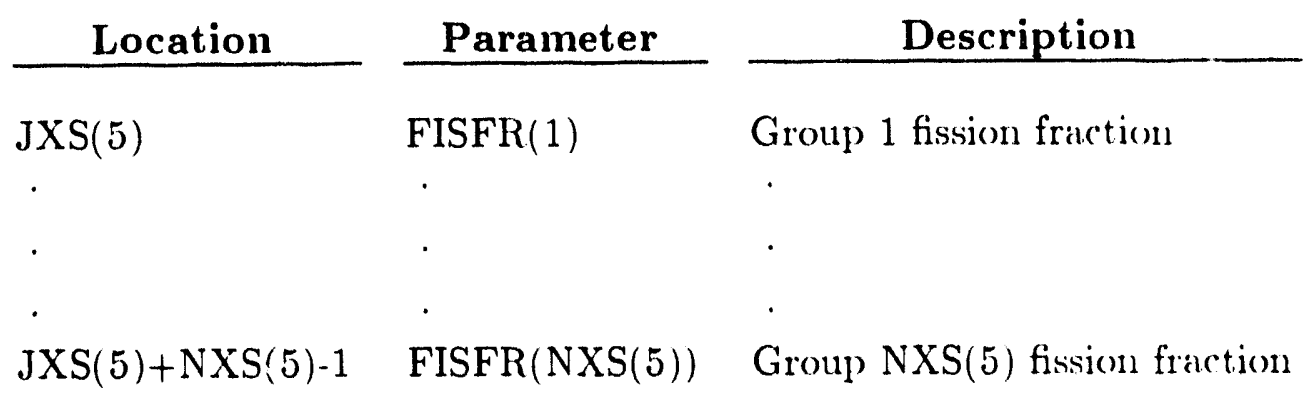

Note: The fission fractions are normalized so that their sum is 1.().

Length: NXS(5)

Exists: If $\mathrm{JXS}(3) \neq 0$ 
TABLE C.VIII

\section{ABS BLOCK}

\begin{tabular}{|c|c|c|}
\hline Location & Parameter & Description \\
\hline $\mathrm{JXS}(6)$ & $\operatorname{SIGABS}(1)$ & Absorption cross section in Group 1 \\
\hline$\cdot$ & & \\
\hline$\cdot$ & & . \\
\hline . & & . \\
\hline $\mathrm{JXS}(6)+\mathrm{NXS}(5)-1$ & SIGABS(NXS(5)) & Absorption cross section in Group NXS(5) \\
\hline Length: NXS(5) & & \\
\hline cists: If $\mathrm{JXS}(6) \neq$ & & \\
\hline
\end{tabular}




\section{TABLE C.IX \\ STOP BLOCK}

\begin{tabular}{|c|c|c|}
\hline Location & Parameter & Description \\
\hline $\mathrm{JXS}(7)$ & $\mathrm{SPOW}(1)$ & Stopping power in (Group 1 \\
\hline ' & r & $\cdot$ \\
\hline . & . & . \\
\hline . & . & . \\
\hline $\mathrm{JXS}(7)+\mathrm{NXS}(5)-1$ & SPOW $(\operatorname{NXS}(5))$ & Stopping power in Group NXS(5) \\
\hline Length: NXS(5) & & \\
\hline Exists: If $\mathrm{JXS}(7) \neq 0$ & & \\
\hline
\end{tabular}


TABLE C.X

MOM BLOCK

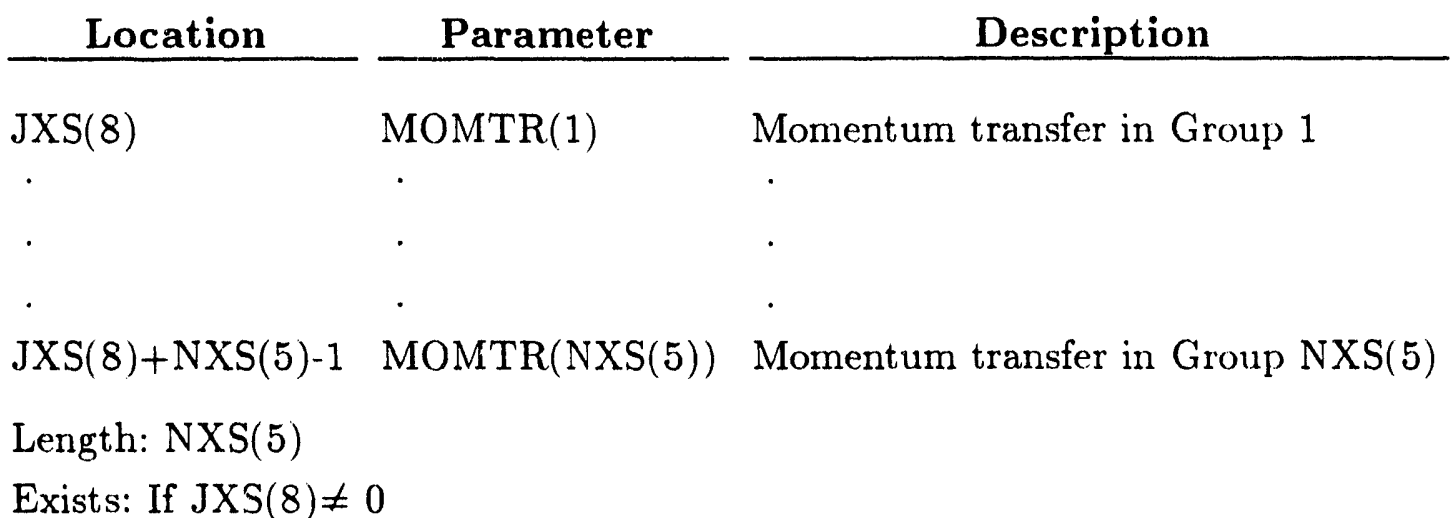

Exists: If $\operatorname{JXS}(8) \neq 0$ 


\section{TABLE C.XI}

\section{MTED BLOCK}

\begin{tabular}{|c|c|c|}
\hline Location & Parameter & Description \\
\hline $\mathrm{JXS}(9)$ & $\mathrm{MT}(1)$ & Identifier for edit reaction 1 \\
\hline . & & \\
\hline$J X S(9)+N X S(4)-1$ & $\operatorname{MT}(\mathrm{NXS}(4))$ & Identifier for edit reaction $\mathrm{NXS}(4)$ \\
\hline $\begin{array}{l}\text { Length: } \operatorname{NXS}(4) \\
\text { Exists: If } \operatorname{JXS}(4) \neq\end{array}$ & & \\
\hline
\end{tabular}


TABLE C.XII

XSED BLOCK

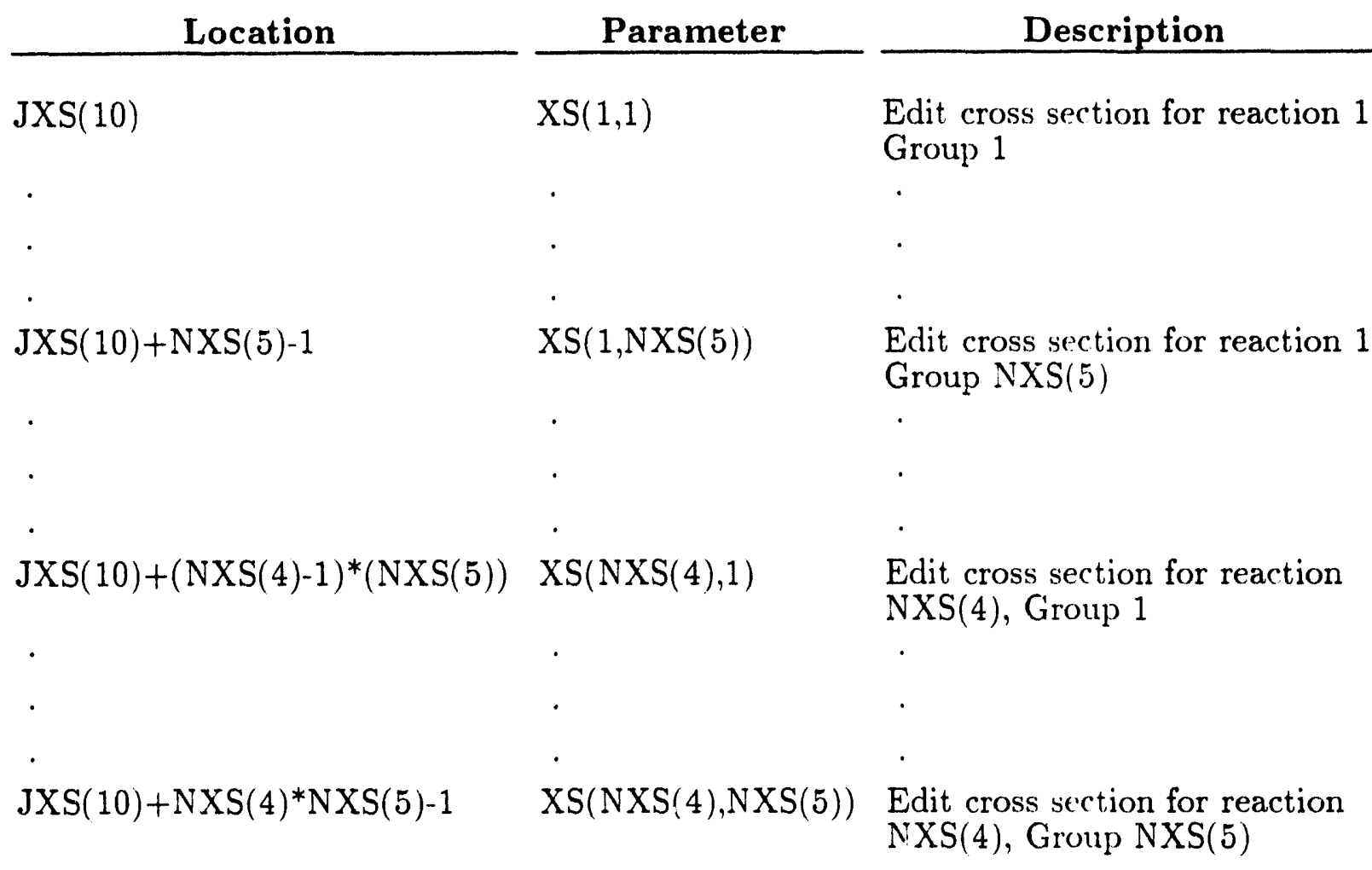

Length: NXS(4)*NXS(5)

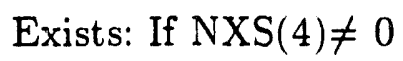




\section{TABLE C.XIII}

\section{IPT BLOCK}

\begin{tabular}{|c|c|c|}
\hline Location & Parameter & Description \\
\hline $\mathrm{JXS}(11)$ & $\operatorname{IPT}(1)$ & Identifier for secondary particle 1 \\
\hline . & . & \\
\hline . & . & \\
\hline . & & \\
\hline $\mathrm{JXS}(11)+\mathrm{NXS}(8)-1$ & $\operatorname{IPT}(\mathrm{NXS}(8))$ & Identifier for secondary particle NXS(8) \\
\hline
\end{tabular}

Note: Present values of IPT are:

IPT $=1$ for neutrons,

$\mathrm{IPT}=2$ for photons

Length: NXS(8)

Exists: If $\mathrm{NXS}(8) \neq 0$ 


\section{TABLE C.XIV}

\section{ERG2L BLOCK}

\begin{tabular}{llll}
\multicolumn{1}{c}{ Location } & \multicolumn{1}{c}{ Parameter } & & \multicolumn{1}{c}{ Description } \\
\cline { 1 - 1 } $\operatorname{JXS}(12)$ & LERG2(1) & & $\begin{array}{l}\text { Location of ERG2 Block* for secondary } \\
\text { particle 1 }\end{array}$ \\
$\cdot$ & $\cdot$ & $\cdot$ \\
$\cdot$ & $\cdot$ & $\cdot$ \\
JXS $(12)+N X S(8)-1$ & LERG2(NXS(8)) & $\begin{array}{l}\text { Location of ERG2 Block* for secondary } \\
\text { particle NXS(8) }\end{array}$
\end{tabular}

Length: NXS(8)

Exists: If $\mathrm{NXS}(8) \neq 0$

* The ERG2 Block for secondary particle $i$ is of the form:

\begin{tabular}{|c|c|c|}
\hline Location & Parameter & Description \\
\hline LERG2(i) & NERG(i) & $\begin{array}{l}\text { Number of energy groups for } \\
\text { secondary particle } i\end{array}$ \\
\hline LERG2(i)+1 & ECENT2(1) & $\begin{array}{l}\text { Center energy of Group } 1 \text { for } \\
\text { secondary particle } i\end{array}$ \\
\hline . & $\cdot$ & . \\
\hline . & . & . \\
\hline . & . & \\
\hline LERG2(i) + NERG(i) & ECENT2(NERG(i)) & $\begin{array}{l}\text { Center energy of Group NERG(i) } \\
\text { for secondary particle } i\end{array}$ \\
\hline LERG2(i) + NERG(i)+1 & EWID2(1) & $\begin{array}{l}\text { Width of Group } 1 \text { for secondary } \\
\text { particle } i\end{array}$ \\
\hline . & & . \\
\hline . & . & . \\
\hline . & . & . \\
\hline LERG2(i) $+2^{*}$ NERG(i) & EWID2(NERG(i)) & $\begin{array}{l}\text { Width of Group NERG(i) for } \\
\text { secondary particle i }\end{array}$ \\
\hline
\end{tabular}

Note: Values of LERG2(i) are from ERG2L Block. Group energies are descending.

Length: $2^{*} \mathrm{NERG}(\mathrm{i})+1$

Exists: If $\mathrm{NXS}(8) \neq 0$, then ERG2 Block is repeated NXS(8) times. 
TABLE C.XV

\section{POL BLOCK}

\begin{tabular}{llll} 
Location & \multicolumn{1}{c}{ Parameter } & & \multicolumn{1}{c}{ Description } \\
$(13)$ & $\operatorname{LPO}(1)$ & Location of PO Block* for incident particle \\
$\cdot$ & $\cdot$ & $\cdot$ \\
$\cdot$ & $\cdot$ & $\cdot$ \\
$\mathrm{JXS}(13)+\mathrm{NXS}(8)$ & $\mathrm{LPO}(\mathrm{NXS}(8)+1)$ & $\begin{array}{l}\text { Location of PO Block* for secondary particle } \\
\text { NXS }(8)\end{array}$
\end{tabular}

Length: $\operatorname{NXS}(8)+1$

Exists: If $\operatorname{JXS}(13) \neq 0$

" The PO Block for particle $i$ is of the form:

\begin{tabular}{|c|c|c|}
\hline Location & Parameter & Description \\
\hline LPO(i) & $\operatorname{SIG}(1 \rightarrow 1)$ & $\begin{array}{l}\text { P0 cross section for scattering from incident } \\
\text { particle Group } 1 \text { to exiting particle Group } 1\end{array}$ \\
\hline . & . & . \\
\hline . & & . \\
\hline . & & . \\
\hline $\mathrm{LPO}(\mathrm{i}+\mathrm{L}-1)$ & $\operatorname{SIG}(N X S(5) \rightarrow K)$ & $\begin{array}{l}\text { P0 cross section for scattering from incident } \\
\text { particle group NXS(5) to exiting particle } \\
\text { Group K }\end{array}$ \\
\hline
\end{tabular}

Note: See Table C.XXIII for a complete description of the ordering and length of the PO block.

Exists: If JXS $(13) \neq 0$, then the PO Block is repeated NXS(8)+1 times. 
TABLE C.XVI

\section{SANG2 BLOCK}

\begin{tabular}{|c|c|c|}
\hline Location & Parameter & Description \\
\hline \multirow[t]{4}{*}{$\mathrm{JXS}(14)$} & ISANG2(1) & $\begin{array}{l}\text { Angular distribution type for secondary } \\
\text { particle } 1\end{array}$ \\
\hline & . & $\cdot$ \\
\hline & . & . \\
\hline & . & . \\
\hline $\mathrm{JXS}(14)+\mathrm{NXS}(8)-1$ & ISANG2(NXS(8)) & $\begin{array}{l}\text { Angular distribution type for secondary } \\
\text { particle NXS }(8)\end{array}$ \\
\hline
\end{tabular}

Note: ISANG2(i) $=0$ for equi-probable cosine bins: ISANG2(i) $=1$ for discrete cosines.

Length: NXS(8)

Exists: If $\mathrm{NXS}(8) \neq 0$ 


\section{TABLE C.XVII}

NLEG2 BLOCK

$\frac{\text { Location }}{\mathrm{JXS}(15)} \frac{\text { Parameter }}{\text { NLEG2(1) }} \frac{\text { Description }}{\begin{array}{l}\text { Number of angular distribution variables } \\ \text { for secondary particle 1 }\end{array}}$
for secondary particle 1

JXS(15)+NXS(8)-1 NLEG2(NXS(8)) Number of angular distribution variables for secondary particle NXS(8)

Length: NXS(8)

Exists: If $\mathrm{NXS}(8) \neq 0$ 
TABLE C.XVIII

\section{XPNL BLOCK}

\begin{tabular}{|c|c|c|}
\hline Location & Parameter & Description \\
\hline $\mathrm{JXS}(16)$ & $\operatorname{LXPN}(1)$ & Location of XPN Block* for incident particle \\
\hline . & 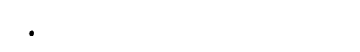 & . \\
\hline . & '. & \\
\hline $\mathrm{JXS}(16)+\mathrm{NXS}(8)$ & $\operatorname{LXPN}(\mathrm{NXS}(8)+1)$ & $\begin{array}{l}\text { Location of XPN Block* for secondary } \\
\text { particle NXS }(8)\end{array}$ \\
\hline
\end{tabular}

Note: If $\operatorname{LXPN}(\mathrm{i})=0$, then all possible scattering is isotropic and no XPN block exists.

Length: NXS(8)+1

Exists: If JXS $(13) \neq 0$

*The XPN Block for particle $i$ is of the form:

\begin{tabular}{|c|c|c|}
\hline Location & Parameter & Description \\
\hline LXPN(i) & $\operatorname{LPND}(1 \rightarrow 1)$ & $\begin{array}{l}\text { Location of PND Block }{ }^{\dagger} \text { for scattering from } \\
\text { incident particle Group } 1 \text { to exiting particle } \\
\text { Group } 1\end{array}$ \\
\hline . & . & . \\
\hline . & . & . \\
\hline . & . & . \\
\hline $\operatorname{LXPN}(i+L-1)$ & $\operatorname{LPND}(\mathrm{NXS}(5) \rightarrow K)$ & $\begin{array}{l}\text { Location of PND Block }{ }^{\dagger} \text { for scattering from } \\
\text { incident particle Group NXS(5) to exiting } \\
\text { particle Group K }\end{array}$ \\
\hline
\end{tabular}

†See Table C.XIX for a description of the PND Block

Note: See Table C.XXIII for a complete description of the ordering and length of the XPN Block. Also see the notes to the PN Block in Table C.XIX for more complete description of the meanings of the LPND parameters.

Exists: If $\mathrm{JXS}(13) \neq 0$, then the XPN Block is repeated $\mathrm{NXS}(8)+1$ times. 


\section{TABLE C.XIX}

PNL BLOCK

\begin{tabular}{|c|c|c|}
\hline Location & Parameter & Description \\
\hline $\mathrm{JXS}(17)$ & LPN(1) & Location of PN Block* for incident particle \\
\hline . & $\cdot$ & . \\
\hline . & . & . \\
\hline . & . & . \\
\hline $\mathrm{JXS}(17)+\mathrm{NXS}(8)$ & $\operatorname{LPN}(\mathrm{NXS}(8)+1)$ & $\begin{array}{l}\text { Location of PN Block }{ }^{*} \text { for secondary } \\
\text { particle NXS(8) }\end{array}$ \\
\hline
\end{tabular}

Note: If $L P N(i)=0$, then all possible scattering is isotropic and no PN Block exists. Length: $\mathrm{NXS}(8)+1$

Exists: If $\mathrm{JXS}(13) \neq 0$.

*The PN Block for particle $i$ is of the form:

\begin{tabular}{|c|c|c|}
\hline Location & Parameter & Description \\
\hline \multirow[t]{4}{*}{$L P N(i)+L P N D(1 \rightarrow 1)-1$} & $\begin{array}{l}\operatorname{PND}(1 \rightarrow 1, I) \\
I=1, N L E G(i)\end{array}$ & $\begin{array}{l}\text { Angular distribution data for scattering } \\
\text { from incident particle Group } 1 \text { to exiting } \\
\text { particle Group } 1\end{array}$ \\
\hline & . & . \\
\hline & . & . \\
\hline & . & . \\
\hline $\begin{array}{l}\operatorname{LPN}(\mathrm{i})+\operatorname{LPND}(\mathrm{NXS}(5) \\
\rightarrow \mathrm{K})-1\end{array}$ & $\begin{array}{l}\operatorname{PND}(\mathrm{NXS}(5) \\
\rightarrow \mathrm{K}, \mathrm{I}), \mathrm{I}=1 \\
\mathrm{NLEG}(\mathrm{i})\end{array}$ & $\begin{array}{l}\text { Angular distribution data for scattering } \\
\text { from incident particle Group NXS(5) } \\
\text { to exiting particle Group } \mathrm{k}\end{array}$ \\
\hline
\end{tabular}

Note: Values of LPND are from the XPN Block (see Table XVIII). Values of LPN(i) are from the PNL Block. If $L P N D>0$, then data exists in the PN Block as described above. If $L P N D=0$, then scattering is isotropic in the laboratory system and no data exist in the PN Block. If $L P N D=-1$, then scattering is impossible for the combination of incident and exiting groups; again no data exist in the PN Block. The appropriate value of NLEG is found in Table C.I or Table C.XVII. The value of ISANG (from Table C.I or Table C.XVI) determines what data are found in the PND array. If ISANG $=0$, then PND contains NLEG cosines, which are boundaries of NLEG-1 equally-probable cosine bins. If $I S A N G=1$, then PND contains (NLEG-1)/ 2 cumulative probabilities followed by $(N L E G+1) / 2$ discrete cosines. The cumulative probability corresponding to the final discrete cosine is defined to be 1.0 .

Exists: If JXS $(13) \neq 0$, then the PN Block is repeated NXS(8)+1 times. 
TABLE C.XX

\section{SIGMA BLOCK}

Location

Parameter

Description

$\mathrm{JXS}(18)$

$\operatorname{SCAT}_{g g}(1)$

Location of within group scattering cross section for group 1 within the PO Block

$\mathrm{JXS}(18)+\mathrm{NXS}(5)-1 \quad \mathrm{SCAT}_{g g}(\mathrm{NXS}(5)) \quad$ Location of within group scattering cross section for group NXS(5) within the PO Block

Note: This block is calculated and used internally within MCNP and does not actually appear on the cross-section file. 


\section{TABLE C.XXI}

\section{SIGSC BLOCK}

Location

JXS(19)

$\operatorname{JXS}(19)+\mathrm{NXS}(5)-1$
Parameter

$\operatorname{SIGSC}(1)$

$\operatorname{SIGSC}(\mathrm{NXS}(5))$
Total P0 scattering cross section for group 1 excluding scattering to secondary particle
Description 


\section{TABLE C.XXII}

\section{SIGSCS BLOCK}

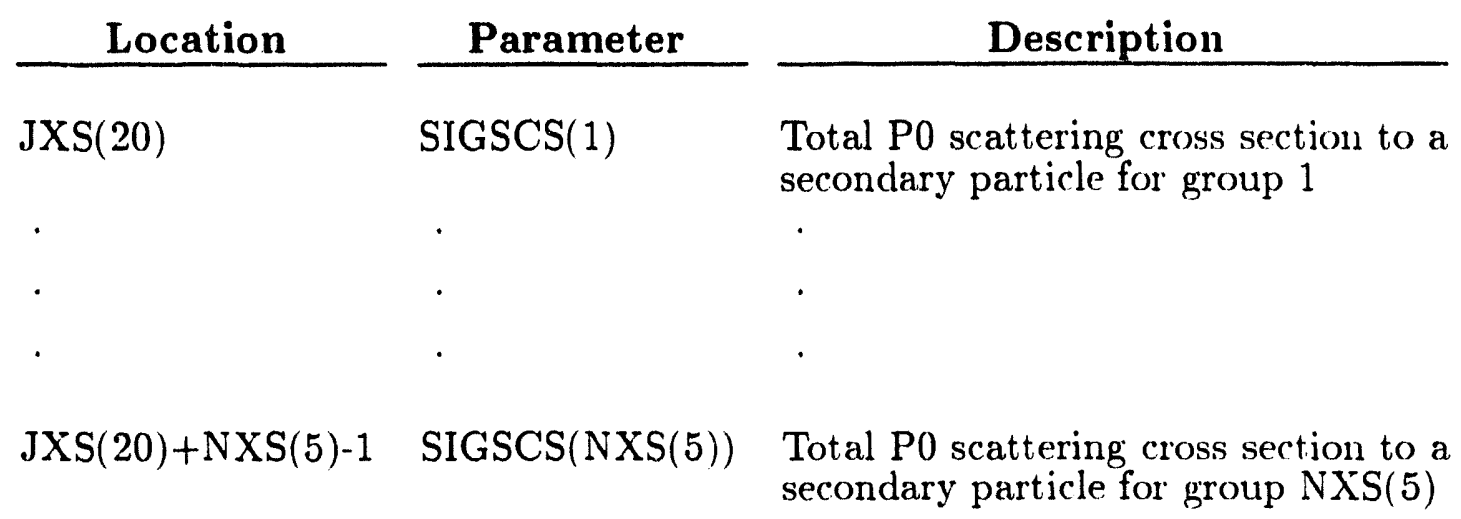

Note: This block is calculated and used internally within MCNP and does not actually appear on the cross-section file. 


\section{TABLE C.XXIII}

\section{ADDITIONAL INFORMATION FOR PO AND XPN BLOCKS}

\section{Ordering}

Entries in these blocks always start with data for scattering from the highest energy group of the incident particle to the highest energy group of the existing particle. The last entry is always data for scattering from the lowest energy group of the exiting particle. The remaining entries are ordered according to the following prescription:

$$
\begin{aligned}
& \mathrm{X}(1 \rightarrow \mathrm{J}), \mathrm{J}=\mathrm{I} 1(1), \mathrm{I} 2(1), \\
& \mathrm{X}(2 \rightarrow \mathrm{J}), \mathrm{J}=\mathrm{I} 1(2), \mathrm{I} 2(2), \\
& \cdot \\
& \cdot \\
& \mathrm{X}(\mathrm{NXS}(5) \rightarrow \mathrm{J}), \mathrm{J}=\mathrm{I} 1(\mathrm{NXS}(5)), \mathrm{I} 2(\mathrm{NXS}(5)) .
\end{aligned}
$$

If the incident and exiting particles are the same:

$$
\begin{aligned}
& \mathrm{I} 1(\mathrm{~K})=\operatorname{MAX}(1, \mathrm{~K}-\mathrm{NXS}(6)) \\
& \mathrm{I} 2(\mathrm{~K})=\operatorname{MIN}(\mathrm{NXS}(5), \mathrm{K}+\mathrm{NXS}(\tau)) .
\end{aligned}
$$

If the incident and exiting particles are different:

$$
\begin{aligned}
& I 1(K)=1 \\
& I 2(K)=N E R G(i) \text { for the appropriate secondary particle from Table C } . X I V .
\end{aligned}
$$

\section{Length}

If the incident and exiting particles are the same:

$L=N X S(5) *(1+N X S(7)+N X S(6))-\frac{(N X S(7) *(N \times S(7)+1))+(N X S(6) *(N X S(6)+1))}{2}$

If the incident and exiting particles are different:

$\mathrm{L}=\mathrm{NXS}(5)^{*} \mathrm{NERG}(\mathrm{i})$, where $\mathrm{NERG}(\mathrm{i})$ is for the appropriate secondary particle from Table C.XIV. 
11

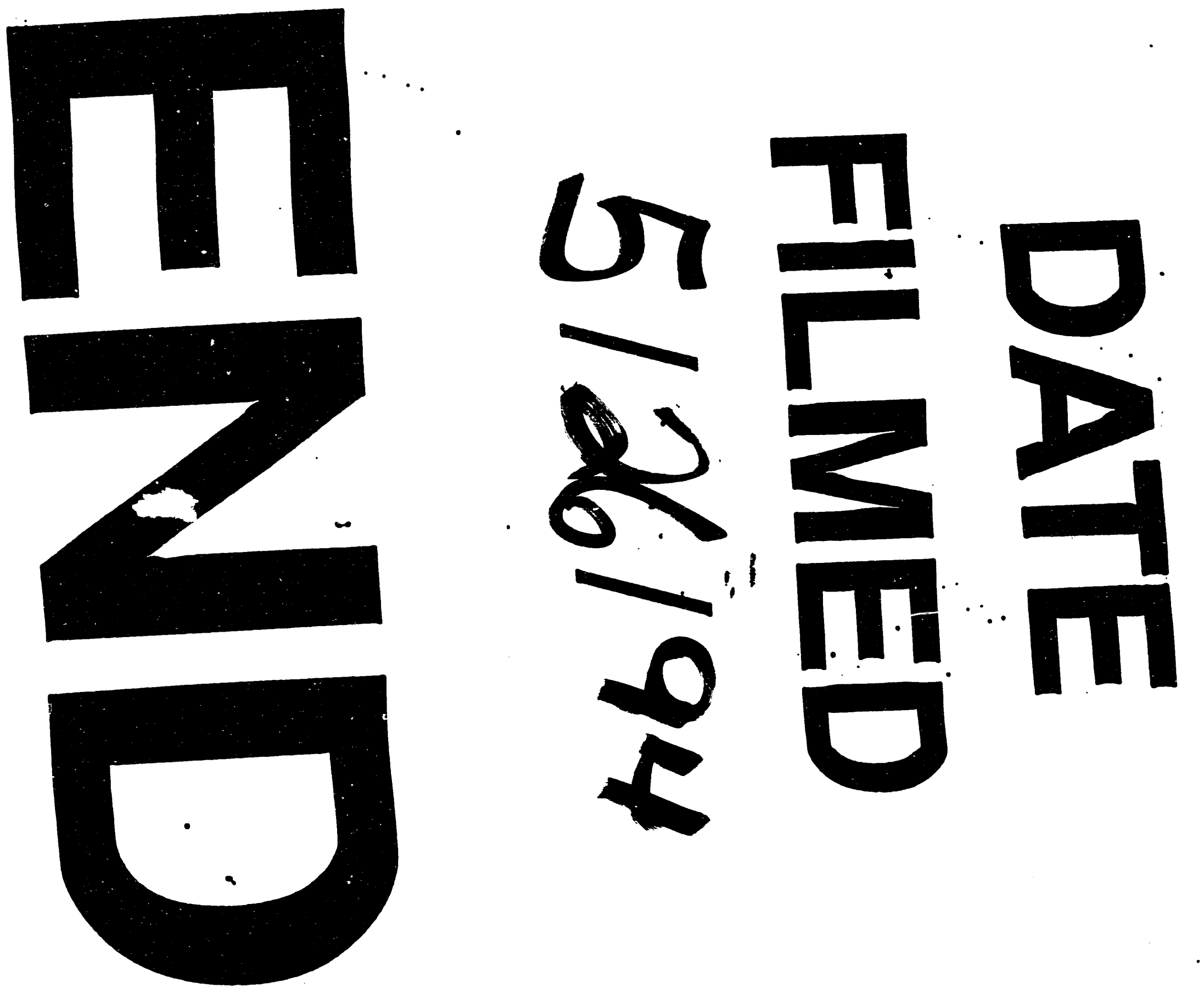


